\title{
Shining light on transition metal sulfides: New choices as highly efficient antibacterial agents
}

\author{
Hecheng Han ${ }^{1}$, Jingjing Yang ${ }^{1}$, Xiaoyan $\mathrm{Li}^{2}$, Yuan Qi', Zhengyi Yang ${ }^{1}$, Zejun Han ${ }^{1}$, Yanyan Jiang ${ }^{1,3,4}(\varangle)$, \\ Martina Stenzel ${ }^{5}$, Hui Li ${ }^{1}$, Yixin Yin $^{6}(\bowtie)$, Yi Du$^{6}$, Jiurong Liu', and Fenglong Wang ${ }^{1,4}(\bowtie)$ \\ ${ }^{1}$ Key Laboratory for Liquid-Solid Structural Evolution and Processing of Materials Ministry of Education, Shandong University, Jinan \\ 250061, China \\ ${ }^{2}$ Department of Endodontics, School and Hospital of Stomatology, Cheeloo College of Medicine \& Shandong Key Laboratory of Oral Tissue \\ Regeneration \& Shandong Engineering Laboratory for Dental Materials and Oral Tissue Regeneration, Shandong University, Jinan 250012, \\ China \\ ${ }^{3}$ Suzhou Institute of Shandong University, Suzhou 215123, China \\ ${ }^{4}$ ShenZhen Research Institute of Shandong University, Shenzhen 518057, China \\ ${ }^{5}$ School of Chemistry, University of New South Wales, Sydney, NSW 2052, Australia \\ ${ }^{6}$ Oral Implantology Center, Jinan Stomatology Hospital, Jinan 250001, China
}

(C) Tsinghua University Press and Springer-Verlag GmbH Germany, part of Springer Nature 2021

Received: 24 September 2020 / Revised: 10 December 2020 / Accepted: 13 December 2020

\begin{abstract}
Globally, millions of people die of microbial infection-related diseases every year. The more terrible situation is that due to the overuse of antibiotics, especially in developing countries, people are struggling to fight with the bacteria variation. The emergence of super-bacteria will be an intractable environmental and health hazard in the future unless novel bactericidal weapons are mounted. Consequently, it is critical to develop viable antibacterial approaches to sustain the prosperous development of human society. Recent researches indicate that transition metal sulfides (TMSs) represent prominent bactericidal application potential owing to the meritorious antibacterial performance, acceptable biocompatibility, high solar energy utilization efficiency, and excellent photo-to-thermal conversion characteristics, and thus, a comprehensive review on the recent advances in this area would be beneficial for the future development. In this review article, we start with the antibacterial mechanisms of TMSs to provide a preliminary understanding. Thereafter, the state-of-the-art research progresses on the strategies for TMSs materials engineering so as to promote their antibacterial properties are systematically surveyed and summarized, followed by a summary of the practical application scenarios of TMSs-based antibacterial platforms. Finally, based on the thorough survey and analysis, we emphasize the challenges and future development trends in this area.
\end{abstract}

\section{KEYWORDS}

antibacterial mechanisms, transition metal sulfides, surface functionalization, strain-selective bactericidal strategies, metabolism and toxicology

\section{Introduction}

Globally, microbial infection-related diseases, such as urinary tract infections, inflammations, sepsis, and peritonitis, pose serious threats to human health and even kill millions of people every year [1-5]. In addition, the lack of efficient antibacterial therapeutic modalities restricts the development of modern medical techniques, such as implant surgery [6-8] and wound disinfection [9-11]. The high economic losses caused by these infections make it unaffordable for the people in many low- and middle-income countries [12-15]. A more serious challenge is that our weapons, i.e antibiotics, to fight against bacterial infections are weakening since the microbial are gaining resistance to the common antibiotics [13, 16-19]. Specifically, the biofilm formed by the self-synthesized extracellular polymeric substances (EPS) acts as a robust barrier to ward off the attack of antibiotics and resist environmental stress, and thus lead to persistent infections or even death [20,21].
Related projections estimate that more than 10 million people will die each year from antibiotic resistance by 2050 unless a global response to the problem of antimicrobial resistance (AMR) is mounted [22]. The US Centers for Disease Control and Prevention (CDC) has been warning for years that humans are approaching a "post-antibiotic era", a stage when bacterial infections will kill more people each year than cancer and other diseases [23]. Given the fact that it takes a long time to develop new antibiotics, exploring antimicrobial agents with broad-spectrum activities instead is of great significance to protect our health.

Past decades witnessed the rapid development of artificial antibacterial materials, among which inorganic bactericidal agents have attracted tremendous research interests owing to their outstanding chemical stability, low toxicity, satisfying efficiency and high cost-effectiveness [24, 25]. Usually, the most investigated inorganic antibacterial materials are based on metal nanoparticles (NPs) or photo-sensitive metal oxides [26-31]. 
Among the metal nanoparticle-based antibacterial materials, Ag has been most studied. The antibacterial effect of Ag NPs proceeds by the generation of reactive oxygen species (ROS) and silver-ions incursion, making damage to DNA, RNA, and proteins $[25,26,32]$. Although Ag NPs enjoy superior antibacterial properties, their high cost and toxicity to the human body (such as argyria, spasms, gastrointestinal disorders, or even death) hamper their wide in vivo applications [26, 33, 34]. In contrast, TMSs not only show good antibacterial properties, but also possess high cost-effectiveness and stability against metal leakage without side effects caused by excessive metal ions $[35,36]$. The most widely researched photocatalysts, including $\mathrm{TiO}_{2}$ and $\mathrm{ZnO}$, have gained great attention for bacterial killing applications [28, 37]. Upon light irradiation with larger energy than the band gap, electron-hole pairs form and result in the production of ROS, which degrades various organic substances [1]. Unfortunately, these materials can only exhibit excellent antibacterial effects under ultraviolet (UV) irradiation, which limits their applications in biotherapy [38, 39]. In terms of electronic structure, TMSs possess a narrower band gap than transition metal oxides due to the larger anion radius of $S$ atoms and the presence of well-dispersed S 3p orbits [40-42]. The suitable energy band structure of TMSs endows them with high capacity in solar energy utilization, resulting in robust photodynamic damage towards bacteria due to the effective generation of ROS. Besides, TMSs exhibit high phototo-thermal energy conversion ability, namely the photothermal effect and this could also lead to efficient bacteria ablation, which opens the second avenue for their therapeutic use. Additionally, the approach mimicking the natural antibacterial mechanism can be easily achieved due to the feasible surface functionalization. For instance, glycosylated TMSs could achieve targeted photo-killing of bacteria due to the carbohydrate-lectin interaction $[43,44]$. In addition, Gram-selective antimicrobial systems also could be realized via the surface charge-conversion of nanozymes [45]. All these, recent investigations indicated that TMSs stand out as suitable choices for the ablation of bacteria because of their high efficacy arising from their narrow band gap, high photo-to-thermal conversion, and minimal invasiveness [35, 46-51]. However, though rapid progress has been achieved in this field, to the best of our knowledge, there is still no systematic summary on the recent advances on TMSs for bactericidal applications, which would be greatly beneficial for the future development prospects in this area. In particular, the concise development history of TMSs for antibacterial applications is shown in Fig. 1(a). Among them, $\mathrm{MoS}_{2}$ and $\mathrm{CuS}$ have been intensively explored as effective scavengers of bacterial. Besides, other TMSs, including $\mathrm{Ag}_{2} \mathrm{~S}, \mathrm{WS}_{2}, \mathrm{CdS}, \mathrm{FeS}, \mathrm{TiS}_{2}$, and $\mathrm{Bi}_{2} \mathrm{~S}_{3}$, are attracting growing research interests for antibacterial applications [35, 46-51]. As depicted in Fig. 1(b), transition metal atoms and sulfur atoms in TMSs interact with each other via strong covalent bonds and form two distinct structures, namely, layered structures $\left(\mathrm{MoS}_{2}, \mathrm{WS}_{2}, \mathrm{TiS}_{2}\right.$, etc.) and stacking structures ( $\mathrm{CuS}, \mathrm{Ag}_{2} \mathrm{~S}, \mathrm{FeS}_{2}$, etc.) [52, 53]. Typical layered structures possess a sandwich structure and the unit cell bond to each other via weak van der Waals forces $[41,54,55]$. Stacking structured TMSs usually exhibit complicated structures, such as zinc-blende, pyrite, and marcasite structure, in which transition metal atoms are tetrahedrally or octahedrally bonded to adjacent sulfur atoms [56-58]. With the above basic understanding of TMSs, we can make a more comprehensive and detailed review on the antibacterial applications of TMSs. In this review paper, we started with the fundamental mechanisms
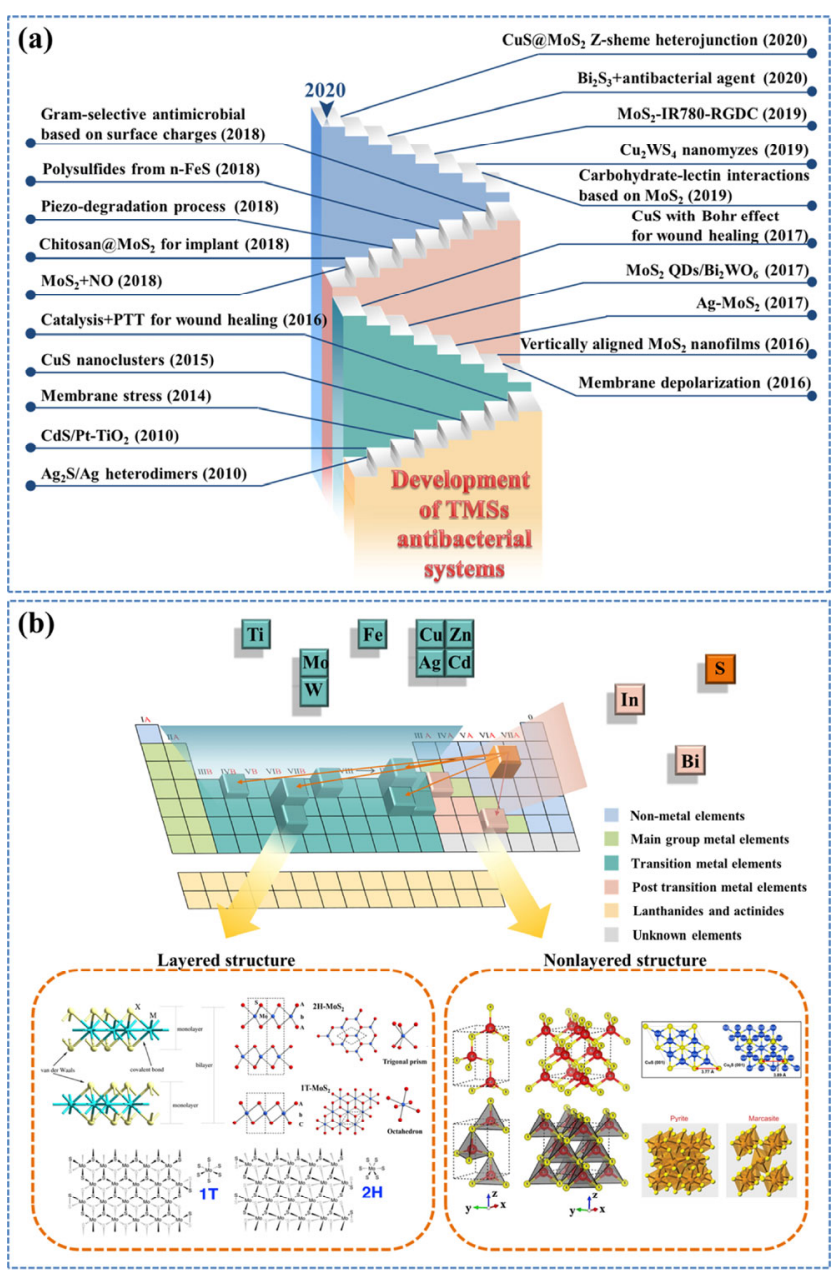

Figure 1 Background and introduction of TMSs antibacterial nanomaterials. (a) The development history of TMSs for antibacterial applications. (b) An overview of TMSs that have been studied for antibacterial applications and their crystal structure. Reproduced with permission from Refs. [41, 54-58], @American Physical Society, @WILEY-VCH Verlag 2016 and 2018, ๑Elsevier B.V. 2016, ๑American Chemical Society 2017, and $\odot$ Royal Society of Chemistry 2013, respectively.

of bacterial ablation using TMSs, and then the state-of-the-art progresses on the TMSs-based antibacterial materials are detailed documented, followed by a summary of the current research progresses on the practical biomedical application of TMSs-based antibacterial agents. Finally, an overall summary for this rapidly advancing research area is outlined and future prospects in this realm will be postulated based on the current status.

\section{Antibacterial mechanisms on TMSs}

TMSs show promise as novel antimicrobial agents due to their broad-spectrum antibacterial activities, satisfactory biocompatibility, high solar energy utilization efficiency and excellent photo-to-thermal conversion capacity [46-50]. It is widely acknowledged that the superb antibacterial activities of TMSs can be ascribed to their multiple bacterial killing mechanisms. A comprehensive understanding of their antibacterial mechanisms will facilitate the development of TMSs. Herein, as depicted in Fig. 2, the bactericidal mechanisms of TMSs, including photocatalytic antibacterial effect, antibacterial nanozymes, piezocatalytic degradation, photothermal effect, membrane damage, and polysulfane release are systematically described. 


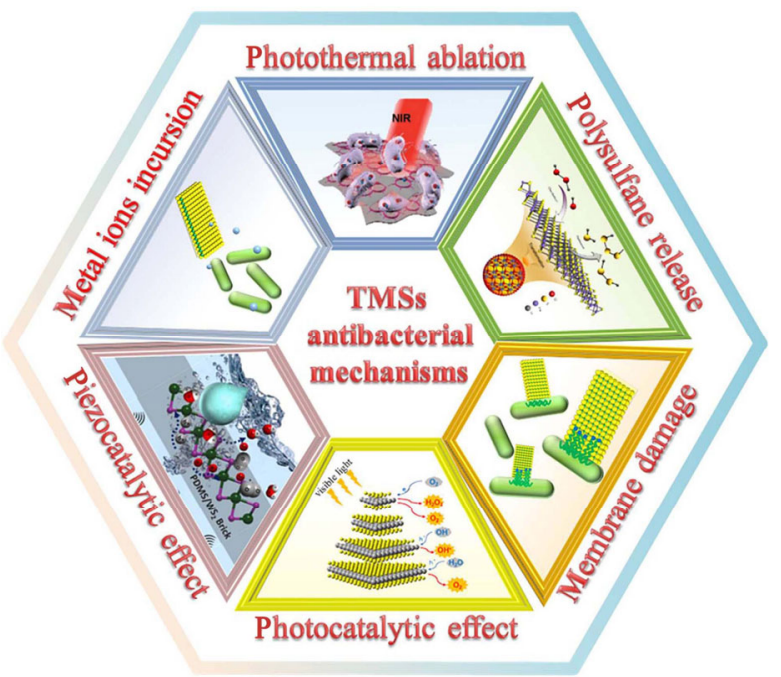

Figure 2 Schematic diagram of the antibacterial mechanisms on TMSs. Reproduced with permission from Refs. [95, 129, 142, 148], @Elsevier B.V. 2018, @Springer Nature 2018, @American Chemical Society 2018, and $\odot$ WILEY-VCH Verlag 2018, respectively.

\subsection{ROS-induced antibacterial mechanism}

ROS can be mainlv categorized into four types, namelv, hydrogen peroxide $\left(\mathrm{H}_{2} \mathrm{O}_{2}\right)$, superoxide species $\left(\mathrm{O}_{2} \cdot{ }^{-}\right)$, singlet oxygen $\left({ }^{1} \mathrm{O}_{2}\right)$, and hydroxyl radicals $(\cdot \mathrm{OH})$ [59-61]. Bacteria possess finely regulated and complicated antioxidant systems, including superoxide dismutase, catalase and glutathione reductase, which could eliminate endogenous ROS to maintain low steady-state concentrations [62-64]. However, this balance can be disturbed by excessive attack by exogenous ROS, causing oxidative stress (OS) $[65,66]$. Besides the antioxidant system, some other biomolecules would be perturbed by ROS as well [67-70]. As such, bacteria show a very high sensitivity to ROS, so we can employ the oxidizing ROS as powerful tools to conquer bacteria. In the next section, we will introduce the ROS-involved antibacterial mechanisms of TMSs.

\subsubsection{Photocatalytic antibacterial mechanism}

In 1972, Fujishima and Honda first reported photocatalysis using $\mathrm{TiO}_{2}$ for water splitting [71], and after that, various photocatalysts were explored for their potential applications in energy conversion [42, 72, 73], environmental remediation [74-76], and antibiosis [77-79]. Upon irradiation with light of higher energy than the band gap, photocatalysts could be excited to produce photo-induced electrons $\left(\mathrm{e}^{-}\right)$/holes $\left(\mathrm{h}^{+}\right)$pairs [80-82]. Most of the photo-induced charge carriers combine in the bulk and the rest will migrate to the surface to react with the adsorbed species. Particularly, the diffused photo-excited electrons will be captured by the pre-adsorbed oxvgen molecules forming the highly oxidizing $\mathrm{O}_{2} \cdot{ }^{-}$. Furthermore, $\mathrm{O}_{2} \cdot^{-}$can accept or donate electrons to yield $\mathrm{H}_{2} \mathrm{O}_{2}$ or ${ }^{1} \mathrm{O}_{2}$ [59]. Simultaneously, the holes left in the valence band (VB) can abstract electrons from hydroxyl ions or water molecules to produce $\bullet \mathrm{OH}$ [83]. These four types of ROS would strongly attack the microbial cells to inhibit their life activity. The generation process and corresponding redox potentials of ROS have been schematically presented in Fig. 3(a) $[59,84]$. It is worth noting that since water molecules and hydroxyl ions participate in the reaction, the generation and interconversion of ROS species are also affected by the solution environment, such as $\mathrm{pH}$ and chemical environment [59].

Besides the generation mechanisms of ROS, mechanistic insights into the interaction between ROS and bacteria also need to be elaborated. The cellular targets of ROS in microbe also have been ascertained in numerous studies [67-70]. $\cdot \mathrm{OH}$ is a strong oxidant that can cause indiscriminate oxidative damage to organic biomolecules, such as proteins, lipids, sugar, enzymes and nucleic acids [67-70]. $\mathrm{H}_{2} \mathrm{O}_{2}$ and ${ }^{1} \mathrm{O}_{2}$ also impose intense damage to proteins, lipids, enzymes and nucleic acids as well [67-70]. According to recent researches, $\mathrm{O}_{2 \cdot} \cdot^{-}$, a potent scavenger, was the most ideal therapeutic agent due to its minimal invasiveness for mammalian cells and high bacteriostatic efficacy $[67,84] . \mathrm{O}_{2} \cdot{ }^{-}$hardly reacts with negatively charged biomolecules due to electrostatic repulsion; but it can be easily electrostatically attracted to biosynthetic enzymes containing

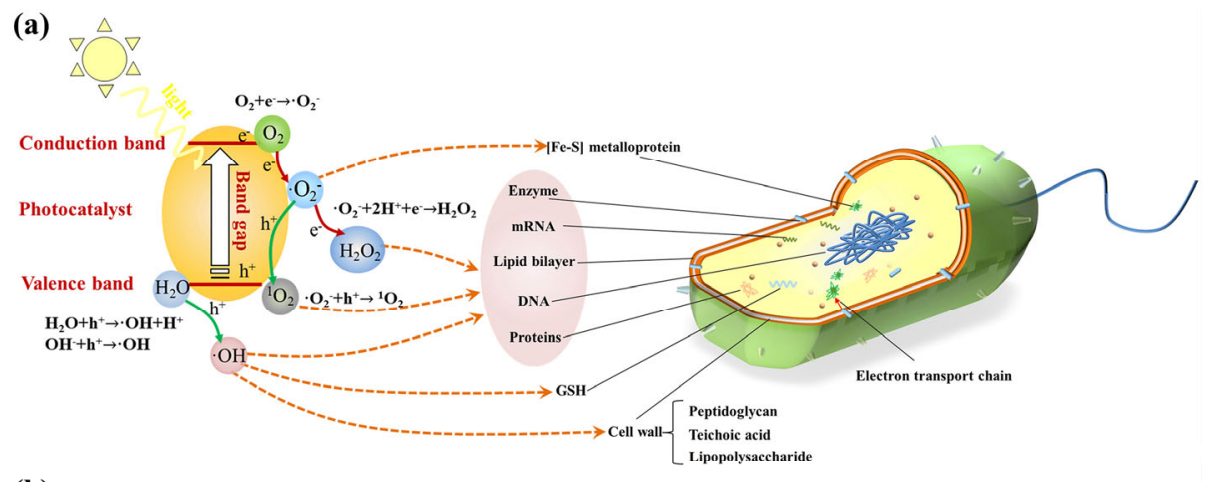

(b)

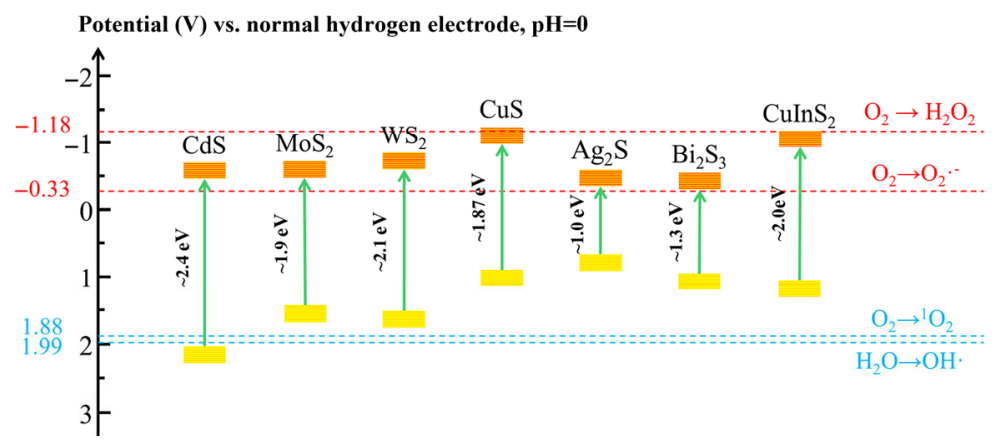

Figure 3 Photocatalytic antibacterial mechanisms. (a) Schematic illustration of photocatalytic antibacterial mechanism. (b) The redox potential for ROS generation and the band structure diagram of several typical TMSs 
labile iron-sulfur clusters [67]. The arise of iron sequestration in host colonization, rather in bacteria, results in the vulnerability of pathogenic bacteria to $\mathrm{O}_{2} \cdot{ }^{-}$with respect to hosts, which leads to selective bacterial elimination [67]. Additionally, Ray et al. found that $\mathrm{O}_{2} \cdot{ }^{-}$mainly perturbed carbon deficient sites of protein and the pi-bond containing carbon chain of fatty acid, thereby destroying cell walls [68].

Besides the redox potential for ROS generation, the band structure diagram of several typical TMSs is also illustrated in Fig. 3(b) [48, 50, 85-87]. Notably, due to the deviation of measurement conditions, there may be slight variations for these data in different literatures [85]. Referring to this diagram, the conduction band (CB) of TMSs is suitably matched for the formation of $\mathrm{O}_{2} \cdot{ }^{-}$, the most ideal scavenger, which determines the outstanding potentiality of TMSs for therapeutic use. Numerous research articles have also evidenced that $\mathrm{O}_{2} \cdot{ }^{-}$could be produced over TMSs through photocatalysis [48, 50, 85-87]. However, for the generation of the other three types of ROS, there still remain controversial issues. Shang et al. found that $\mathrm{O}_{2} \cdot{ }^{-}$and ${ }^{1} \mathrm{O}_{2}$ were generated on $\mathrm{CdS}$, which was well accordant with its energy band structure. However, $\mathrm{O}_{2} \cdot{ }^{-},{ }^{1} \mathrm{O}_{2}$, and $\cdot \mathrm{OH}$ were produced on $\mathrm{MoS}_{2}$ and $\mathrm{WS}_{2}$, which was inconsistent with their energy band potential. The authors attributed this phenomenon to the positive shift of the VB caused by quantum confinement effects of the ultra-small-sized nanoparticles [88]. In fact, the energy band structure can be tuned with many approaches including microstructure engineering and surface functionalization. Thus, the antimicrobial properties of TMSs can be regulated by appropriate modification strategies, and this aspect will be highlighted later in this review.

\subsubsection{Enzyme-like functions of TMSs}

Over the past few decades, tremendous progresses in the synthesis of nanomaterials has stimulated people's interest in exploring nanomaterial-based artificial enzymes (nanozymes), which exhibit unexpected enzyme-like activities [89-91]. To date, many types of nanozymes, including iron-based, vanadium-based, noble metal-based, carbon-based, metalorganic framework-based, and TMSs based nanostructures, have been explored and investigated for antibacterial applications [45, 63, 89, 90, 92, 93]. Among these materials,
TMSs exhibit enzyme-like (oxidase and peroxidase) properties, leading to the effective generation of ROS [92-94]. With aid of density functional theory (DFT) calculations, Qu's group calculated the free energy of different types of $\mathrm{MoS}_{2}$ nanozymes in $\mathrm{H}_{2} \mathrm{O}_{2}$ catalytic process (Fig. 4(a)) and built a typical model to discuss the $\mathrm{H}_{2} \mathrm{O}_{2}$ activation process on the surface of various types of $\mathrm{MoS}_{2}$ nanozymes and the absorption energy of the process, with the activation process of S-defect $\mathrm{MoS}_{2}$ nanozymes being shown in Fig. 4(b). They indicated that the defect-rich edges of $\mathrm{MoS}_{2}$ nanozymes led to higher intrinsic peroxidaselike activity and antibacterial effect with respect to pristine structure owing to their lower absorption energies of $\mathrm{H}_{2} \mathrm{O}_{2}$ and intermediate $\mathrm{OH}^{*}$ as well as the more negative free energies for the whole reaction [92]. As shown in Fig. 4(c), Shan and colleagues put forward a hypothesis that $\mathrm{Cu}_{2} \mathrm{WS}_{4}$ (CWS) nanocrystals possessed enzyme-like (oxidase and peroxidase) properties, which could catalyze the physiologically relevant antioxidants $\left(\mathrm{AH}_{2}\right)$ in bacteria to generate $\mathrm{H}_{2} \mathrm{O}_{2}$ and oxidative product $\mathrm{A}$ in the present of $\mathrm{O}_{2}$ and then decompose $\mathrm{H}_{2} \mathrm{O}_{2}$ to form $\cdot \mathrm{OH}$, following the process shown in the following Eqs. (1) and (2) [93].

$$
\begin{aligned}
& \mathrm{AH}_{2}+\mathrm{O}_{2} \stackrel{\text { CWs }}{\rightarrow} \mathrm{A}+\mathrm{H}_{2} \mathrm{O}_{2} \\
& \mathrm{H}_{2} \mathrm{O}_{2} \stackrel{\mathrm{CwS}}{\longrightarrow} \cdot \mathrm{OH}
\end{aligned}
$$

\subsubsection{Piezocatalytic degradation process}

In addition to the above two antibacterial pathways, the bactericidal potential based on piezoelectric effect originated from the asymmetric lattice of TMSs has also been observed [95, 96]. As depicted in Figs. 5(a) and 5(b), Wu's group elucidated the generation mechanisms of ROS on the surface of singlelayer $\mathrm{WS}_{2}$ nanoflowers (NFs) under the ultrasonic vibration, which was ascribed to the piezo-generated electron and hole pairs separations caused by spontaneous polarization. They embedded the abundant $\mathrm{WS}_{2}$ NFs in the polydimethylsiloxane and the obtained composite displayed a $99.99 \%$ killing rate of Escherichia coli through the piezoelectric effect within $60 \mathrm{~min}$ ultrasonic vibration [95]. Based on the previous investigations, their group further investigated the piezoelectric effect of $\mathrm{MoS}_{2}$

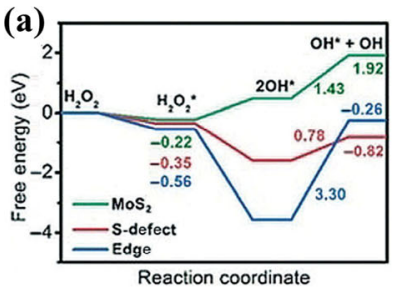

(b)

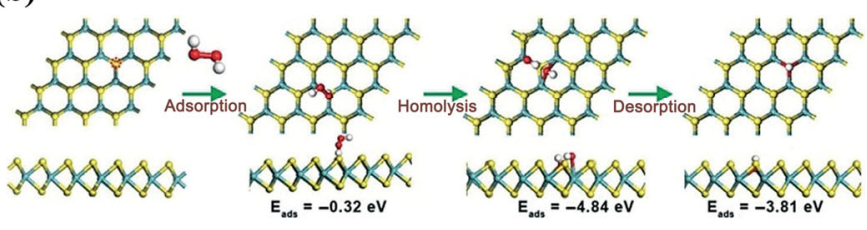

(c)

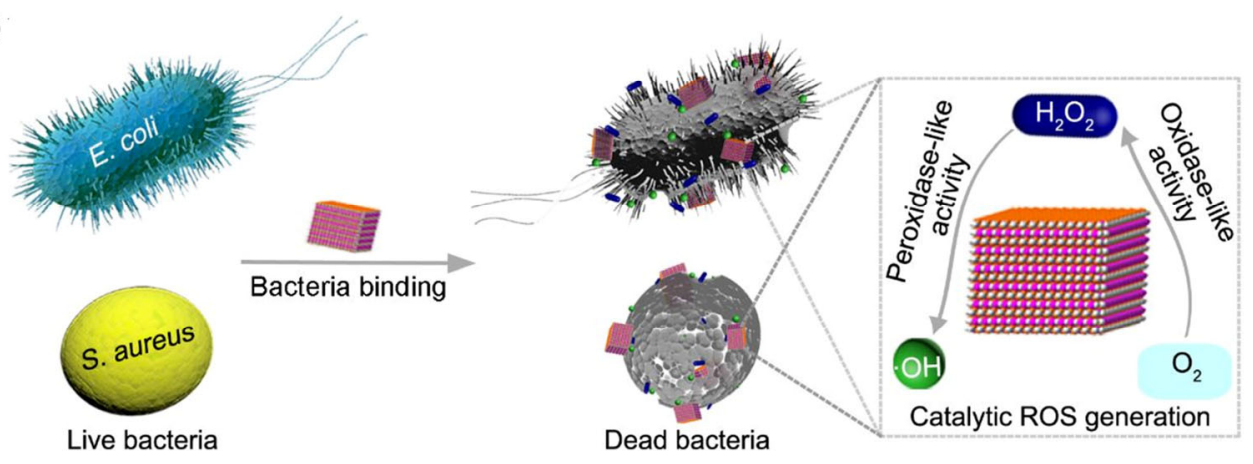

Figure 4 The catalytic activity of TMSs based nanozymes. (a) The free energies of pristine, S-defect, and edge $\mathrm{MoS}_{2}$ in $\mathrm{H}_{2} \mathrm{O}_{2}$ catalytic process. (b) $\mathrm{H}_{2} \mathrm{O}_{2}$ activation process occurred on S-defect $\mathrm{MoS}_{2}$ nanozymes. The $\mathrm{S}, \mathrm{Mo}, \mathrm{H}$, and $\mathrm{O}$ atoms are shown in yellow, blue, gray, and red balls, respectively. The red dashed circle indicate the S-defect. Reproduced with permission from Ref. [92], () WILEY-VCH Verlag 2019. (c) Schematic illustration of antibacterial process of $\mathrm{Cu}_{2} \mathrm{WS}_{4}$ nanozymes. Reproduced with permission from Ref. [93], ๔ American Chemical Society 2019. 
(a)

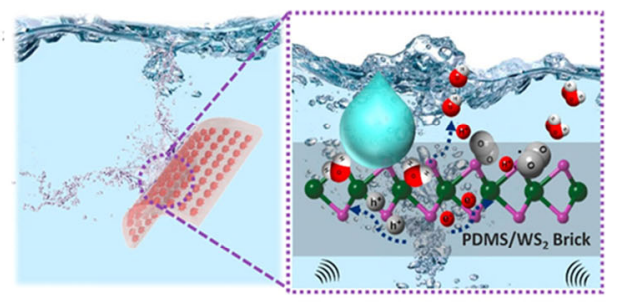

(c)

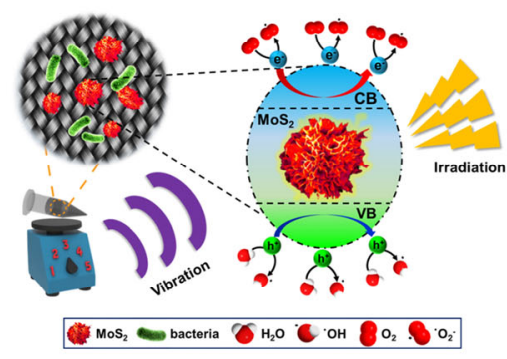

(b)
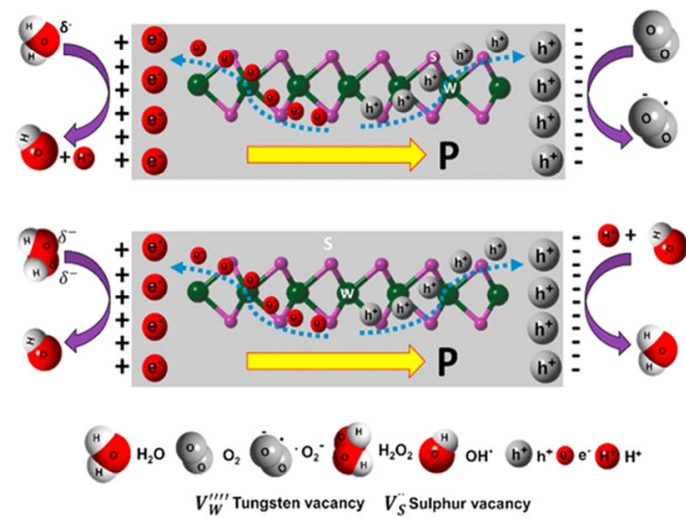

(d)

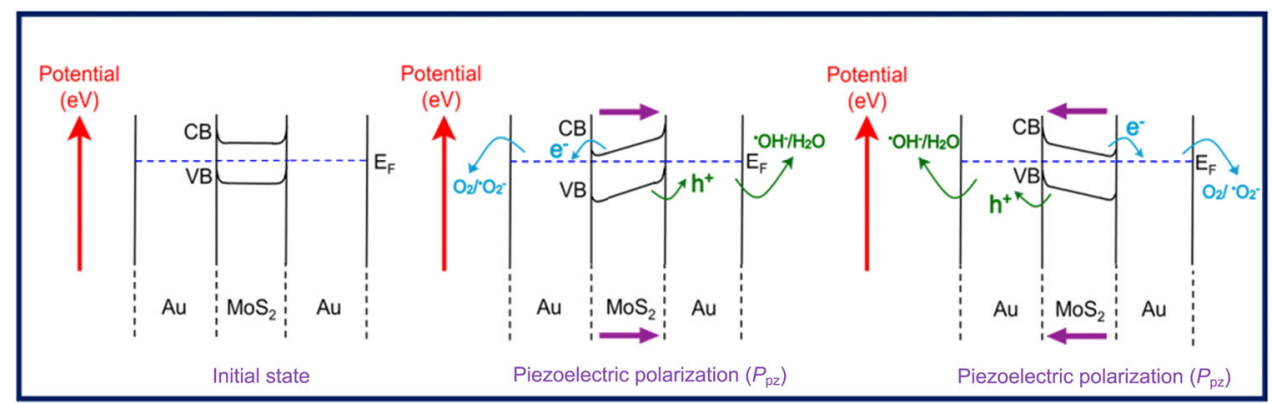

Figure 5 Piezocatalytic degradation mechanism. (a) Schematic illustration of working mechanism of polydimethylsiloxane/WS ${ }_{2}$ nanoflowers in water. (b) Generation mechanisms of ROS based on piezoelectric effect. Reproduced with permission from Ref. [95], (Elsevier B.V. 2018. (c) Schematic diagram of the hybridization of the piezoelectric and photocatalytic effects for bacteria elimination. (d) Schematic diagram of the piezocatalytic reaction in $\mathrm{Au}-\mathrm{MoS} 2$ to promote the generation of ROS and charge carriers separation. Reproduced with permission from Ref. [96], @Elsevier B.V. 2019.

on bacterial elimination and explored the hybridization of the piezoelectric and photocatalytic effects (Fig. 5(c)). They revealed that the deposition of Au NPs on the surface of $\mathrm{MoS}_{2}$ could enhance the piezoelectric effect of $\mathrm{MoS}_{2}$ through the improved charge carriers separation (Fig. 5(d)) [96].

\subsection{Synergistic contribution between photothermal and photodynamic processes}

Near-infrared (NIR) laser-induced photothermal therapy (PTT) exhibiting high light-to-thermal conversion has attracted much research attention in biotechnology [46, 97-99]. However, it is still a controversy on the understandings of the photothermal conversion mechanisms of TMSs. For example, some researchers described that the photothermal effect of $\mathrm{Cu}_{2-x} \mathrm{~S}$ should be attributed to their localized surface plasmon resonances (LSPR) rendered by the collective oscillations of holes [46, 100-102]. Some believed that CuS NPs can transform light into heat due to the $\mathrm{d}-\mathrm{d}$ energy band transition of $\mathrm{Cu}^{2+}$ ions $[103,104]$. Some other researchers suggested that when TMSs are irradiated by NIR light, the electrons can be exited from VB, creating the so-called photo-induced charge carriers. The recombination of these charge carriers releases most of the absorbed photon energy as heat via non-radiative decay, causing the local temperature rising dramatically and rapidly [105]. Although the photothermal conversion mechanism of TMSs is still elusive and controversial, there is no doubt about its lethal effects of hyperthermia on bacteria [106].

During the PTT process, bacterial cell walls become wrinkled and damaged due to the high local temperature followed by the disruption of the cell membrane. Finally, the leakage of intracellular material leads to cell death $[103,107,108]$.
Additionally, recent investigations elaborated the immense potential of synergistic antibacterial strategy between photothermal and photodynamic processes. Li et al. stressed that the leakage of proteins from damaged bacteria caused by PTT was accelerated with the assistance of ROS [109]. Zhang and colleagues indicated that PTT could also enhance the cell membrane permeability, allowing ROS to penetrate into the cell walls to destroy intracellular proteins thus bringing about rapid bacterial elimination [70]. Gu's group revealed that the catalytic oxidation of organic thiols into disulfides was a temperature-depending process. Glutathione (GSH) oxidation could be accelerated due to the NIR light irradiation which strengthened the invasiveness of ROS. Through the combined contribution between laser-induced hyperthermia and generated ROS, the PEG-MoS $\mathrm{S}_{2}$ nanoflowers can result in bacterial death effectively [110]. The above results suggested that oxidative lesions induced by a small quantity of ROS could work together well with PTT, which resulted in much higher synergistic antibacterial efficacy $[70,109]$. In order to give audience a better illustration of the photothermal therapy of TMSs for antibacterial purpose, we summarize key parameters of TMSs in Table 1, where $C_{1}, C_{2}, T_{1}$, and $T_{2}$ represent concentration and irradiation period during the photothermal effect and in vitro antibacterial assay, respectively.

\subsection{Membrane damaging mechanisms}

Two-dimensional (2D) materials, such as graphene, transition metal dichalcogenides (TMDs), phosphorene, tellurene, and Mxene, have attracted much attention for various biological applications due to their unique properties including low cytotoxicity, big surface area, high chemical stability, and excellent 
Table 1 Representative photothermal therapy studies on TMSs

\begin{tabular}{|c|c|c|c|c|c|c|c|c|c|c|c|}
\hline TMSs & $\begin{array}{l}\text { Antibacterial } \\
\text { mechanism }\end{array}$ & $C_{1}$ & NIR laser & $T_{1}$ & $\begin{array}{l}\text { Photothermal } \\
\text { conversion } \\
\text { efficiency }\end{array}$ & $T_{2}$ & $C_{2}$ & $\begin{array}{l}\text { Light source } \\
\text { (output power/ } \\
\text { intensity; } \\
\text { wavelength) }\end{array}$ & Bacterial & $\begin{array}{c}\text { Antibacteria } \\
\text { l effect }\end{array}$ & Ref. \\
\hline PEG-MoS 2 & PTT, PDT & $500 \mathrm{ppm}$ & $\begin{array}{c}808 \mathrm{~nm}, \\
1.00 \mathrm{~W} / \mathrm{cm}^{2}\end{array}$ & $10 \mathrm{~min}$ & $43.72 \%$ & $10 \mathrm{~min}$ & $150 \mu \mathrm{g} / \mathrm{mL}$ & $\begin{array}{c}808 \mathrm{~nm}, \\
1.00 \mathrm{~W} / \mathrm{cm}^{2}\end{array}$ & $\begin{array}{c}\text { E. coli } \\
\text { B. subtilis }\end{array}$ & $\begin{array}{l}97.00 \% \\
99.00 \%\end{array}$ & [110] \\
\hline BSA-CuS & $\begin{array}{l}\mathrm{PTT}, \mathrm{Cu}^{2+} \\
\text { release }\end{array}$ & $100 \mathrm{ppm}$ & $\begin{array}{c}980 \mathrm{~nm}, \\
1.59 \mathrm{~W} / \mathrm{cm}^{2}\end{array}$ & $10 \mathrm{~min}$ & $25.68 \%$ & $45 \mathrm{~min}$ & $50 \mathrm{ppm}$ & $\begin{array}{c}980 \mathrm{~nm}, \\
1.59 \mathrm{~W} / \mathrm{cm}^{2}\end{array}$ & $\begin{array}{c}\text { S. aureus } \\
\text { E. coli }\end{array}$ & $\begin{array}{l}86.30 \% \\
83.80 \%\end{array}$ & [103] \\
\hline PEG-Cu $9 \mathrm{~S}_{8}$ & PTT, PDT & $500 \mu \mathrm{g} / \mathrm{mL}$ & $\begin{array}{c}808 \mathrm{~nm}, \\
1.00 \mathrm{~W} / \mathrm{cm}^{2}\end{array}$ & $10 \mathrm{~min}$ & $41.55 \%$ & $10 \mathrm{~min}$ & $125 \mu \mathrm{g} / \mathrm{mL}$ & $\begin{array}{c}808 \mathrm{~nm}, \\
1.00 \mathrm{~W} / \mathrm{cm}^{2}\end{array}$ & S. aureus & $\begin{array}{l}\text { Inhibit the } \\
\text { formation of } \\
\text { biofilm }\end{array}$ & [128] \\
\hline $\begin{array}{c}\mathrm{CuS} / \mathrm{mSiO}_{2-} \\
\mathrm{MPS}\end{array}$ & $\begin{array}{l}\mathrm{PTT}, \mathrm{PDT}, \\
\mathrm{Cu}^{2+} \text { release }\end{array}$ & $1.5 \mathrm{mg} / \mathrm{mL}$ & $\begin{array}{c}808 \mathrm{~nm}, \\
2.0 \mathrm{~W} / \mathrm{cm}^{2}\end{array}$ & $10 \mathrm{~min}$ & - & $10 \mathrm{~min}$ & $1.5 \mathrm{mg} / \mathrm{mL}$ & - & $\begin{array}{c}\text { S.aureus } \\
\text { E.coli }\end{array}$ & $\begin{array}{l}99.80 \% \\
99.94 \%\end{array}$ & [197] \\
\hline $\begin{array}{c}\text { PEG-CuS@g- } \\
\qquad \mathrm{C}_{3} \mathrm{~N}_{4}\end{array}$ & $\begin{array}{l}\mathrm{PTT}, \mathrm{Cu}^{2+} \\
\text { release }\end{array}$ & $200 \mu \mathrm{g} / \mathrm{mL}$ & $\begin{array}{c}808 \mathrm{~nm}, \\
1.00 \mathrm{~W} / \mathrm{cm}^{2}\end{array}$ & $20 \mathrm{~min}$ & $59.64 \%$ & $20 \mathrm{~min}$ & $200 \mathrm{mg} / \mathrm{ml}$ & $\begin{array}{c}808 \mathrm{~nm} \text {, } \\
2.50 \mathrm{~W}\end{array}$ & $\begin{array}{c}\text { S.aureus } \\
\text { E.coli }\end{array}$ & $\begin{array}{l}99.00 \% \\
99.00 \%\end{array}$ & [107] \\
\hline
\end{tabular}

thermal conductivity and electron mobility [99, 111-113]. Especially, graphene-based materials and TMSs have shown bright prospects for antibacterial applications [85, 112, 114]. Recent investigations deciphered the processes of membrane depolarization, dents formation, and phospholipid extraction processes occurring on the membrane of bacteria on contact with 2D TMSs nanosheets [115-119]. Yang and colleagues indicated that the electron transfer from the bacterial membrane to chemically exfoliated $\mathrm{MoS}_{2}\left(\mathrm{ce}-\mathrm{MoS}_{2}\right)$ nanosheets led to the change of membrane potential, causing membrane depolarization [115]. Wu et al. unraveled the interaction mechanism between ce- $\mathrm{MoS}_{2}$ nanosheets and the bacterial membrane through a combined approach of molecular dynamics simulation and experiments. According to their study, the interaction process between the nanosheets and bacteria could be divided into three stages, including contact, the formation of dents and extraction of phospholipids (Fig. 6(a)). As shown in Fig. 6(b), the interaction between the ce- $\mathrm{MoS}_{2}$ nanosheets and phospholipids increases drastically after the contact course, indicating that the nanosheets can disrupt the organizational structure of the lipid membranes by making dents on its surface and extracting large amounts of phospholipids to reduce the integrity of the membrane, which was attributed to the synergistic effect of the dispersion interaction of $S$ atoms with lipid tails and the electrostatic interactions between lipid head groups and the lateral edges of ce- $\mathrm{MoS}_{2}$ nanosheets. This result could be observed in the image of scanning electron microscopy (SEM) as well (Fig. 6(c)) [116]. As depicted in Fig. 6(d), Jaiswal's group further elucidated the subsequent physiological process, including the inactivation of bacterial respiratory pathway and disruption of the antioxidant defense system, and ascertained a relatively integrated antibacterial process for membrane damage mechanism. The cell structure of E. coli before and after destruction was shown in Figs. 6(e) and 6(f), which verified the membrane damage process [117].

\subsection{Other antibacterial mechanisms of TMSs}

Besides the antibacterial mechanisms discussed above, some other bacterial inhibition pathways have also been involved in the discussion on TMSs-based microbial killing agents. Although numerous researches have indicated that metal ions, such as $\mathrm{Ag}$ and $\mathrm{Cd}$ ions, exhibit strong bactericidal effects, they are (a)

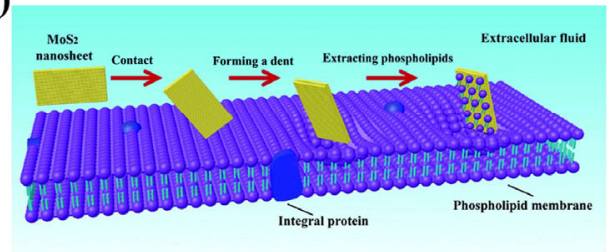

(d)

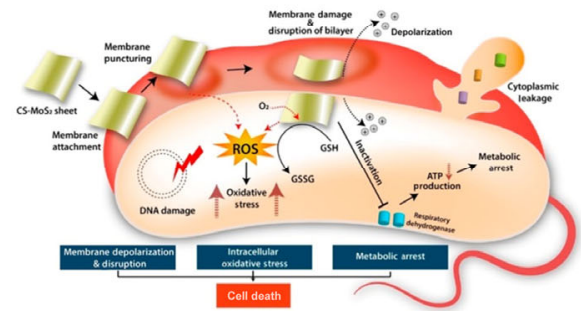

(b)
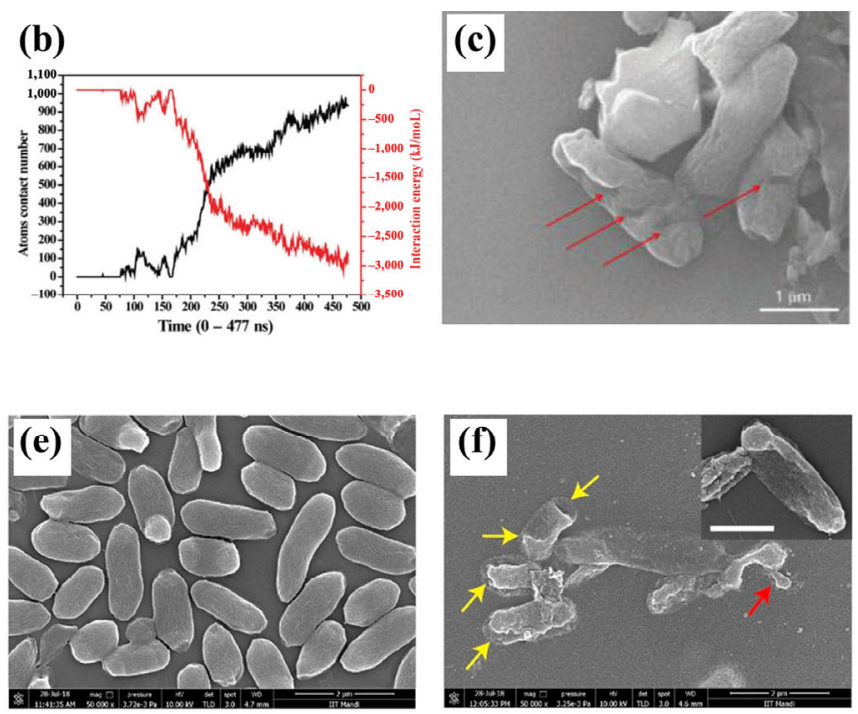

Figure 6 Membrane damage mechanisms of $\mathrm{MoS}_{2}$ nanosheets. (a) Phospholipid extraction process. The MoS nanosheet and the bacterial cell membrane are shown as a yellow rectangular block and the purple double layer, respectively. (b) The atom contact number (the number of phospholipid atoms presented around the $\mathrm{MoS}_{2}$ nanosheet within a range of $5 \AA$ ) and the interaction energy between the MoS 2 nanosheet and the membrane. (c) SEM image of damaged E. coli cells treated with $\mathrm{MoS}_{2}$ nanosheets. The red arrows indicate the dents on the surface of bacteria. Reproduced with permission from Ref. [116], (C) Royal Society of Chemistry 2018. (d) Integrated antibacterial process for membrane damage mechanism. SEM image of (e) untreated E. coli cells and (f) damaged E. coli cells. Yellow arrows indicate the damage caused by the nanosheets and the inset exhibits the extent of membrane damage. Reproduced with permission from Ref. [117]. (C)American Chemical Society 2019. 
also cytotoxic at the same time and thus need to be used at much lower concentrations [120-122]. Due to the strong covalent interaction between metal atoms and sulfur atoms, TMSs often exhibit high stability against metal leakage, which is beneficial for controlling the metal ions at a very low concentration $[52,53]$. It has been also reported that the release of metal ions from TMSs has been considered as one of the possible factors responsible for their bacteriostatic efficacy [120, 123, 124]. This postulation was evidenced in $\mathrm{CdS}, \mathrm{Ag}_{2} \mathrm{~S}$, and $\mathrm{CuS}$ except for $\mathrm{MoS}_{2}[88,103,125,126]$. Particularly, $\mathrm{Cu}^{2+}$ could form chelates (such as copper-peptide complexes) with biomolecules or dislodge the metal ions in some metalloproteins, causing dysfunctional proteins and further cell inactivation [124, 127]. Huang et al. found that the release of $\mathrm{Cu}^{2+}$ could be accelerated owing to local high-temperature ablation rendered by the photothermal effect [103]. Additionally, $\mathrm{Cu}^{2+}$, as a necessary trace amount element in human body, plays a promoting role in the process of angiogenesis and osteogenic differentiation, and can be used in wound healing and implant surgery $[126,128]$. In addition to the aforementioned effects, $\mathrm{Xu}$ and colleagues explored a novel therapeutic approach mimicking the natural sterilization mechanism for the organosulfur compounds in bulbs of plants. During the oxidation of cysteine-FeS flakes to $\mathrm{Fe}_{2} \mathrm{O}_{3}$ nanoparticles, the hydrogen polysulfanes were released and exhibited potent bactericidal activity (Fig. 7(a)). As shown in Figs. 7(b) and 7(c), the confocal three-dimensional (3D) images and SEM images indicated that cysteine-FeS could effectively disrupt the biofilm and the hydrogen polysulfanes permeated into bacterial biofilm to suppress bacterial growth [129]. Besides, Huang's team found that $\mathrm{MoS}_{2}$ could significantly affect several metabolic pathways of E. coli, such as amino acid related metabolism and pyruvate metabolism [130].

The previous pioneering researches indicated that TMSs can be promising candidates for antibacterial applications. However, up to now, their relatively low efficiency for bactericidal purposes still impedes their wide applications in our daily life, and thus more studies should be conducted to further unravel the complicated mechanisms for bacterial ablation and explore new strategies to improve the antibacterial activity of TMSs-based materials.

\section{Recent advances on construction TMSs-based materials for efficient antimicrobial applications}

In the previous section, the antibacterial mechanisms of TMSs have been systematically summarized. In consideration of their versatile antibacterial mechanisms, TMSs stand out as a promising candidate. However, though TMSs show great potential as antibacterial agents, their efficacy is still limited by the factors including quick recombination and weak reactivity of the charge carriers and needs to be further improved to meet the requirement for practical applications [131-133]. Additionally, pristine TMSs are difficult to disperse in water, and easy to agglomerate, exhibiting inert nature, which restricts its sterilization effect as well $[54,110,134]$. To circumvent the deficiency of TMSs, various strategies have been explored for improving the antibacterial behaviors of the pristine TMSs, as discussed in this section.

\subsection{Microstructure engineering}

The photo-excited electron-hole pairs could easily recombine in TMSs due to their narrow band gaps, which seriously limits the generation of ROS [131-133]. It has been reported that the band gaps of TMSs can be enlarged when decreasing their sizes and layer thicknesses owing to the quantum confinement effect [131-133]. More positive VB and more negative CB result in stronger redox activities and more production of ROS [88]. Additionally, TMSs with ultrathin nanoarchitecture are more likely to invade the internal environment of microbes to hamper their core metabolic pathways [63]. Consequently, the construction of nanoscale TMSs with suitable electronic structure is a meritorious strategy to facilitate the elimination of microbe. Apart from the size effect, $0 \mathrm{D}$ and 2D microstructure usually lead to larger surface area, more surface defects, higher charge carrier mobility, shorter transportation distance, and bigger flexibility in terms of tuning their electronic properties. These advantageous properties have proven beneficial for the exposure of active sites for adsorption of oxygen or water molecules and catalytic reactions and the long time survival of photo-induced charge carriers [49, 92, 115, 135-137]. As shown in Fig. 8(a), Tian et al. found that compared with bulk $\mathrm{MoS}_{2}$ with band gap of ca.1.2 eV, $\mathrm{MoS}_{2}$ quantum dots (QDs) with band gap of $\sim 1.8 \mathrm{eV}$ exhibited more active edges, higher charge carrier mobility and bigger special surface area, resulting in better photocatalytic activity (loss of GSH, see Fig. 8(b)) and antibacterial performance [132]. Qiao and colleagues also found that $\mathrm{CuS}$ nanodots (NDs) $(\sim 6 \mathrm{~nm})$ showed higher ROS signal and antimicrobial performance than CuS NPs $(\sim 20 \mathrm{~nm})$ [126]. Wang et al. introduced HS- $\left(\mathrm{CH}_{2}\right)_{11}-\left(\mathrm{OCH}_{2} \mathrm{CH}_{2}\right)_{6}-\mathrm{OH}$ into the intermediate solutions with $\mathrm{CuCl}_{2}, \mathrm{Na}_{2} \mathrm{~S}$ and sodium citrate to trap the intermediate, and obtained water-soluble, monodispersed $\mathrm{CuS}$ nanoclusters (NCs). The value of minimum inhibitory concentration (MIC) against E. coli of CuS NCs (a)

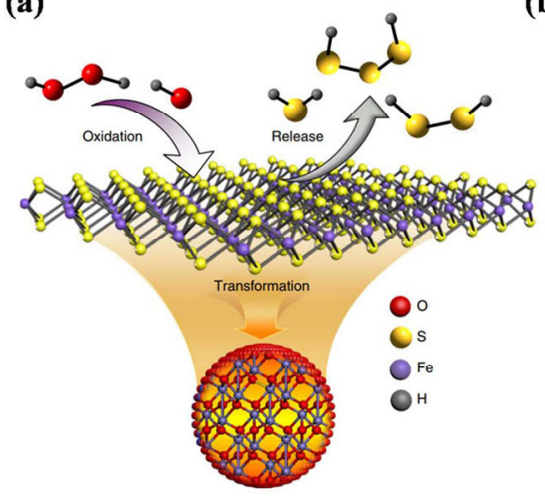

(b)

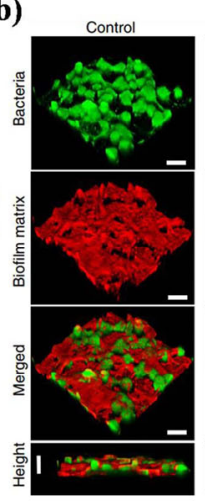

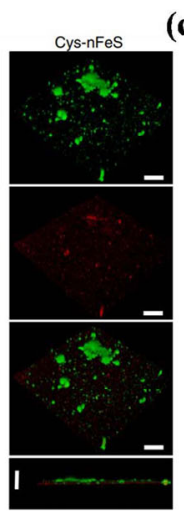

Figure 7 The antibacterial mechanism based on polysulfane. (a) polysulfane release from meter-sized iron sulfides. (b) Confocal 3D image of S. mutans biofilms with or without the treatment of cysteine-FeS (scale bars: $100 \mu \mathrm{m}$ ). (c) S. mutans biofilms formed on the surface of a human tooth. (d) SEM image of $S$. mutans biofilms with or without the treatment of cysteine-FeS. The red arrows indicate extracellular polysaccharide. Left scale bars are $100 \mu \mathrm{m}$. Right scale bars are $3 \mu \mathrm{m}$. Reproduced with permission from Ref. [129], @Springer Nature 2018. 
(a)

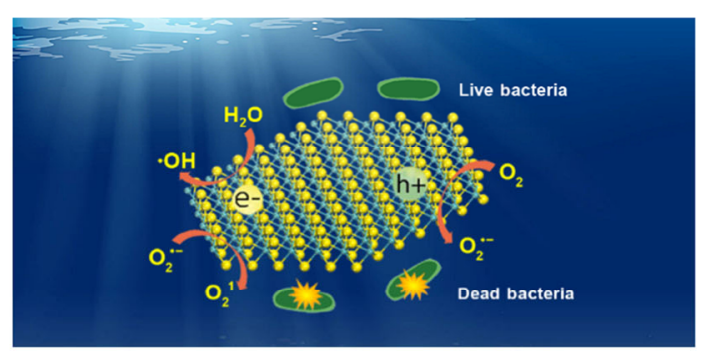

(c)

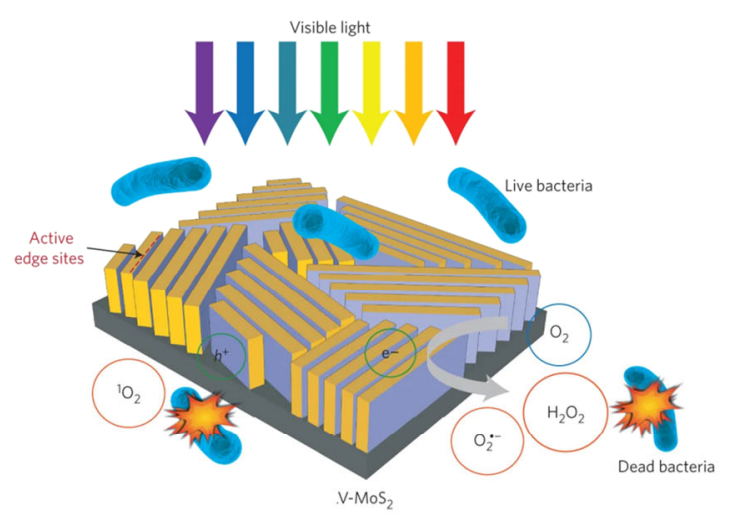

(b)

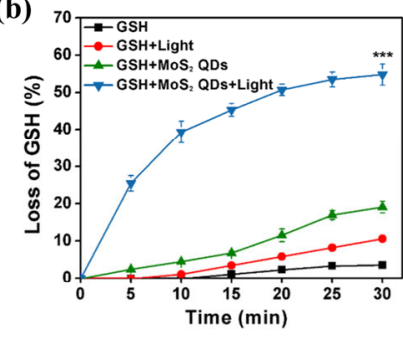

(d)

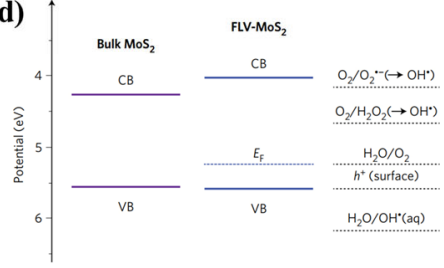

(e)

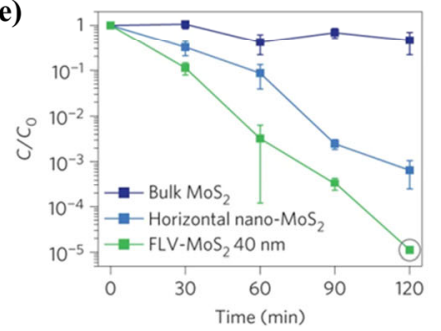

Figure 8 The enhanced generation of ROS and antibacterial effect stemming from microstructure engineering. (a) Schematic diagram of MoS 2 quantum dots for antibacterial effect. (b) Loss of GSH after the treatment with different nanomaterials. Reproduced with permission from Ref. [132], @American Chemical Society 2018. (c) Schematic illustration of FLV-MoS 2 for eradicating bacteria under the irradiation of visible light. (d) The band position of FLV-MoS 2 with respect to the bulk $\mathrm{MoS}_{2}$ band position. (e) Antibacterial performances of FLV-MoS 2 compared with those of horizontal aligned MoS 2 nanofilms and bulk $\mathrm{MoS}_{2}$. Reproduced with permission from Ref. [133], @Springer Nature 2016.

reached $800 \mu \mathrm{M}(76.8 \mu \mathrm{g} / \mathrm{mL})$ [138]. Besides reducing the sizes of TMSs, decreasing their layer thicknesses is an effective strategy as well. Compared with bulk $\mathrm{MoS}_{2}, \mathrm{MoS}_{2}$ nanosheets with fewer layers possess wider band gaps. For instance, the band gap of single-layer $\mathrm{MoS}_{2}(\sim 1.8 \mathrm{eV})$ is wider than that of few-layer $\mathrm{MoS}_{2}(\sim 1.5 \mathrm{eV})$ [106]. As shown in Figs. 8(c) and 8(d), Liu et al. observed thickness-dependent antibacterial performances on few-layered vertically aligned $\mathrm{MoS}_{2}$ nanofilms $\left(\mathrm{FLV}-\mathrm{MoS}_{2}\right)$ with thinner nanosheets showing higher efficacy. The authors attributed this to the promoted ROS generation on thinner sheets resulted from the wider band gap and shorter transportation distance of photo-induced charge carriers. The FLV-MoS 2 achieved a $\sim 15$ times better log inactivation rate of E. coli with respect to the bulk $\mathrm{MoS}_{2}$ (Fig. 8(e)) [133]. Besides, some other works also indicated that by reducing the number of layers, $\mathrm{MoS}_{2}$, and $\mathrm{WS}_{2}$ could change from indirect semiconductors to direct semiconducting materials due to dielectric screening $[132,139,140]$. Some scientists believed that the transition of band gap was instrumental in improving photocatalytic behavior $[132,141]$. However, this viewpoint has not yet been widely recognized, and further research is needed.

Additionally, enhanced bacteriostatic efficacy also appeared in some special morphology, stemming from similar mechanisms. Zhang's team utilized chemical vapor deposition to grow a pyramid-type $\mathrm{MoS}_{2}$ on a transparent glass and the density of reaction active sites was improved compared to monolayer $\mathrm{MoS}_{2}$ owing to stacking layers with reducing sizes in the pyramid shape. Next, several nanometers thicknesses silver layer was thermally deposited on the pyramid $\mathrm{MoS}_{2}$ to further enhance the production of ROS. This pyramid-type $\mathrm{MoS}_{2} @ \mathrm{Ag}$ could kill $99.99 \%$ of $E$. coli within 40 min under simulated visible light irradiation [142]. Besides, it was also found that rough surface of $\mathrm{MoS}_{2}$ was instrumental in the bacterial adhesion, which facilitated the capture of bacteria and kill them [92]. To sum up, tuning the microstructure can be a meritorious route for enhancing the antibacterial properties of TMSs and the flexibly tunable electronic properties of TMSs provide lots of space for the exploration of their antibacterial potentials. The aforementioned pioneering investigations showed that the bactericidal activity of TMSs can be manipulated by altering their microstructure including size and morphology and we expect more work coming in this realm in the future.

\subsection{Surface functionalization}

To further fully harness their capabilities, pristine TMSs, showing inert nature, are very imperative to be functionalized $[54,134]$. Due to the unique surface properties of TMSs including large specific surface area and abundant surface defects, organic molecules could be easily anchored onto the surfaces of TMSs via physisorbed interaction or chemisorbed interaction $[54,134,143]$. These ligands dramatically alter the surface states and electronic properties of the TMSs, which offers us a powerful route to enhance the antibacterial performance. As most bacteria are negatively charged on the surface, TMSs with positive charges can be more easily adhered to bacteria and exert a greater bacteriostatic efficacy $[45,106,131,143,144]$. Many studies have also evidenced this phenomenon. Zhu et al. elucidated that the bacteria in suspension can be easily adsorbed to chitosan on the surface of $\mathrm{Ag} / \mathrm{MoS}_{2}-\mathrm{Ti}$ coating. After $\mathrm{Ag} / \mathrm{MoS}_{2}-\mathrm{Ti}$ is equipped with chitosan, under the irradiation of $660 \mathrm{~nm}$ visible light for $20 \mathrm{~min}$, the antibacterial efficiency towards E. coli and Staphylococcus aureus was improved from $86.2 \%$ and $84.27 \%$ to $99.77 \%$ and $98.66 \%$, respectively [106]. Therefore, tailoring TMSs with positively charged ligands is a prerequisite. Additionally, although the 
amphiphilic nature of cationic polymers has rarely been considered in tailoring bacterial inhibitory agents, it also virtually plays an important role during bactericidal processes $[131,144,145]$. Karunakaran and colleagues exfoliated and directly functionalized $2 \mathrm{H}-\mathrm{MoS}_{2}$ simultaneously using surfactant thiol ligand with amphiphilic nature (Fig. 9(a)). Their work indicated that with the hydrophobicity in the positive headgroup increasing, the cell membrane depolarization (Fig. 9(b)) and interaction between bacteria and nanosheets (Figs. 9(c)-9(j)) could be enhanced, leading to stronger antibacterial activity [143]. Dai and colleagues used poly(5-(2-ethyl acrylate)-4methylthiazole-g-butyl) to functionalize CuS NCs and found that the amphiphilic nature and positive charges of the cationic polymer could aid the interaction between the hybrids and the negatively charged cell membrane via electrostatic interaction which resulted in the facile penetration of these inorganicorganic hybrids into the lipid bilayer interior. These conjugated nanoclusters exhibited MIC value against levofloxacin-resistant S. aureus, E. coli, Pseudomonas aeruginosa, and Bacillus amyloliquefaciens at $5.5 \mu \mathrm{g} / \mathrm{mL}$ under NIR laser irradiation (980 nm, $\left.1.5 \mathrm{~W} / \mathrm{cm}^{2}, 5 \mathrm{~min}\right)$ [144]. Pandit et al. fabricated functionalized ce- $\mathrm{MoS}_{2}$ nanosheets with different alkane chains to impart different hydrophobicity to the surface of nanosheets and the antibacterial performance evaluation results showed that with the increase of hydrophobicity (the length of alkane chains), the hydrophobic interaction of long alkane chains with the pathogens cell membrane would result in stronger cell membrane depolarization and thus the MIC and minimum bactericidal concentration (MBC) against $S$. aureus and $P$. aeruginosa of functionalized ce- $\mathrm{MoS}_{2}$ decreased significantly, all reaching $78 \mathrm{ppb}$ [131]. Based on the above analysis, TMSs equipped with finely tailored ligands can more accurately act on the surface of pathogens and eradicate them, which is an effective means to improve antibacterial performance.

The second point is that the metal-sulfur bonds in TMSs are going to be weakened due to covalently bound organic functional groups, and this would dramatically alter the electronic properties of the TMSs [54]. Nguyen and colleagues deciphered that the mild Lewis basicity of the thiols led to an overall electron donating effect, shifting the band edge and Fermi level of the $\mathrm{MoS}_{2}$ flakes to more positive values. As shown in Figs. 10(a) and 10(b), the extent of the valence and conduction bands shift is consistent with the intensity of basicity [146]. Additionally, Zheng's group found that S-vacancies were related to the new gap states and with increasing S-vacancies, the bands of $\mathrm{MoS}_{2}$ migrate closer to the Fermi level (Fig. 10(c)). The introduced organic ligands may occupy S-vacancies, which led to the alteration in the electronic structure as well [147]. However, it is worth noting that the alteration of the band edge may promote or inhibit the generation of ROS. As displayed in Fig. 10(d), Pandit et al. ascertained that alkane chains functionalized ce- $-\mathrm{MoS}_{2}$ generated less OS than ce- $\mathrm{MoS}_{2}$ by GSH oxidation assay, which indicated that the generation of ROS from functionalized ce- $\mathrm{MoS}_{2}$ was reduced [131]. Actually, the alteration of energy band structure caused by ligands is often neglected. Based on the above findings, taking the alteration of energy band structure into consideration during the optimization of antibacterial properties via the design of surface functionalization is our urge suggestion to researchers. (a)

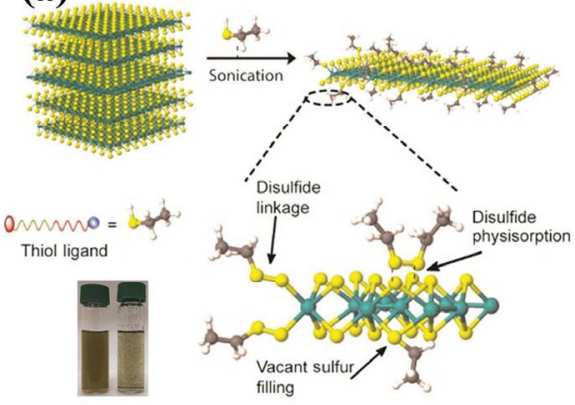

(b)

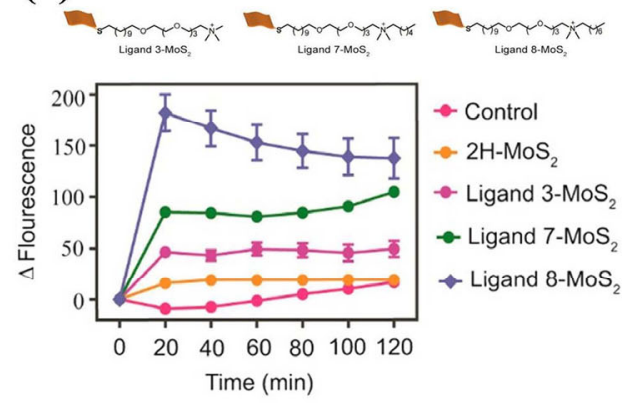

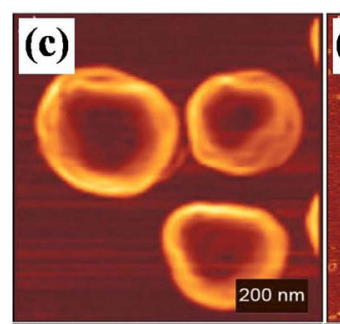
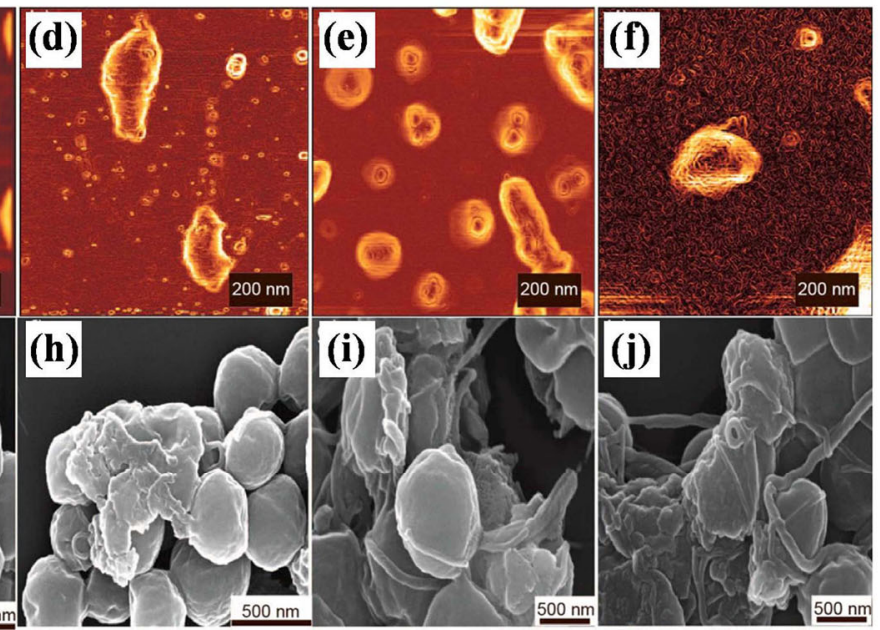

Figure 9 The enhanced antibacterial based on ligands with amphiphilic nature. (a) Schematic illustration of the ligand-induced exfoliation and possible modalities of $\mathrm{MoS}_{2}$ surface functionalization. The inset shows the colloidal stability of functionalized and nonfunctionalized $\mathrm{MoS}_{2}$. (b) Quantification of membrane depolarization of methicillin-resistant S. aureus (MRSA) using 3,3'-dipropylthiadicarbocyanine iodide. The fluorescence was monitored using $622 \mathrm{~nm}$ excitation wavelength and $670 \mathrm{~nm}$ emission wavelength. The inset shows the structure of ligands. Morphological changes of MRSA treated with functionalized $\mathrm{MoS}_{2}$ observed by AFM and SEM images. (c) and (g) Control only MRSA. (d) and (h) Ligand 3-MoS treated MRSA. (e) and (i) Ligand 7-MoS 2 treated MRSA. (f) and (j) Ligand 8-MoS 2 treated MRSA. Reproduced with permission from Ref. [143], ๑ American Chemical Society 2018. 
(a)

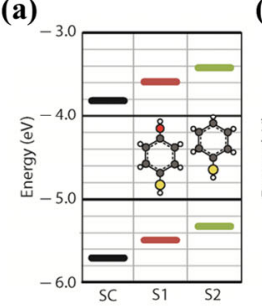

(c)

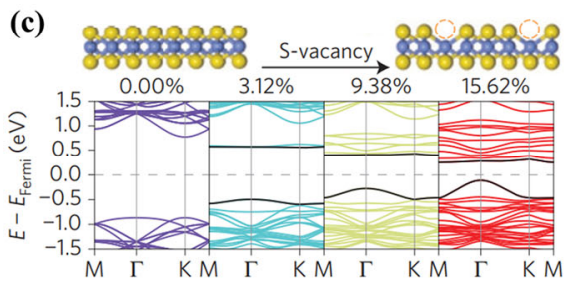

(b)

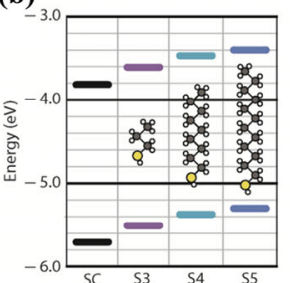

(d)

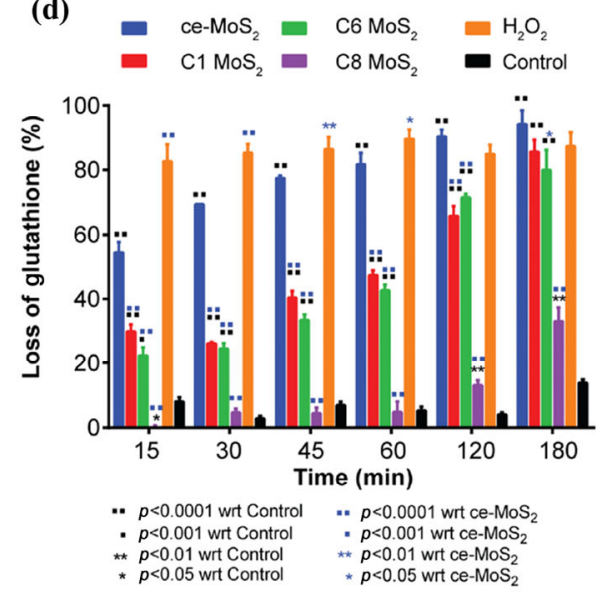

Figure 10 The alteration of energy band structure stemming from the influence of ligands. Energy diagram of the as exfoliated and thiol functionalized $\mathrm{MoS}_{2}$ where (a) compares the aromatic thiols and (b) compares the thiol chain lengths. The thiols used in this work can be described as exfoliated MoS (SC) p-mercaptophenol (S1), thiophenol (S2), 1-propanethiol (S3), 1-nonanethiol (S4), and 1-dodecanethiol (S5). Reproduced with permission from Ref. [146], (OWILEY-VCH Verlag 2015. (c) The alteration of the band structure with increasing S-vacancies (calculated using the full $4 \times 4$ unit cell). The gap states nearest to the Fermi level are represented in black. Reproduced with permission from Ref. [147], OSpringer Nature 2016. (d) Abiotic glutathione oxidation assay for quantification of oxidative stress generated. The hydrophobicity of the ce- $\mathrm{MoS}_{2}$ was altered by altering the alkane chain length with methyl (C1 MoS $)$, hexyl $\left(\mathrm{C} 6 \mathrm{MoS}_{2}\right)$, and octayl $\left(\mathrm{C} 8 \mathrm{MoS}_{2}\right)$ groups at the quaternary ammonium center. Reproduced with permission from Ref. [131], @American Chemical Society 2016.

Besides the above strategies, some novel biomimetic designs can be easily achieved via surface functionalization. For example, some strain-selective bactericidal strategies can be feasibly constructed to achieve targeted killing and these fascinating architectures will be detailed discussed in the following section [43,45]. Additionally, the approach mimicking the natural antibacterial mechanism can be stimulated by lightto-thermal conversion, which opens broad avenue for bacterial inhibitory applications. Gao et al. reported a novel NIR lasermediated nitric oxide (NO)-releasing nanovehicle $\left(\mathrm{MoS}_{2-}\right.$ BNN6) for bacteria ablation through the simple assembly of a heat-sensitive NO donor $N, N^{\prime}$-di-sec-butyl- $N, N^{\prime}$-dinitroso-1,4phenylenediamine (BNN6) on a-cyclodextrin-modified $\mathrm{MoS}_{2}$ nanosheets. Under the irradiation of $808 \mathrm{~nm}$ laser, the composite not only displayed PTT efficacy, but also generated oxidative/ nitrosative stress by precisely controlling the release of nitric oxide (NO). Within $10 \mathrm{~min}$, the $\mathrm{MoS}_{2}-\mathrm{BNN} 6$ with PTT/NO synergetic antibacterial function reached more than $97.2 \%$ inactivation of bacteria [148]. According to the above case studies, surface functionalization of TMSs using organic species show their promise in improving the bacterial ablation capacity and more work should be carried out in this line to clarify the complicated mechanisms behind.

\subsection{Heterogeneous structure construction}

Photo-excitation of TMSs results in the production of ROS that can inactivate microorganisms [67-70]. Though TMSs can be easily excited due to their narrow band gaps, the production of ROS is still limited mainly because of the quick recombination and weak reactivity of the charge carriers [131-133]. The construction of effective heterogeneous structure can greatly improve the charge carrier separation rate and thus is an effective strategy to obviate their intrinsic deficiency. According to previous reports, heterogeneous structure can be classified into the following five categories of heterojunctions: type-I heterojunction, type-II heterojunction, $\mathrm{p}-\mathrm{n}$ heterojunction,
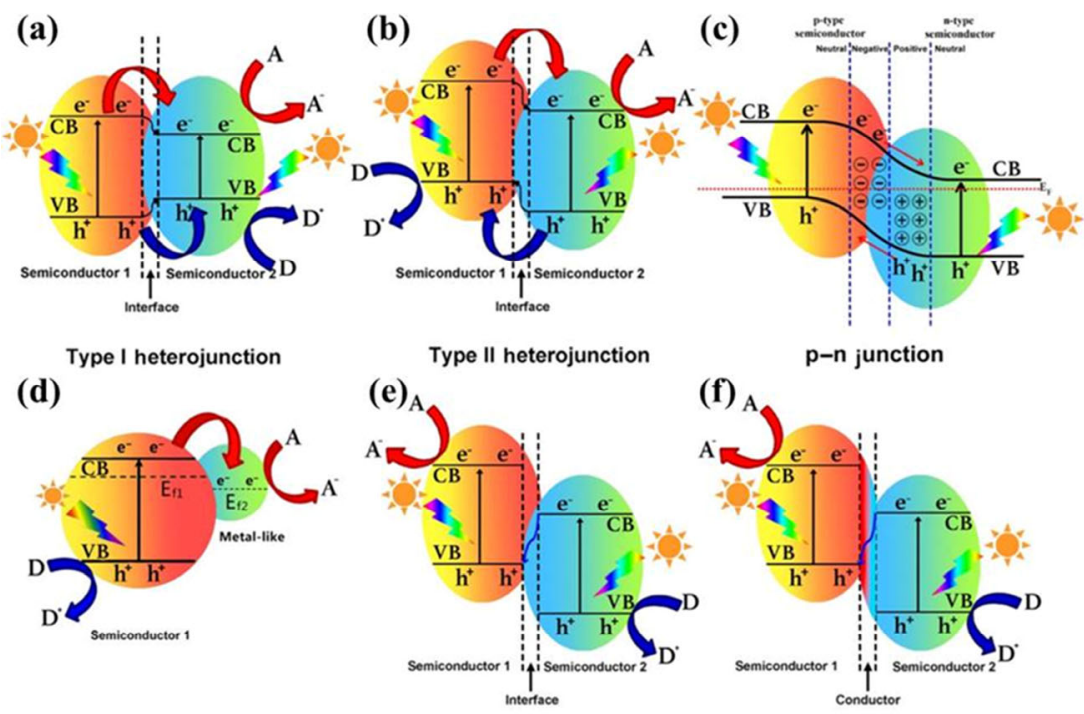

Schottky junction

Z-scheme heterojunction

Z-scheme heterojunction

Figure 11 Band structure of various types of heterogeneous structure: (a) type I heterojunction, (b) type II heterojunction, (c) p-n junction, (d) Schottky junction, (e) direct Z-scheme heterojunction (without an electron mediator), and (f) indirect Z-scheme (with an electron mediator). A, D, and $E_{F}$ represent electron acceptor, electron donor, and fermi level, respectively. Reproduced with permission from Ref. [149], @Elsevier B.V. 2019. 
Schottky junction and Z-scheme heterojunction (Fig. 11) $[149,150]$. In the following section, recent progresses in the fabrication of TMSs-based heterogeneous structure for antibacterial application are detailed summarized.

\subsubsection{Semiconductor-semiconductor heterojunction construction}

The construction of effective heterostructure between semiconducting materials with suitable band alignment can dramatically facilitate the charge carrier separation, leading to the enhanced generation of ROS and antibacterial performance $[86,123,151]$. For the type-I heterojunction photocatalysts, the photo-excited electrons and holes migrate to the same semiconductor with weak redox abilities [150]. Consequently, the shortcoming of TMSs could not be warded off via the construction of type-I heterojunction. For the type-II heterojunction photocatalysts, although TMSs also bear the expense of redox abilities of electrons and holes, which indicates that some specific photocatalytic reaction cannot proceed due to the weakened driving force. However, the establishment of the staggered gap promotes the spatial separation of electron-hole pairs, facilitating the generation of ROS. Based on the aforementioned reasons, the construction of type-II heterojunction is an effective method to improve the antibacterial behaviors of TMSs and enormous fruitful efforts are summarized in Table 2.

Nevertheless, type-II heterojunction could not inhibit the ultrafast electron-hole recombination, which limits their ulterior development. Thus, $\mathrm{p}-\mathrm{n}$ heterojunction concept was proposed by scientists. When the $\mathrm{p}$ - and n-type semiconductors are in contact forming $\mathrm{p}-\mathrm{n}$ junction, the diffusion of charge carriers between them will lead to a built-in electric field, which can greatly promote charge carriers transfer $[152,153]$. Zhang's group combined p-type $\mathrm{MoS}_{2}$ QDs and n-type $\mathrm{Bi}_{2} \mathrm{WO}_{6}$ to build $\mathrm{p}-\mathrm{n}$ junction and the enhanced charge carrier separation rate owing to the built-in electric field and the interspersed $\mathrm{MoS}_{2}$ QDs was observed. After incubation with $1 \mathrm{mg} / \mathrm{mL}$ materials for $60 \mathrm{~min}$ under visible light irradiation, only $6.7 \% \pm 3.53 \%$ of E. coli were survived [154].

\subsubsection{Z-scheme heterojunction construction}

However, the redox ability of $\mathrm{p}-\mathrm{n}$ heterojunction is still relatively unsatisfying [155]. In order to overcome this problem, in 1979, Bard et al. first reported the concept of Z-scheme heterojunction photocatalyst [156]. According to recent investigations, Z-scheme can be classed into three categories: traditional Z-scheme heterojunction, all-solid-state Z-scheme heterojunction and direct $Z$-scheme heterojunction $[155,157]$. Among that, a reversible redox ion pair (such as $\mathrm{Cu}^{2+} / \mathrm{Cu}^{1+}$ ) and an electron conductor (such as Cu NPs) are necessary in traditional Z-scheme heterojunction and all-solid-state Z-scheme heterojunction, respectively. Direct Z-scheme heterojunctions are constructed by direct contact between two semiconductors with suitable energy band structures [155, 157]. Due to strong reduction and oxidation abilities, Z-scheme heterojunction has shown tremendous application potential and has been widely concerned [155, 157-159]. Chen et al. proposed a Z-scheme photocatalytic system using $\mathrm{Ag}$ as a mediator for charge carriers between $\mathrm{Ag}_{2} \mathrm{~S}$ and $\mathrm{AgVO}_{3}$. The photo-excited electrons of $\mathrm{AgVO}_{3}$ recombined with the photo-generated holes of $\mathrm{Ag}_{2} \mathrm{~S}$ on Ag NPs, which enhanced the generation of ROS because the high-energy photo-induced charge carriers survived. This Z-scheme photocatalytic system could completely kill E. coli within 36 min under the visible light irradiation [160]. Zhang and colleagues constructed $\mathrm{Z}$-scheme heterojunction of RGO/ $\mathrm{MoS}_{2} / \mathrm{Ag}_{3} \mathrm{PO}_{4}$ composites with RGO acting as electron-mediator. The antibacterial efficiency of the composites against $S$. aureus and E. coli after 660 and $808 \mathrm{~nm}$ dual lights irradiation for $10 \mathrm{~min}$ achieved $97.8 \%$ and $98.33 \%$, respectively [161]. Hereafter, they envisaged CuS@MoS 2 composites and suggested that ${ }^{1} \mathrm{O}_{2}$ and $\cdot \mathrm{OH}$ were generated on the materials under the irradiation of 660 and $808 \mathrm{~nm}$ dual laser, which indicated the strong reduction and oxidation abilities were maintained, and a direct Z-scheme heterojunction was successfully constructed. Specifically, the electrons in the $\mathrm{CB}$ of $\mathrm{MoS}_{2}$ could easily recombine with holes in the $\mathrm{VB}$ of $\mathrm{CuS}$ on the interfaces, leaving the electrons and holes with strong reduction and oxidation abilities. Moreover, under 660 and 808 nm dual lights irradiation, CuS@MoS microspheres exhibited synergistic antibacterial mechanisms between photothermal and photodynamic processes, achieving the antibacterial rates of $99.3 \%$ and $99.5 \%$ towards E. coli and $S$. aureus within $15 \mathrm{~min}$ at $12.5 \mathrm{mg} / \mathrm{mL}$, respectively [86]. Additionally, recent advances in TMSs-based Z-scheme photocatalysts for many applications, such as water splitting, $\mathrm{CO}_{2}$ reduction, and photodegradation of organic contaminants, were reviewed, which indicated the feasibility for the construction of TMSs-based Z-scheme heterojunction [162]. Based on the

Table 2 Recent progresses in construction of type-II heterojunction based on TMSs for antibacterial applications

\begin{tabular}{|c|c|c|c|c|c|c|c|}
\hline Material & ROS & $\begin{array}{l}\text { Light source(output power/ } \\
\text { intensity; wavelength) }\end{array}$ & $\begin{array}{l}\text { Irradiation } \\
\text { period }\end{array}$ & Concentration & Bacteria & Antibacterial effect & Ref. \\
\hline $\mathrm{TiO}_{2} / \mathrm{MoS}_{2}-\mathrm{Ti}$ & ${ }^{1} \mathrm{O}_{2}$ and $\cdot \mathrm{OH}$ & $\begin{array}{l}\text { Dual light sources }\left(0.5 \mathrm{~W} / \mathrm{cm}^{2} \text {; }\right. \\
660 \mathrm{~nm}, 808 \mathrm{~nm})\end{array}$ & $10 \mathrm{~min}$ & - & S. aureus & $99.9 \%$ & [70] \\
\hline $\begin{array}{l}\mathrm{MoS}_{2} / \mathrm{a}_{-} \\
\mathrm{NiMoO}_{4}\end{array}$ & $\mathrm{O}_{2} \cdot{ }^{-}$ & Visible light & $2.5 \mathrm{~h}$ & $10 \mathrm{mg} / \mathrm{mL}$ & S. aureus & $99.9 \%$ & {$[68]$} \\
\hline \multirow{2}{*}{$\mathrm{MoS}_{2} / \mathrm{AgBr}-\mathrm{Ti}$} & \multirow{2}{*}{${ }^{1} \mathrm{O}_{2}$} & \multirow{2}{*}{ visible light $\left(2 \mathrm{~kW} / \mathrm{m}^{2}\right)$} & \multirow{2}{*}{$20 \mathrm{~min}$} & \multirow{2}{*}{ - } & S. aureus & $99.79 \%$ & \multirow{2}{*}[201]{} \\
\hline & & & & & E. coli & $99.94 \%$ & \\
\hline $\begin{array}{c}\mathrm{Ag}_{3} \mathrm{PO}_{4} / \\
\mathrm{MoS}_{2} \text { hydrogel }\end{array}$ & ${ }^{1} \mathrm{O}_{2}$ and $\cdot \mathrm{OH}$ & $\begin{array}{l}\text { Dual light sources }\left(0.6 \mathrm{~W} / \mathrm{cm}^{2} \text {; }\right. \\
\quad 660 \mathrm{~nm}, 808 \mathrm{~nm})\end{array}$ & $5 \mathrm{~min}$ & $\begin{array}{c}50 \mathrm{mg} \mathrm{Ag}_{3} \mathrm{PO}_{4} / \mathrm{MoS}_{2} \\
\text { composites in } 3 \mathrm{~mL} \text { of } \\
\text { PVA solution }\end{array}$ & S. aureus & 99\% & [151] \\
\hline $\mathrm{MoS}_{2} / \mathrm{ZnO}$ & $\cdot \mathrm{OH}$ & - & - & $400 \mu \mathrm{g} / \mathrm{mL}$ & E. coli & $\begin{array}{l}\text { Better than pure } \mathrm{ZnO} \\
\text { and } \mathrm{MoS}_{2}\end{array}$ & [202] \\
\hline \multirow{2}{*}{$\mathrm{Ag}_{2} \mathrm{~S} / \mathrm{WS}_{2}$} & \multirow{2}{*}{-} & \multirow{2}{*}{$\begin{array}{c}\text { NIR }\left(0.40 \text { to } 0.50 \mathrm{~W} / \mathrm{cm}^{2} ;\right. \\
808 \mathrm{~nm})\end{array}$} & \multirow{2}{*}{$20 \mathrm{~min}$} & \multirow{2}{*}{$2 \mathrm{mg} / \mathrm{mL}$} & S. aureus & $99.93 \%$ & \multirow{2}{*}{ [87] } \\
\hline & & & & & E. coli & $99.84 \%$ & \\
\hline $\mathrm{Fe}_{3} \mathrm{O}_{4} / \mathrm{CdS}$ &. $\mathrm{OH}$ & sunlight & $30 \mathrm{~min}$ & - & S. aureus & $\begin{array}{l}\text { MIC and MBC value was } \\
3.0 \mathrm{mg} / \mathrm{mL}, 5.0 \mathrm{mg} / \mathrm{mL}\end{array}$ & {$[203]$} \\
\hline $\mathrm{TiO}_{2} / \mathrm{CdS}$ & $\mathrm{O}_{2} \cdot{ }^{-}$, and $\cdot \mathrm{OH}$ & $\begin{array}{l}\text { Visible light }\left(100 \mathrm{~mW} / \mathrm{cm}^{2} ;\right. \\
\geq 420 \mathrm{~nm})\end{array}$ & $10 \mathrm{~min}$ & $100 \mu \mathrm{g} / \mathrm{mL}$ & E. coli & $99.9 \%$ & [204] \\
\hline
\end{tabular}


aforementioned analysis, the construction of Z-scheme photocatalysts is a promising strategy to improve the antibacterial performance of TMSs.

\subsubsection{Plasmonic metal-TMSs heterogeneous composites}

According to previous researches, plasmonic metals ( $\mathrm{Au}, \mathrm{Ag}$, $\mathrm{Cu}, \mathrm{Pt}$, etc.) deposition results in pronounced improvements of semiconductors in photocatalytic efficiency [163-165]. As is reported, plasmonic metals exhibit excellent localized surface plasmon resonance (LSPR) effect [164, 166-169]. LSPR effect in the visible and infrared regions is conducive to improving the utilization of the solar spectrum for TMSs $[123,165]$. In addition, the Fermi level of plasmonic metals usually lies below the CB of TMSs and this energy gradient could efficiently facilitate the electron migration from TMSs to plasmonic metals leading to a space-charge separation region which can be used as an efficient electron trap preventing charge carriers recombination in photocatalysis and enhancing the generation of ROS and thus this could lead to the improved antibacterial performance $[2,152,170]$. Simultaneously, plasmonic metals deposited onto the TMSs also act as catalytic centers and further promote the production of ROS $[133,165]$. Liu and colleagues reported that, $\mathrm{Cu}$ or $\mathrm{Au}$ deposited on the top of FLV-MoS $\mathrm{M}_{2}$ could promote the generation of ROS via improving the electron-hole pair separation of $\mathrm{MoS}_{2}$ and the catalytic effect of metals. They found that $\mathrm{Cu}-\mathrm{MoS}_{2}$ exhibited better antibacterial effect, achieving rapid water disinfection with $5 \log 99.999 \%$ inactivation of $E$. coli in $20 \mathrm{~min}$ with a trace amount of material $(1.6 \mathrm{mg} / \mathrm{L})$ under visible light irradiation [133]. Addae found that $\mathrm{Au} / \mathrm{CuS}$ core/shell NPs exhibited higher antibacterial activity against $B$. anthracis compared with pristine $\mathrm{CuS}$ [124]. Additionally, as a traditional antibacterial agent, $\mathrm{Ag}$ is also widely used to construct semiconductor-metal (S-M) heterojunctions $[106,152]$. As shown in Figs. 12(a) and 12(b), $\mathrm{Zhu}$ et al. prepared chitosan-modified $\mathrm{Ag} / \mathrm{MoS}_{2}$ composited coating with the antibacterial rates of $99.77 \%$ and $98.66 \%$ towards E. coli and S. aureus, respectively [106]. Pang and colleagues found that deposition of $\mathrm{Ag}$ on the surface of $\mathrm{Ag}_{2} \mathrm{~S}$ could efficiently broaden the light absorption region and enhance the separation of photo-induced charge carriers thus promoting the production of ROS (Fig. 12(c)). Except for the bactericidal processes of ROS, $\mathrm{Ag}_{2} \mathrm{~S} / \mathrm{Ag}$ heterodimers can be anchored onto the surfaces of the bacterial cells and generate a closed intracellular circuit loop, resulting in the evacuation of the intracellular material (Figs. 12(d) and 12(e)). The aforementioned effects brought about better antibacterial activity against E. coli, as shown in Fig. 12(f) [123].

\subsection{Other strategies}

In addition to the above strategies, some researchers showed that heteroatom doping could also bring in improved antibacterial properties of TMSs. On one hand, the addition of heteroatom will create new energy levels in the band structure causing the band gap changes of TMSs; on the other hand, the doped atoms can be dissolved during practical applications which might also play a positive role in enhancing the antibacterial performances [171, 172]. Fakhri obtained $\mathrm{Cu}$ doped $\mathrm{Ag}_{2} \mathrm{~S}$ NPs exhibiting enhanced photocatalytic and antibacterial performance, which was attributed to the increased chargecarrier trapping efficiency caused by the energy levels of the $\mathrm{Cu}$ dopant [173]. Tang et al. prepared iron-doped $\mathrm{MoS}_{2}$ nanosheets with the synergistic antibacterial effect between ROS generation and ions incursion. They suggested that the released $\mathrm{Fe}^{2+}$ ions could promote the generation of ROS via Fenton-like reactions [172]. Patel et al. reported a chemical route to synthesize $\mathrm{Mn}$ incorporated CdS NPs at room temperature, which exhibited the synergistic antibacterial effect. In addition to the oxidative stress of ROS, the released $\mathrm{Mn}$ ions were incorporated into Fe-S clusters, resulting in the inactivation of the Fe-S proteins in cells [174]. (a)

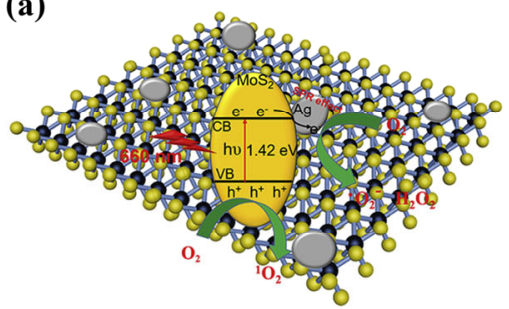

(d)

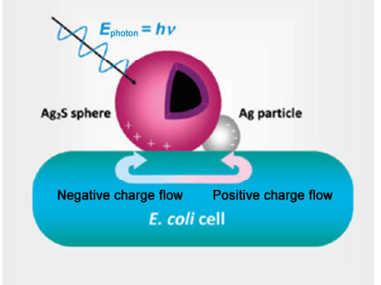

(b)
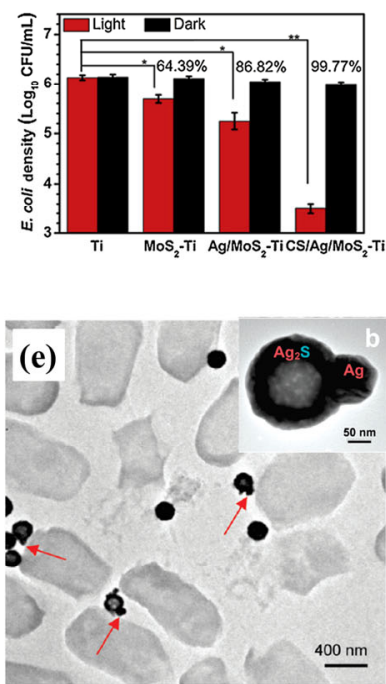

(c)

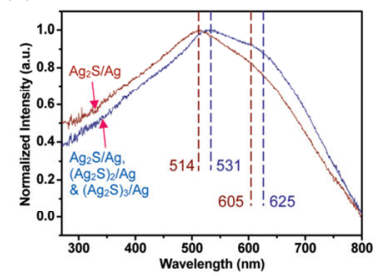

(f)

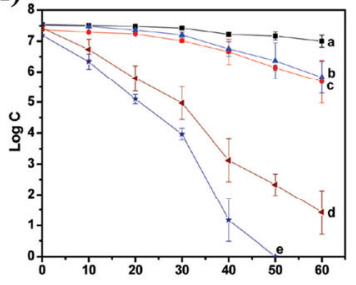

Figure 12 The effect of plasmonic metals deposition. (a) The schematic diagram of the enhanced ROS production of chitosan-modified Ag/MoS 2 composited coating. (b) The antibacterial effect of chitosan-modified Ag/MoS 2 composited coating against E. coli. Reproduced with permission from Ref. [106], ( EElsevier Inc. 2020. (c) UV-visible spectra (in transmission mode) for the as-prepared $\mathrm{Ag}_{2} \mathrm{~S} / \mathrm{Ag}$ heterodimers and the $\mathrm{mixture}$ of $\mathrm{Ag} 2 \mathrm{~S} / \mathrm{Ag},(\mathrm{Ag} 2 \mathrm{~S})_{2} / \mathrm{Ag}$, and $\left(\mathrm{Ag}_{2} \mathrm{~S}\right)_{3} / \mathrm{Ag}$ heterostructures. Schematic illustration in (d) depicts a possible mechanism for bactericidal effect with the surface-anchored $\mathrm{Ag}_{2} \mathrm{~S} / \mathrm{Ag}$ heterodimers. With the illuminate of UV light and charge separation, a closed intracellular circuit loop may be built with the anchored surface dimer, which enhances lysis of the bacterial cell. (e) TEM images of $E$. coli mixed with the anchored $\mathrm{Ag}_{2} \mathrm{~S} / \mathrm{Ag}$ heterodimers. The red arrow indicates the closed intracellular circuit loop. Inset shows the morphology of $\mathrm{Ag}_{2} \mathrm{~S} / \mathrm{Ag}$ heterodimers. (f) Investigation of the antibacterial efficiency against $E$. coli and broken line of Fig. 12(f) represent: a control group, E. coli suspension without $\mathrm{Ag}_{2} \mathrm{~S} / \mathrm{Ag}$, (b) E. coli suspension without $\mathrm{Ag}_{2} \mathrm{~S} / \mathrm{Ag}$ under UV irradiation, (c) E. coli suspension with $0.10 \mathrm{mg} / \mathrm{mL} \mathrm{Ag}_{2} \mathrm{~S} / \mathrm{Ag}$ incubated in a rotary shaker at $37^{\circ} \mathrm{C}$, (d) E. coli suspension with $0.01 \mathrm{mg} / \mathrm{mL}$ of $\mathrm{Ag}_{2} \mathrm{~S} / \mathrm{Ag}$ dimers irradiated by UV light, and (e) E. coli suspension with $0.10 \mathrm{mg} / \mathrm{mL}$ of $\mathrm{Ag}_{2} \mathrm{~S} / \mathrm{Ag}$ dimers irradiated by UV light. Reproduced with permission from Ref. [123], $\odot \mathrm{American}$ Chemical Society 2010. 
In recent years, carbon materials such as carbon quantum dots (CQDs), grapheme, and carbon nanotubes have also be utilized to hybridize TMSs for enhanced bactericidal effect due to their good photostability, low cytotoxicity, and excellent conductivity [60, 69, 175-178]. Han et al. reported that, under the irradiation of $660 \mathrm{~nm}$ visible light, $\mathrm{MoS}_{2}$ modified with $\mathrm{N}$-doped CQDs showed antibacterial efficiency of $99.38 \%$ and $99.99 \%$ against $S$. aureus and E. coli, respectively. N-doped CQDs in this composite served as electron transporter, which could prevent the recombination of photo-induced charge carriers, and finally enhance the generation of ROS [179]. Kim et al. suggested that the electrons migrated from the cell membrane to the surface of GO-MoS nanosheets, causing disruption of intracellular components and even the death of bacteria via oxidation. After incubation with $\mathrm{GO}-\mathrm{MoS}_{2}$ nanosheets for 6 h, $96.4 \%$ of $E$. coli was destroyed [69].

In addition, researchers also proposed some other effective approaches. Wang et al. prepared sea urchin-like $\mathrm{Bi}_{2} \mathrm{~S}_{3}$ hollow microspheres via sacrificed template strategy and 1-tetradecanol (TD) combined antibacterial agents (Linalool) were infused into the hollow cavity of microspheres to achieve the synergistic effects between photothermal killing and antibacterial agent releasing. The MIC values against E. coli and S. aureus of TD/Linalool@ $\mathrm{Bi}_{2} \mathrm{~S}_{3}$ were 180 and $280 \mu \mathrm{g} / \mathrm{mL}$, respectively [180]. Shan and colleagues synthesized cuboid-like CWS nanozymes $(\sim 20 \mathrm{~nm})$ via microwave irradiation in aqueous solution, exhibiting better antibacterial performance than antibiotics (vancomycin and daptomycin). These CWS nanozymes could efficiently attach to the cell wall of bacteria via the interaction between copper atoms from nanocrystals and amino groups from peptidoglycan and then generate ROS through enzymelike (oxidase and peroxidase) properties to kill bacteria. At very low concentration $(\sim 2 \mu \mathrm{g} / \mathrm{mL})$, these nanozymes realized more than $99.999 \%$ inactivation efficiency against both $E$. coli and $S$. aureus no matter in the dark or under ambient light [93]. Zhang and colleagues reported a photoelectrochemical bactericidal strategy based on $\mathrm{Ti} / \mathrm{MoS}_{2} / \mathrm{MoO}_{x}$ photoanode. At first, under the irradiation of visible light, the photo-excited electrons from the $\mathrm{CB}$ of $\mathrm{MoO}_{x}$ could recombine with photoexcited holes from the $\mathrm{VB}$ of $\mathrm{MoS}_{2}$. The holes left in photoanode oxidized chloride (presented in $\mathrm{NaCl}$ electrolyte) to generated chorine radicals species and the electrons left in the photoanode transferred to the Ti foil cathode to produce $\mathrm{O}_{2} \cdot{ }^{-}$and $\mathrm{H}_{2} \mathrm{O}_{2}$ to destroy bacteria cell. With $0.5 \mathrm{~V}$ bias in $2 \mathrm{~h}$ under the irradiation of visible light, E. coli in $\mathrm{NaCl}$ electrolyte was completely inactivated [181].

\section{Practical application trials using TMSs-based antibacterial agents}

The antibacterial mechanisms of TMSs and the state-of-theart research progresses on the strategies for promoting the antibacterial properties of TMSs have been thoroughly surveyed and summarized in the previous sections. Based on these investigations, we can conclude that TMSs-based materials exhibit excellent bactericidal effect. In terms of practical applications, the ability to rapidly disinfect water using these potent scavengers has been explored. Compared to the ultraviolet water purification and the ultraviolet light dependent photocatalytic water disinfection based on $\mathrm{TiO}_{2}$, the water disinfection approach using TMSs-based materials not only exhibited widespectrum solar energy harvesting, but also greatly accelerated the water disinfection process $[133,142,182]$. After the irradiation of real sunlight for $60 \mathrm{~min}$, Liu et al. found that FLV-MoS exhibited better log inactivation efficiency (5 log, >99.999\%) than that of $\mathrm{TiO}_{2}$ films with the same thickness ( $3 \log$, 99.9\%) and simultaneously this inactivation time can be reduced to 20 min with the presence of $\mathrm{Cu}$ deposits [133].

In addition, the in vivo biosafety of TMSs-based antibacterial agents has proven to be satisfactory by a large number of investigations. Specifically, no appreciable abnormalities or damages of major organs were observed in the mice during the treatment process using TMSs-based antibacterial agents, which indicated their negligible side effects [47, 70, 109, 183-187]. Additionally, Levard and colleagues suggested that the toxicity and potential environmental risks of Ag NPs
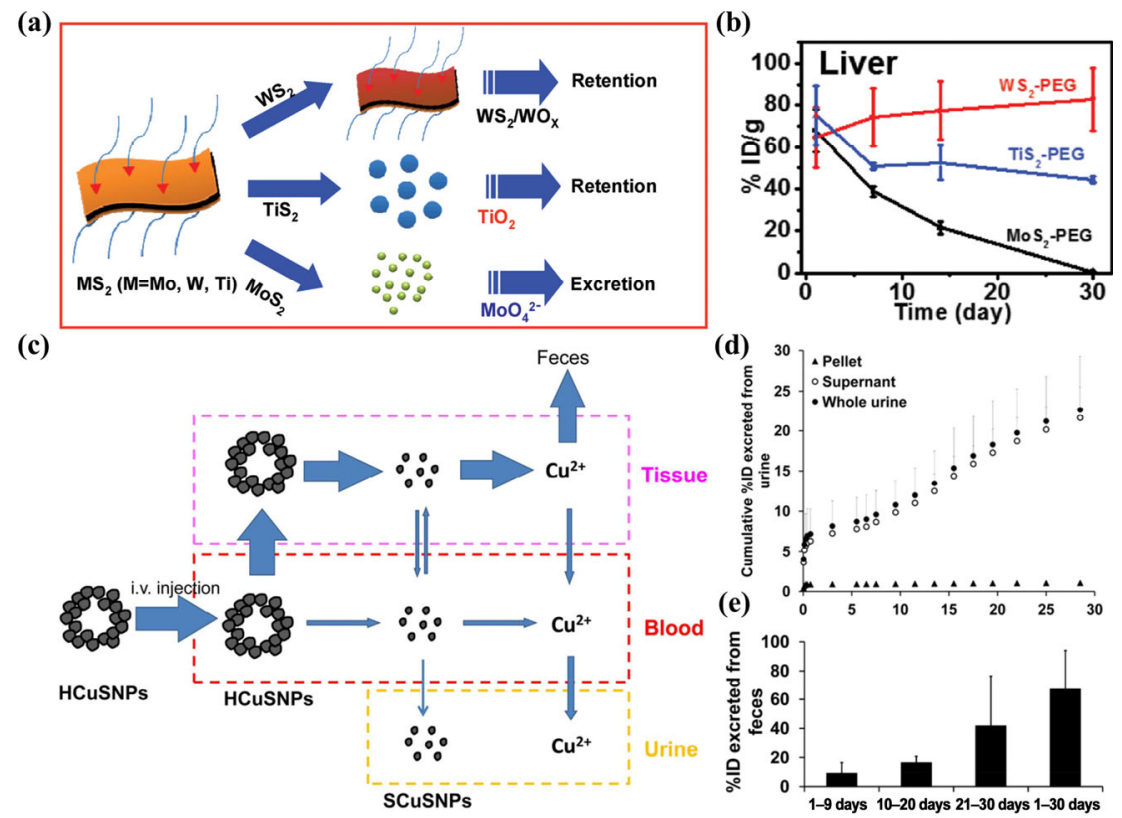

Figure 13 The metabolism and toxicology of TMSs. (a) Schematic diagram of the different excretion pathways of PEG-MS 2 nanosheets $(M=\mathrm{Mo}, \mathrm{W}$, and Ti). Cytotoxicity of PEG-MS 2 after incubation at different weight concentrations for $24 \mathrm{~h}$. (b) The concentrations of PEG-MS 2 nanosheets in the liver of mice at different time points after i.v. injection. Reproduced with permission from Ref. [47], (OWILEY-VCH Verlag 2017. (c) The metabolism pathways of hollow CuS in vivo after i.v. injection. The cumulative excreted percentage of hollow CuS from (d) urine and (e) feces. Reproduced with permission from Ref. [36], ๑)American Chemical Society 2013. 
could be significantly reduced by sulfidation [35]. As plotted in Fig. 13(a), Hao et al. investigated the excretion and toxicology profiles of TMSs in the organism and proposed their distinctive in vivo excretion behaviors. Without exhibiting significant cytotoxicity, PEG functionalized $\mathrm{MS}_{2} \quad(\mathrm{M}=\mathrm{Mo}, \mathrm{W}, \mathrm{Ti})$ accumulated in reticuloendothelial systems, including liver and spleen, after intravenous (i.v.) injection and then was degraded via different biochemical pathway and finally excreted. It was noteworthy that $\mathrm{MoS}_{2}$ could be rapidly oxidized into watersoluble $\mathrm{Mo}^{\mathrm{VI}}$-oxide species (e.g., $\mathrm{MoO}_{4}{ }^{2-}$ ) and was vanished in the organism within one month (Fig. 13(b)) [47]. As shown in Fig. 13(c), Guo and colleagues explored the biodegradability, metabolism and toxicology of PEG-hollow CuS (PEG-HCuS) NPs and found that the PEG-hollow CuS NPs with polycrystalline structure could disintegrate into small CuS (SCuS) NPs in blood and tissue. Then, they dissociated to $\mathrm{Cu}$ ions and finally were excreted to the outside of the body through feces and urine. Within 30 days, almost all PEG-CuS NPs have been metabolized by mice (Figs. 13(d) and 13(e)) [36]. Consequently, with the assistance of potent TMSs-based antibacterial agents, we can envisage more seminal biological therapeutic strategies to achieve a quantum leap in healthcare. Based on this, a systematic summary based on the recent advances of TMSs-based antibacterial agents for biological therapeutic strategies is an urgent requirement to provide guidance for future development.

\subsection{Strain-selective bactericidal strategies}

The vigorous development of the healthcare industry evokes people's higher demands on modern therapeutic methods. At present, the bactericidal therapeutics of novel antibacterial agents are often based on ROS generation, but ROS could bring indiscriminate oxidative damage to both microbes and normal cells [67-70]. It is an urgent desire that harmful bacteria can be selectively killed without damaging normal cells and probiotic bacteria. Therefore, the interest in strain-selective bactericidal strategies is rapidly growing in recent years and some seminal strain-selective bactericidal architecture based on TMSs-based antibacterial agents has been successfully fabricated [43, 45, 188]. The finely regulated and complicated outer membranes of microorganisms provide boundless possibilities for the design of strain-selective bactericidal strategies. Bacterial lectins are recognized as adhesion molecules triggering early attachment and biofilm formation $[189,190]$. Many articles have identified that several lectins can selectively recognize specific carbohydrates through the formation of a hydrogen-bond network [189-192]. As depicted in Figs. 14(a) and 14(b), Novoa and colleagues explored the possible interaction based on tetramer lectin LecA and tailored a library to elucidate the lead interactions, which made it possible for rational ligand design [190]. Based (a)
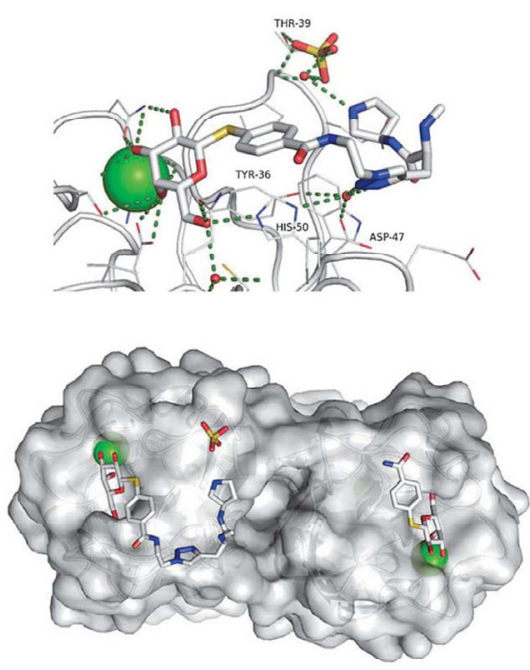

(d)
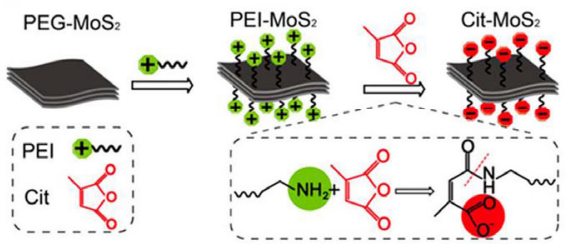

(f)

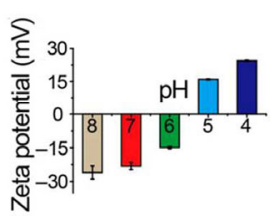

(g)

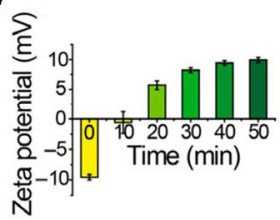

(b)

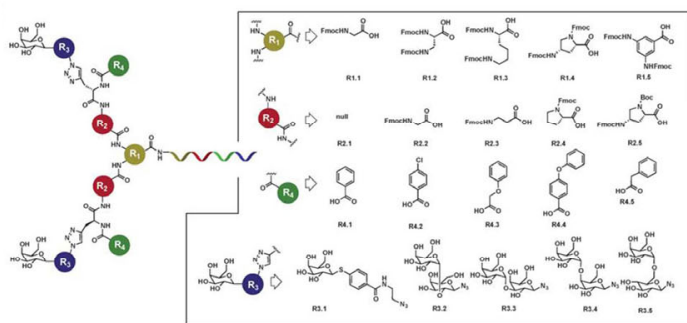

(c)

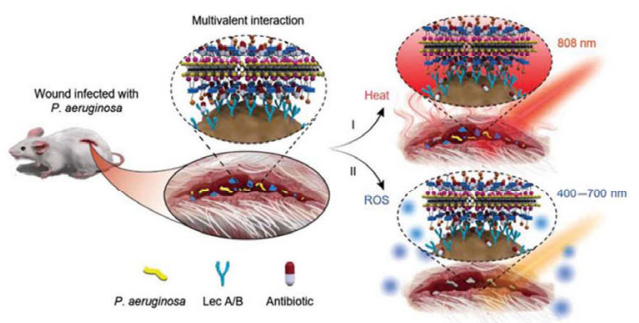

(e)

(h)

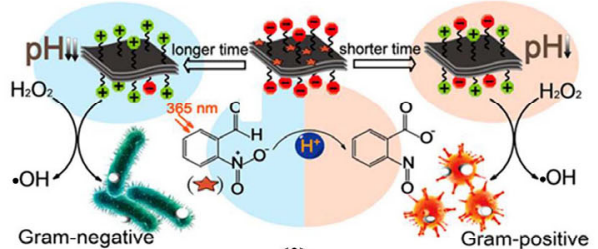

(i)

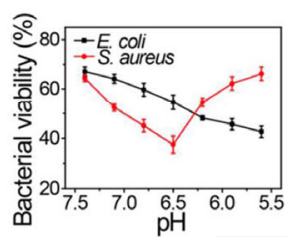

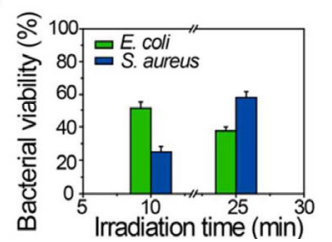

Figure 14 The construction of strain-selective bactericidal system. (a) Crystal structure of LecA complexed with divalent galactose compound. (b) Some organic structure that can selectively identify LecA. Reproduced with permission from Ref. [190], @WILEY-VCH Verlag 2014. (c) Schematic illustration of the antibacterial glycosheets for double light-driven selective capture of $P$. aeruginosa on wounds. Reproduced with permission from Ref. [43], @WILEY-VCH Verlag 2019. (d) Preparation process of Cit-MoS . (e) Illustration of light-modulated nanozyme based on cit-MoS 2 to obtain selective bacteria capture. (f) Charge-conversion of Cit-MoS ${ }_{2}$ in PBS buffer $(5 \mathrm{mM})$ with different $\mathrm{pH}$ values ranged from 8 to 4 . (g) Zeta potentials of the mixture of Cit-MoS 2 and 2-NBA with different illumination times. (h) The result of Growth-inhibition assay. All groups were conducted in LB medium with different pH values. $\left[\mathrm{Cit}-\mathrm{MoS}_{2}\right]=90 \mu \mathrm{g} / \mathrm{mL}$. (i) Growth-inhibition assay with pretreatment of the Cit-MoS $2(90 \mu \mathrm{g} / \mathrm{mL})$ and 2-NBA $(600 \mu \mathrm{M})$ mixture with different illumination times, $\left[\mathrm{H}_{2} \mathrm{O}_{2}\right]=50 \mu \mathrm{M}$. Reproduced with permission from Ref. [45], ๑American Chemical Society 2018. 
on the carbohydrate-lectin interaction, some scavengers for targeted photokilling of bacteria have been explored. Hou et al. observed that galactose-modified $\mathrm{Cu}_{2-x} \mathrm{~S}$ NPs could electively kill $P$. aeruginosa [44]. Hu and colleagues found that thin-layered $\mathrm{MoS}_{2}$ anchored with a glyco-layer on the surface could effectively capture $P$. aeruginosa selectively owing to the multivalent carbohydrate-lectin interaction (galactose- and fucose-based ligands could be recognized by lectins, Lec A, and Lec B, on the surface of $P$. aeruginosa, respectively). It was also shown that by combination of the modified $\mathrm{MoS}_{2}$ with antibiotics, ceftazidime (CAZ), the obtained composites displayed enhanced antibacterial behavior under wide-spectrum light irradiation because of the NIR driven antibiotic release and visible-light induced ROS evolution (Fig. 14(c)) [43].

Additionally, the different components of bacterial cell wall result in the nonhomogeneous negative charges quantity located on the surface of bacteria, causing different electrostatic interactions, which can be specifically used for the construction of strain-selective bactericidal strategies. For instance, the components of the E. coli cell wall are lipopolysaccharides and phospholipids, which means more negative charges with respect to $S$. aureus (the cell wall composed mainly of peptidoglycan and teichoic acid) [45]. As plotted in Figs. 14(d) and 14(e), Qu's team tailored an intelligent strain-selective antibacterial nanozymes based on charge-tunable $\mathrm{MoS}_{2}$ nanozymess and a photoacid molecule. Under the irradiation of $365 \mathrm{~nm}$ light, a photoexcited intramolecular rearrangement of the photoacid generator, 2-nitrobenzaldehyde (2-NBA), occurred, leading to the fast release of 2-nitro benzoic acid and protons, and thus the $\mathrm{pH}$ of the system was decreased. Meanwhile, the citraconic anhydride-modified polyethylenimine- $\mathrm{MoS}_{2}\left(\mathrm{Cit}-\mathrm{MoS}_{2}\right)$ achieved surface charge-conversion from negative to positive and activation of the enzymatic activity (Figs. 14(f) and 14(g)). Crucially, the extent of the above two reactions could be modulated by the time of irradiation, achieving a Gram-selective antimicrobial system by light. Within shorter irradiation time, Cit- $\mathrm{MoS}_{2}$ could more effectively attach to $S$. aureus and thus facilely eradicate them; as opposed to this result, in longer irradiation time, more E. coli was growth suppressed than S. aureus (Figs. 14(h) and 14(i)) [45]. Besides, the cell penetration mechanisms might be different on the materials with various morphologies, owing to the different cell wall structures in Gram-positive and Gram-negative bacteria (thickness of peptidoglycan and organic constituent) [63]. Shalabayev compared the bacterial ablation performances of spherical and needlelike CuS NPs and found that spherical CuS NPs possessed high antibacterial activity against $E$. coli, but no activity against S. aureus. In contrast, needle-like CuS NPs demonstrated a pronounced antibacterial performance against both types of bacteria [188]. In combination, although some investigations have achieved the antibacterial selectivity, our knowledge reserve in this category is still exceedingly limited so far. More bacterial targets and other strain-selective bactericidal mechanisms remain to be further explored, and we look forward to more superior works in this area.

\subsection{Wound healing}

Microbial infections, especially multidrug-resistant bacterial infections, impair the healing of wounds rendered by deepburn injuries, diabetic foot ulceration, or other reasons, resulting in a high mortality rate among these patients and a heavy economic burden on the healthcare system [43, 79, 183]. However, we are still suffering from the lack of effective therapeutic methods to obviate wound infection and accelerate wound healing $[43,79,183]$. Consequently, the development of feasible therapeutic methods to improve wound healing is urgent and mandatory. The acute wound-healing process usually includes four overlapping stages, namely, hemostasis, inflammation, proliferation, and scar-remodeling [183]. When the physical barrier of the epidermis has been compromised, vasoconstriction occurs. Simultaneously, the generation of thrombin and fibrin form a mesh to prevent the blood from flowing out and pathogens from invading. Macrophages, such as neutrophils and white blood cells, will travel through the blood to reach the incisional sites and then phagocytose pathogens and damaged tissue $[193,194]$. Subsequently, growth factors arouse the proliferative stage. Numerous complex and dynamic biological processes occur in this period, leading to angiogenesis, collagen deposition, granulation tissue formation, epithelialization, and wound contraction, which requires a coordinated cellular response involving myofibroblasts, keratinocytes, fibroblasts and, vascular endothelial cells $[100,195,196]$. Eventually, after the above complicated physiological processes, the skin tissue regeneration is accomplished. It was noteworthy that bacteria invasion occurs throughout the whole wound healing process and is the culprit of wound infection. Thus, the elimination of bacteria is the prerequisite of successful wound healing. TMSs have been proven effective for bactericidal effect and noninvasive for major organs, and thus represent a promising therapeutic platform for wound healing [43, 45, 100, 144, 197]. Actually, large research efforts have been inspired into exploring the successful wound treatment using TMSs-based therapeutic platforms with fruitful results. Generally, little or no erythema, bacterial abscess and edema appear at the traumas during treatment. Then scabs are formed in a shorter period, usually within 2-3 days, and then wound sizes decrease rapidly as well (Fig. 15(a)) [43, 45, 100, 144, 197]. Yin et al. treated the wound using PEG- $\mathrm{MoS}_{2}$ NFs assisted with $\mathrm{H}_{2} \mathrm{O}_{2}$, and this could effectively kill bacteria and achieve the successful wound healing. On the fifth day, the migration of keratinocytes from normal tissue to wound site and the regeneration of collagen fibers were observed in the treatment group and the wound size decreased rapidly [110]. As depicted in Fig. 15(c), Hu and colleagues indicated that, after six days of white and NIR double light-driven treatment using fucose-functionalized $\mathrm{MoS}_{2}$ loaded with CAZ, more densely packed keratinocytes, well-developed dermis, and more collagen and granulation tissue deposition could be clearly observed, which indicated the accelerated wound healing process. On day 12, double light-driven group displayed more uniform and straight collagen bundles and dermis, approaching to normal tissue with adequate thickness. Simultaneously, the results of the bacteria count in wound tissue also identified that the composites exhibited the best bactericidal effect with respect to the controls (Fig. 15(b)) [43]. Wu' group suggested that a large number of macrophages, especially neutrophils, were observed in the controls through H\&E staining, indicating that there is still an army of pathogenic microorganisms in the wound. In contrast, similar phenomena cannot be observed in the treatment group using mesoporous silica modified CuS NPs [197]. The above obvious treatment effects indicated that the treatment group using TMSs-based therapeutic is apparently superior to the controls. The successful wound healing promoted by TMSsbased therapeutic platforms could also proceed through other meritorious processes. Wu's group suggested that the released $\mathrm{Cu}^{2+}$ ions from CuS NPs stimulate fibroblast proliferation and angiogenesis [197]. Qiao and colleagues chose human foreskin fibroblast cell (HFF-1) to identify this effect through in vitro scratch assay, and this result indicated that $\mathrm{Cu}^{2+}$ ions could promote the migration of HFF-1 [126]. Wang and colleagues indicated that the hypoxia inducible factor 1 alpha (HIF-1a) and vascular endothelial growth factor (VEGF) which resulted 

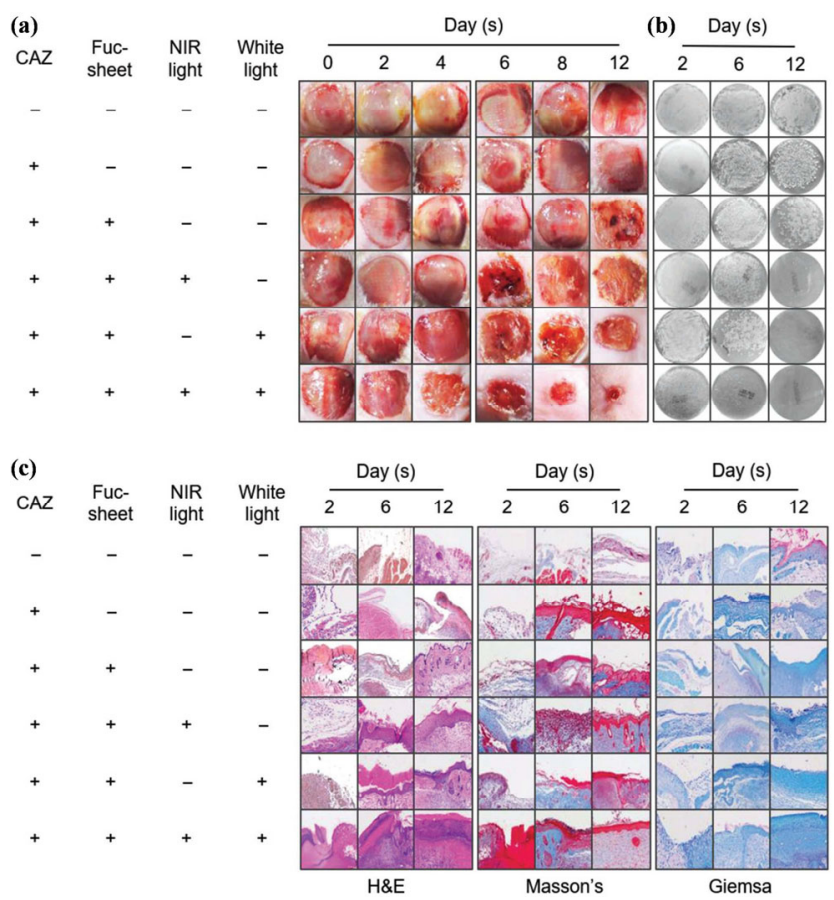

Figure 15 Wound healing process with or without the treatment of TMSs-based antibacterial agents. Light-driven wound healing process using fucose-functionalized $\mathrm{MoS}_{2}$ loaded with CAZ (Fuc-sheet@CAZ). Representative photographs of (a) P. aeruginosa -infected wounds and (b) bacterial cultures from the infected wounds. During the therapy without $(-)$ and with $(+)$ treatment of CAZ or Fuc-sheet@CAZ without $(-)$ and with (+) light irradiation (NIR light alone for $2 \mathrm{~h}$, white light alone for 1 or $2 \mathrm{~h}$ of NIR followed by $1 \mathrm{~h}$ of white light irradiation). (c) Histologic analysis of wound tissue taken out from the mice using H\&E, Masson's trichrome, and Giemsa staining. The NIR and white light source using in the treatment is $808 \mathrm{~nm}\left(1 \mathrm{~W} / \mathrm{cm}^{2}\right)$ and $400-700 \mathrm{~nm}\left(1 \mathrm{~W} / \mathrm{cm}^{2}\right)$, respectively. Reproduced with permission from Ref. [43], ๑WILEY-VCH Verlag 2019.

in compromised neovascularization in response to hypoxia could be stimulated by $\mathrm{Cu}^{2+}$ ions released by cuprous sulfide nanoparticles at low concentration $(0.064$ to $32 \mu \mathrm{g} / \mathrm{mL})$ in human bone marrow stromal cells and thus accelerate the wound healing process [100]. This superior effect has been verified by other studies $[86,183] . \mathrm{CO}_{2}$ administration has been known to promote microcirculation and local oxygen supply in the wound through the Bohr effect that is favorable to wound healing. Yeh's group prepared a hollow porous $\mathrm{CuS}$ bridged both dopamine and bicarbonate, which can release $\mathrm{CO}_{2}$ under the irradiation of NIR lamp and achieve the Bohr effect to accelerate the wound healing [183]. To summarize, TMSs-based therapeutic platform brings unprecedented opportunities for pursuing efficient and effective wound treatment means owing to their versatile meritorious processes. We also look forward to the development of more seminal and efficient wound treatment methods using TMSs-based therapeutic platform.

\subsection{TMSs-based antibacterial coatings on medical implants}

Pathogens tend to colonize and adhere to the surfaces of medical implants and form biofilms, leading to implantassociated infections and even implant failure [7, 109, 198, 199]. Currently, the prevalence of peri-implant mucositis and periimplantitis remain at a high level, reaching approximately $47 \%$ and $20 \%$, respectively [200]. Additionally, even after traditional antibiotic therapy, biofilm infections are still difficult to be completely eradicated which results in recurring symptoms [109]. The removal of bacteria-infected implants is usually regarded as the only viable remedy, causing prolonged hospitalization periods and increased healthcare costs $[109,198]$. Insufficient bone tissue integration is another pivotal issue restricting the development of medical implants [70]. Consequently, besides the excellent bacteriostatic efficacy, satisfying biocompatibility and osteogenic activity are also urgent demands for ideal bone implants [70]. To circumvent these issues, great efforts have been dedicated to developing high-performance antimicrobial implant surfaces. In recent years, due to its remarkable characteristics such as satisfactory bacteriostatic efficacy and minimal invasiveness for mammalian cells, TMSs have been intensively studied as a promising candidate for versatile implant surfaces. Wu's group reported that an antibacterial rate of $99.84 \%$ and $99.65 \%$ against E. coli and S. aureus could be achieved on a chitosan-assisted $\mathrm{MoS}_{2}$ hybrid coating under both 660 and $808 \mathrm{~nm}$ dual-light irradiation for $10 \mathrm{~min}$. This coating exhibited the synergistic antibacterial effects between (a)

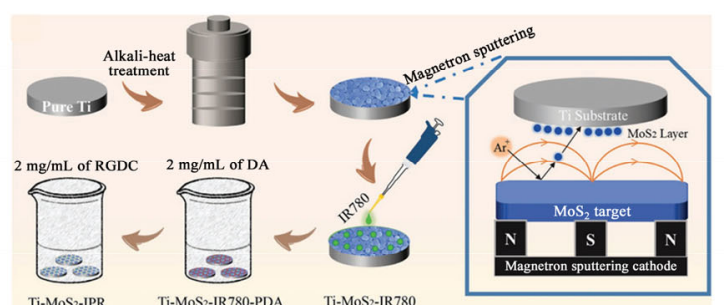

(b)

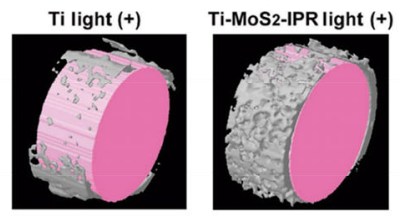

(c)

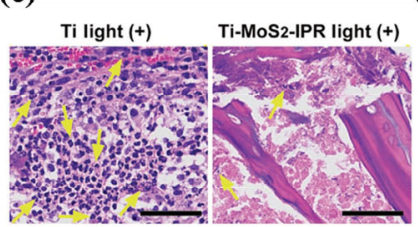

(d)

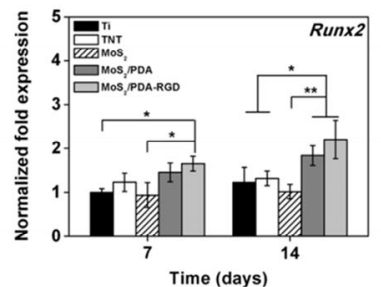

(f)

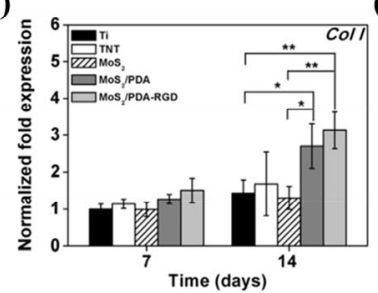

(e)

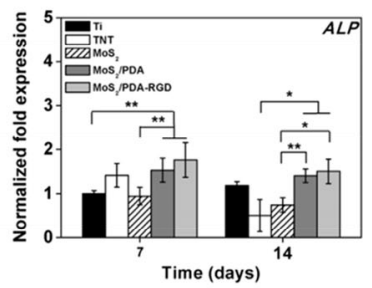

(g)

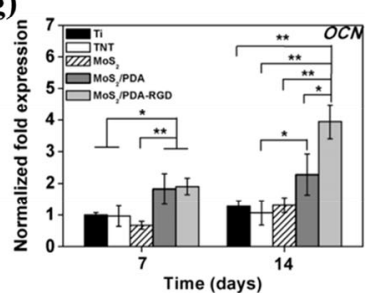

Figure 16 TMSs-based medical implant coatings with both bacteriostatic efficacy and osteogenic activity. (a) The preparation process diagram of Ti-MoS $-\mathrm{IPR}$ implants. (b) 3D images micro-CT of Ti and Ti-MoS $\mathrm{S}_{2} \mathrm{IPR}$ implants. The pink rod (inner) represents implant and the gray coating (outer) represents new bone. (c) Images of H\&E staining infer the infectious degree after cultured for three days with different samples, in which the bacteria marked by yellow arrows (scale bars, $50 \mu \mathrm{m}$ ). Reproduced with permission from Ref. [109], (OWILEY-VCH Verlag 2019, Relative osteogenic-specific mRNA expressions of mesenchymal stem cells cultured on different surface: (d) Runx2, (e) ALP, (f) Col I, and (g) OCN. Reproduced with permission from Ref. [186], (อElsevier B.V. 2019. 
PDT and PTT, which gave the Ti implant with rapid in situ bacteria-killing ability [187]. Hereafter, as depicted in Fig. 16(a), their group envisaged a biocompatible antibacterial implant surface based on $\mathrm{MoS}_{2}$, IR780 photosensitizer, and arginineglycine-aspartic acid-cysteine (RGDC), in which $\mathrm{MoS}_{2}$ exhibits high photothermal conversion efficiency, while IR780 is a photocatalyst that can transfer the energy of NIR lamp to dissolved oxygen molecules to produce ${ }^{1} \mathrm{O}_{2} \cdot \mathrm{MoS}_{2}$ was deposited on the surfaces of Ti implants via magnetron sputtering and subsequently positively charged IR780 can be adsorbed into the $\mathrm{MoS}_{2}$ layer with negative charges through electrostatic interaction. The polydopamine (PDA) can also be used as the reaction points to graft $\mathrm{RGDC}$ onto $\mathrm{Ti}$ implants and simultaneously RGDC coating could facilitate cell adhesion and proliferation and thus promote osteogenic differentiation. prepared Ti-MoS 2 -IR780-PDA-RGDC (Ti-MoS - IPR) antibacterial surfaces exhibited excellent antibacterial effect in vivo and accelerated osseointegration (Figs. 16(b) and 16(c)) [109]. Similarly, Yuan and colleagues fabricated a multifunctional $\mathrm{MoS}_{2} / \mathrm{PDA}$-arginine-glycine-aspartic acid (RGD) coating on Ti plates which not only endowed orthopedic implant with effective antibacterial ability under irradiation of NIR light but also promoted the osteogenesis of mesenchymal stem cells through up-regulating osteogenesis-related genes including alkaline phosphatase $(A L P)$, runt-related transcription factor 2 (Runx2), type I collagen ( $\mathrm{Col} \mathrm{I})$, and osteocalcin (OCN) (Figs. 16(e)-16(g)). Moreover, under NIR irradiation, the $\mathrm{MoS}_{2} /$ PDA-RGD implant effectively improved new bone formation even in an infected microenvironment in vivo [186]. According to the aforementioned investigations, TMSs equipped with natural bioactive materials could bring about medical implants with satisfactory bacteriostatic efficacy and biocompatibility, which provides great possibilities for the development of medical implants.

\section{Conclusions and perspectives}

Globally, millions of people lose their lives because of bacterial infection-related diseases every year. In order to protect human health and improve the quality of life, the development of efficient and minimally invasive bactericidal therapeutic agents is paramount, and as a result, research interests on nano-antibacterial materials are rapidly growing. TMSs offer new opportunities to solve this dilemma because of their excellent antibacterial performance, satisfactory biocompatibility, high solar energy utilization efficiency, and excellent photo-tothermal conversion characteristics. In this review article, an introduction to the development of bactericidal weapons is provided with a particular focus on transition metal sulfides based antibacterial agents. It is followed by an overview of the current state-of-the-art studies on investigations into the mechanisms behind the bactericidal process of TMSs, including oxidative stress, photothermal effects, cell entrapment, piezocatalytic degradation, metal ions incursion, and polysulfane release. With the aim to further enhance the antibacterial performance on TMSs, several effective strategies, such as microstructure engineering, surface functionalization with organic ligands, and construction of heterogeneous architecture, have been developed. Eventually, the possibility of TMSs-based antibacterial agents in practical application including strain-selective bactericidal strategies and wound healing is detailed discussed, which clearly illustrates the bright prospects of this research area. These pioneering works significantly highlight the potential of TMS-based antibacterial agents for bactericidal therapeutic applications. Based on the aforementioned survey in this field, more studies should be conducted to further unravel the elusive mechanisms for bacterial ablation, develop novel strategies to improve the antibacterial activity of TMSs-based materials and explore their practical applications in clinic trials. In order to achieve this, we would like to emphasize the following points:

(I) Although various fundamental mechanisms of bacterial ablation using TMSs have been proposed, there is still a big space for us to explore. For instance, it is necessary to unveil the mechanisms of the various surface chemical reaction processes involved, including the adsorption and conversion of oxygen or water molecules into the ROS. Specifically, more research efforts should be devoted to improving the understanding on how surface energy and reactivity of TMSsbased nanomaterials affect the adsorption energy and activation energy of oxygen or water molecules, thus constructing a rational model for ROS formation. Additionally, the generation mechanism of organosulfur during the bactericidal processes of TMSs is still elusive and this novel therapeutic approach mimicking the natural sterilization mechanism may inject new vitality into antibacterial research. Besides, mechanistic insights into the interactions between TMSs-based nanomaterials and bacteria, such as the electrostatic interactions and electron transfer processes, also need to be elaborated. Based on the in-depth understanding on the bactericidal mechanism, we can try to comprehensively employ the versatile antimicrobial mechanisms of TMSs to achieve more effective synergistic bactericidal effect. Creditably, these intensive investigations on the bactericidal mechanisms could provide theoretical guidance for the development of suitable candidate antibacterial agents in the future.

(II) Although a lot of seminal progresses in enhancing the antibacterial performances of TMSs have been made in recent years, the quick recombination and weak reactivity of the charge carriers and inert nature still restrict their practical applications and thus the construction of TMSs-based materials for efficient and noninvasive antimicrobial applications is still an imperative issue. Owing to the controllable electronic energy structure and intense membrane destruction capability, TMSs with 2D microstructure have proven fascinating candidates. Meanwhile, the 2D TMSs can construct the van der Waals heterojunction, which greatly broadens the scope of material design for scavengers and arouses the interest of researchers. In consideration of the feasible surface functionalization and excellent light-to-thermal conversion, the development of a multifunctional synergistic antibacterial system using TMSsbased nanomedicine will open the broad avenue for bacterial inhibitory applications, which provides unprecedented opportunities for researchers in this area. Additionally, some other emerging novel antibacterial strategies, such as Z-scheme heterojunction and photoelectrochemical sterilization, are still in the development stage and are worthy of continued exploration by researchers.

(III) Since the ultimate pursuit for our investigations on TMSs-based antimicrobial platform is to achieve a quantum leap in the healthcare industry, the development and envisagement of effective and efficient antibacterial therapeutic modalities for practical applications are our urgent demands. The prerequisite for the responsible development of TMSs-based nanomedicine is excellent biosafety, which needs to be further verified by more works. Meanwhile, we still face many challenges during the clinical translation of TMSs-based nanomedicine as well. It is worth noting that hyperthermia and ROS generation are commonly involved in photothermal and photodynamic therapy processes. These antibacterial therapeutic modalities are difficult to achieve selectivity. In other words, during the treatment process, normal tissue cells in the wound are also attacked. 
Consequently, it is an urgent desire that only harmful bacteria will be selectively killed without damaging normal cells and probiotic bacteria when using such antibacterial agents. In this review article, we have introduced that TMSs-based antibacterial agents with specific shapes or equipped with specific organic molecules can selectively capture the finely regulated and complicated outer membranes of microorganisms, leading to the construction of strain-selective bactericidal strategies. To further fully explore these capabilities, more bacterial targets and other strain-selective bactericidal mechanisms remain to be further elaborated. Additionally, we also need precise drug delivery modalities to control the concentration of scavengers at a reasonable threshold. Thereafter, the development of feasible therapeutic methods to facilitate wound healing and osteogenic differentiation is urgent and mandatory. Due to their high biocompatibility and bacteriostatic efficacy, TMSs has great potential to be developed in these aspects, which is worth more research efforts.

In conclusion, owing to people's urgent demand for better life, more and more research efforts for antibacterial agents need to be made. TMSs-based bacterial inhibitory agents will certainly continue to attract increasing research interests in the future due to their excellent antibacterial performance and minimal invasiveness for mammalian cells. From this viewpoint, it is very urgent to review the recent progress on the studies in antibacterial mechanisms and strategies for promoting their antibacterial properties. We hope that this review article can give researchers some enlightenment.

\section{Acknowledgements}

This work was supported by the National Natural Science Foundation of China (Nos. 21902085 and 51572157), the Natural Science Foundation of Shandong Province (Nos. ZR2019QF012 and ZR2019BEM024), Shenzhen Fundamental Research Program (Nos. JCYJ20190807093205660 and JCYJ20190807092803583), the Natural Science Foundation of Jiangsu Province (No. BK20190205), and the Guangdong Basic and Applied Basic Research Foundation (No. 2019A1515110846), the Fundamental Research Funds for the Central Universities (Nos. 2018JC046 and 2018JC047), Medical and Health Science and Technology Development Project of Shandong Province (No. 2018WSA01018), Science Development Program Project of Jinan (No. 201805048), the Dean's Research Assistance Foundation of Ji Nan Stomatology Hospital (2018-02) and the Qilu Young Scholar Program of Shandong University (Nos. 31370088963043 and 31370088963056).

\section{References}

[1] Ganguly, P.; Byrne, C.; Breen, A.; Pillai, S. C. Antimicrobial activity of photocatalysts: Fundamentals, mechanisms, kinetics and recent advances. Appl. Catal. B Environ. 2018, 225, 51-75.

[2] Kang, Q.; Lu, Q. Z.; Liu, S. H.; Yang, L. X.; Wen, L. F.; Luo, S. L.; $\mathrm{Cai}, \mathrm{Q}$. Y. A ternary hybrid $\mathrm{CdS} / \mathrm{Pt}-\mathrm{TiO}_{2}$ nanotube structure for photoelectrocatalytic bactericidal effects on Escherichia coli. Biomaterials 2010, 31, 3317-3326.

[3] Rizzello, L.; Pompa, P. P. Nanosilver-based antibacterial drugs and devices: Mechanisms, methodological drawbacks, and guidelines. Chem. Soc. Rev. 2014, 43, 1501-1518.

[4] Li, X.; Bai, H. T.; Yang, Y. C.; Yoon, J.; Wang, S.; Zhang, X. Supramolecular antibacterial materials for combatting antibiotic resistance. Adv. Mater. 2019, 31, 1805092.

[5] Du, S.; Zhou, N. Y.; Gao, Y. J.; Xie, G.; Du, H. Y.; Jiang, H.; Zhang, L. B.; Tao, J.; Zhu, J. T. Bioinspired hybrid patches with self-adhesive hydrogel and piezoelectric nanogenerator for promoting skin wound healing. Nano Res. 2020, 13, 2525-2533.
[6] Wang, S. L.; Huang, Q. M.; Liu, X. Y.; Li, Z.; Yang, H.; Lu, Z. Rapid antibiofilm effect of $\mathrm{Ag} / \mathrm{ZnO}$ nanocomposites assisted by dental led curing light against facultative anaerobic oral pathogen streptococcus mutans. ACS Biomater. Sci. Eng. 2019, 5, 2030-2040.

[7] Nagay, B. E.; Dini, C.; Cordeiro, J. M.; Ricomini-Filho, A. P.; de Avila, E. D.; Rangel, E. C.; da Cruz, N. C.; Barao, V. A. R. Visiblelight-induced photocatalytic and antibacterial activity of $\mathrm{TiO}_{2}$ codoped with nitrogen and bismuth: New perspectives to control implant-biofilm-related diseases. ACS Appl. Mater. Inter. 2019, 11, 18186-18202.

[8] Di Martino, A.; Sittinger, M.; Risbud, M. V. Chitosan: A versatile biopolymer for orthopaedic tissue-engineering. Biomaterials 2005, 26, 5983-5990.

[9] Mao, C. Y.; Xiang, Y. M.; Liu, X. M.; Cui, Z. D.; Yang, X. J.; Yeung, K. W. K.; Pan, H. B.; Wang, X. B.; Chu, P. K.; Wu, S. L. Photoinspired antibacterial activity and wound healing acceleration by hydrogel embedded with $\mathrm{Ag} / \mathrm{Ag} @ \mathrm{AgCl} / \mathrm{ZnO}$ nanostructures. ACS Nano 2017, 11, 9010-9021.

[10] Zhao, Y.; Guo, Q. Q.; Dai, X. M.; Wei, X. S.; Yu, Y. J.; Chen, X. L.; Li, C. X.; Cao, Z. Q.; Zhang, X. E. A biomimetic non-antibiotic approach to eradicate drug-resistant infections. Adv. Mater. 2019, 31, 1806024.

[11] Qiu, H.; Pu, F.; Liu, Z. W.; Liu, X. M.; Dong, K.; Liu, C. Q.; Ren, J. S.; $\mathrm{Qu}, \mathrm{X}$. G. Hydrogel-based artificial enzyme for combating bacteria and accelerating wound healing. Nano Res. 2020, 13, 496-502.

[12] Prestinaci, F.; Pezzotti, P.; Pantosti, A. Antimicrobial resistance: A global multifaceted phenomenon. Pathog. Glob. Health 2015, 109, 309-318.

[13] Liu, Y.; Shi, L.; Su, L. Z.; van der Mei, H. C.; Jutte, P. C.; Ren, Y. J.; Busscher, H. J. Nanotechnology-based antimicrobials and delivery systems for biofilm-infection control. Chem. Soc. Rev. 2019, 48, 428-446.

[14] Wang, S.; Xu, M.; Huang, K. W.; Zhi, J. H.; Sun, C.; Wang, K.; Zhou, Q.; Gao, L. L.; Jia, Q. Y.; Shi, H. F. et al. Biocompatible metal-free organic phosphorescent nanoparticles for efficiently multidrugresistant bacteria eradication. Sci. China Mater. 2020, 63, 316-324.

[15] Zhang, X. D.; Xia, L. Y.; Chen, X. K.; Chen, Z.; Wu, F. G. Hydrogelbased phototherapy for fighting cancer and bacterial infection. Sci. China Mater. 2017, 60, 487-503.

[16] Lemire, J. A.; Harrison, J. J.; Turner, R. J. Antimicrobial activity of metals: Mechanisms, molecular targets and applications. Nat. Rev. Microbiol. 2013, 11, 371-384.

[17] Costerton, J. W.; Stewart, P. S.; Greenberg, E. P. Bacterial biofilms: A common cause of persistent infections. Science 1999, 284, 13181322.

[18] Davies, D. Understanding biofilm resistance to antibacterial agents. Nat. Rev. Drug Discov. 2003, 2, 114-122.

[19] Huang, Y.; Gao, Q.; Li, X.; Gao, Y.; Han, H. J.; Jin, Q.; Yao, K.; Ji, J. Ofloxacin loaded $\mathrm{MoS}_{2}$ nanoflakes for synergistic mild-temperature photothermal/antibiotic therapy with reduced drug resistance of bacteria. Nano Res. 2020, 13, 2340-2350.

[20] Chen, Z. W.; Wang, Z. Z.; Ren, J. S.; Qu, X. G. Enzyme mimicry for combating bacteria and biofilms. Acc. Chem. Res. 2018, 51, 789-799.

[21] Chen, Z. W.; Ji, H. W.; Liu, C. Q.; Bing, W.; Wang, Z. Z.; Qu, X. G. A multinuclear metal complex based dnase-mimetic artificial enzyme: Matrix cleavage for combating bacterial biofilms. Angew. Chem., Int. Ed. 2016, 55, 10732-10736.

[22] Willyard, C. Drug-resistant bacteria ranked. Nature 2017, 543, 15.

[23] Gupta, A.; Mumtaz, S.; Li, C. H.; Hussain, I.; Rotello, V. M. Combatting antibiotic-resistant bacteria using nanomaterials. Chem. Soc. Rev. 2019, 48, 415-427.

[24] Wang, Y.; Yang, Y.; Shi, Y.; Song, H.; Yu, C. Z. Antibiotic-free antibacterial strategies enabled by nanomaterials: Progress and perspectives. Adv. Mater. 2019, 18, 1904106.

[25] Chernousova, S.; Epple, M. Silver as antibacterial agent: Ion, nanoparticle, and metal. Angew. Chem., Int. Ed. 2013, 52, 1636-1653.

[26] Rtimi, S.; Dionysiou, D. D.; Pillai, S. C.; Kiwi, J. Advances in catalytic/photocatalytic bacterial inactivation by nano $\mathrm{Ag}$ and $\mathrm{Cu}$ coated surfaces and medical devices. Appl. Catal. B Environ. 2019, 240, 291-318.

[27] Foster, H. A.; Ditta, I. B.; Varghese, S.; Steele, A. Photocatalytic disinfection using titanium dioxide: Spectrum and mechanism of 
antimicrobial activity. Appl. Microbiol. Biotechnol. 2011, 90, 18471868.

[28] Ma, H. B.; Williams, P. L.; Diamond, S. A. Ecotoxicity of manufactured $\mathrm{ZnO}$ nanoparticles-A review. Environ. Pollut. 2013, 172, 76-85.

[29] Wang, Z. P.; Fang, Y. S.; Zhou, X. F.; Li, Z. B.; Zhu, H. G.; Du, F. L.; Yuan, X.; Yao, Q. F.; Xie, J. P. Embedding ultrasmall ag nanoclusters in luria-bertani extract via light irradiation for enhanced antibacterial activity. Nano Res. 2020, 13, 203-208.

[30] Shi, Q. B.; Zhang, H. W.; Zhang, H. P.; Zhao, P.; Zhang, Y.; Tang, Y. H. Polydopamine/silver hybrid coatings on soda-lime glass spheres with controllable release ability for inhibiting biofilm formation. Sci. China Mater. 2020, 63, 842-850.

[31] Zhang, M.; Zhang, C.; Zhai, X.; Luo, F.; Du, Y.; Yan, C. Antibacterial mechanism and activity of cerium oxide nanoparticles. Sci. China Mater. 2019, 62, 1727-1739.

[32] Zhu, Y.; Xu, J.; Wang, Y. M.; Chen, C.; Gu, H. C.; Chai, Y. M.; Wang, Y. Silver nanoparticles-decorated and mesoporous silica coated single-walled carbon nanotubes with an enhanced antibacterial activity for killing drug-resistant bacteria. Nano Res. 2020, 13, 389400.

[33] AshaRani, P. V.; Mun, G. L. K.; Hande, M. P.; Valiyaveettil, S. Cytotoxicity and genotoxicity of silver nanoparticles in human cells. ACS Nano 2009, 3, 279-290.

[34] Ivask, A.; ElBadawy, A.; Kaweeteerawat, C.; Boren, D.; Fischer, H.; Ji, Z.; Chang, C. H.; Liu, R.; Tolaymat, T.; Telesca, D. et al. Toxicity mechanisms in Escherichia coli vary for silver nanoparticles and differ from ionic silver. ACS Nano 2014, 8, 374-386.

[35] Levard, C.; Hotze, E. M.; Colman, B. P.; Dale, A. L.; Truong, L.; Yang, X. Y.; Bone, A. J.; Brown, G. E., Jr.; Tanguay, R. L.; Di Giulio, R. T. et al. Sulfidation of silver nanoparticles: Natural antidote to their toxicity. Environ. Sci. Technol. 2013, 47, 13440-13448.

[36] Guo, L. R.; Panderi, I.; Yan, D. D.; Szulak, K.; Li, Y. J.; Chen, Y. T.; Ma, H.; Niesen, D. B.; Seeram, N.; Ahmed, A. et al. A comparative study of hollow copper sulfide nanoparticles and hollow gold nanospheres on degradability and toxicity. ACS Nano 2013, 7, 8780-8793.

[37] Qiu, X. Q.; Miyauchi, M.; Sunada, K.; Minoshima, M.; Liu, M.; Lu, Y.; $\mathrm{Li}$, D.; Shimodaira, Y.; Hosogi, Y.; Kuroda, Y. et al. Hybrid $\mathrm{Cu}_{x} \mathrm{O} / \mathrm{TiO}_{2}$ nanocomposites as risk-reduction materials in indoor environments. ACS Nano 2012, 6, 1609-1618.

[38] Kim, B. C.; Jeong, E.; Kim, E.; Hong, S. W. Bio-organic-inorganic hybrid photocatalyst, $\mathrm{TiO}_{2}$ and glucose oxidase composite for enhancing antibacterial performance in aqueous environments. Appl. Catal. B Environ. 2019, 242, 194-201.

[39] Karaolia, P.; Michael-Kordatou, I.; Hapeshi, E.; Drosou, C.; Bertakis, Y.; Christofilos, D.; Armatas, G. S.; Sygellou, L.; Schwartz, T.; Xekoukoulotakis, N. P. et al. Removal of antibiotics, antibioticresistant bacteria and their associated genes by graphene-based $\mathrm{TiO}_{2}$ composite photocatalysts under solar radiation in urban wastewaters. Appl. Catal. B Environ. 2018, 224, 810-824.

[40] Ge, P.; Zhang, C. Y.; Hou, H. S.; Wu, B. K.; Zhou, L.; Li, S. J.; Wu, T. J.; Hu, J. G.; Mai, L. Q.; Ji, X. B. Anions induced evolution of $\mathrm{Co}_{3} \mathrm{X}_{4}(\mathrm{X}=\mathrm{O}, \mathrm{S}, \mathrm{Se})$ as sodium-ion anodes: The influences of electronic structure, morphology, electrochemical property. Nano Energy 2018, 48, 617-629.

[41] Kuc, A.; Zibouche, N.; Heine, T. Influence of quantum confinement on the electronic structure of the transition metal sulfide $\mathrm{TS}_{2}$. Phys. Rev. B 2011, 83, 245213.

[42] Wang, F. L.; Jin, Z. M.; Jiang, Y. J.; Backus, E. H. G.; Bonn, M.; Lou, S. N.; Turchinovich, D.; Amal, R. Probing the charge separation process on $\mathrm{In}_{2} \mathrm{~S}_{3} / \mathrm{Pt}-\mathrm{TiO}_{2}$ nanocomposites for boosted visible-light photocatalytic hydrogen production. Appl. Catal. B Environ. 2016, $198,25-31$

[43] Hu, X. L.; Chu, L. Y.; Dong, X. J.; Chen, C. R.; Tang, T. T.; Chen, D. J.; He, X. P.; Tian, H. Multivalent glycosheets for double light driven therapy of multidrug-resistant bacteria on wounds. $A d v$. Funct. Mater. 2019, 29, 1806986.

[44] Hou, S.; Mahadevegowda, S. H.; Van Cuong, M.; Chan-Park, M. B.; Duan, H. Glycosylated copper sulfide nanocrystals for targeted photokilling of bacteria in the near-infrared II window. Adv. Ther. 2019, 2, 1900052 .
[45] Niu, J. S.; Sun, Y. H.; Wang, F. M.; Zhao, C. Q.; Ren, J. S.; Qu, X. G. Photomodulated nanozyme used for a gram-selective antimicrobial. Chem. Mat. 2018, 30, 7027-7033.

[46] Tian, Q. W.; Jiang, F. R.; Zou, R. J.; Liu, Q.; Chen, Z. G.; Zhu, M. F.; Yang, S. P.; Wang, J. L.; Wang, J. H.; Hu, J. Q. Hydrophilic $\mathrm{Cu}_{9} \mathrm{~S}_{5}$ nanocrystals: A photothermal agent with a $25.7 \%$ heat conversion efficiency for photothermal ablation of cancer cells in vivo. ACS Nano 2011, 5, 9761-9771.

[47] Hao, J. L.; Song, G. S.; Liu, T.; Yi, X.; Yang, K.; Cheng, L.; Liu, Z. In vivo long-term biodistribution, excretion, and toxicology of pegylated transition-metal dichalcogenides $\mathrm{MS}_{2}(\mathrm{M}=\mathrm{Mo}, \mathrm{W}, \mathrm{Ti})$ nanosheets. Adv. Sci. 2017, 4, 1600160.

[48] Nozik, A. J. Photoelectrochemistry: applications to solar-energy conversion. Annu. Rev. Phys. Chem. 1978, 29, 189-222.

[49] Han, J. H.; Kwak, M.; Kim, Y.; Cheon, J. Recent advances in the solution-based preparation of two-dimensional layered transition metal chalcogenide nanostructures. Chem. Rev. 2018, 118, 6151-6188.

[50] Ipe, B. I.; Lehnig, M.; Niemeyer, C. M. On the generation of free radical species from quantum dots. Small 2005, 1, 706-709.

[51] Liu, L.; Sun, M. Q.; Zhang, H. J.; Yu, Q. L.; Li, M. C.; Qi, Y.; Zhang, C. D.; Gao, G. D.; Yuan, Y. J.; Zhai, H. H. et al. Facet energy and reactivity versus cytotoxicity: The surprising behavior of CdS nanorods. Nano Lett. 2016, 16, 688-694.

[52] Argueta-Figueroa, L.; Martínez-Alvarez, O.; Santos-Cruz, J.; GarciaContreras, R.; Acosta-Torres, L. S.; De La Fuente-Hernández, J.; Arenas-Arrocena, M. C. Nanomaterials made of non-toxic metallic sulfides: A systematic review of their potential biomedical applications. Mater. Sci. Eng. C 2017, 76, 1305-1315.

[53] Guo, Y. N.; Park, T.; Yi, J. W.; Henzie, J.; Kim, J.; Wang, Z. L.; Jiang, B.; Bando, Y.; Sugahara, Y.; Tang, J. et al. Nanoarchitectonics for transition-metal-sulfide-based electrocatalysts for water splitting. Adv. Mater. 2019, 31, 1807134.

[54] Chen, X.; McDonald, A. R. Functionalization of two-dimensional transition-metal dichalcogenides. Adv. Mater. 2016, 28, 5738-5746.

[55] Fang, Y. Q.; Pan, J.; He, J. Q.; Luo, R. C.; Wang, D.; Che, X. L.; Bu, K. J.; Zhao, W.; Liu, P.; Mu, G. et al. Structure re-determination and superconductivity observation of bulk $1 \mathrm{~T} \mathrm{MoS}_{2}$. Angew. Chem., Int. Ed. 2018, 57, 1232-1235.

[56] Zhang, J. F.; Wageh, S.; Al-Ghamdi, A.; Yu, J. G. New understanding on the different photocatalytic activity of wurtzite and zinc-blende CdS. Appl. Catal. B Environ. 2016, 192, 101-107.

[57] Liu, Y.; Liu, M. X.; Swihart, M. T. Reversible crystal phase interconversion between covellite $\mathrm{CuS}$ and high chalcocite $\mathrm{Cu}_{2} \mathrm{~S}$ nanocrystals. Chem. Mat. 2017, 29, 4783-4791.

[58] Kong, D. S.; Cha, J. J.; Wang, H. T.; Lee, H. R.; Cui, Y. First-row transition metal dichalcogenide catalysts for hydrogen evolution reaction. Energy Environ. Sci. 2013, 6, 3553-3558.

[59] Nosaka, Y.; Nosaka, A. Y. Generation and detection of reactive oxygen species in photocatalysis. Chem. Rev. 2017, 117, 11302-11336.

[60] Liu, S. B.; Zeng, T. H.; Hofmann, M.; Burcombe, E.; Wei, J.; Jiang, R. R.; Kong, J.; Chen, Y. Antibacterial activity of graphite, graphite oxide, graphene oxide, and reduced graphene oxide: Membrane and oxidative stress. ACS Nano 2011, 5, 6971-6980.

[61] Bhaumik, J.; Mittal, A. K.; Banerjee, A.; Chisti, Y.; Banerjee, U. C. Applications of phototheranostic nanoagents in photodynamic therapy. Nano Res. 2015, 8, 1373-1394.

[62] Lushchak, V. I. Free radicals, reactive oxygen species, oxidative stress and its classification. Chem. Biol. Interact. 2014, 224, 164-175.

[63] Fang, G.; Li, W. F.; Shen, X. M.; Perez-Aguilar, J. M.; Chong, Y.; Gao, X.; Chai, Z. F.; Chen, C. Y.; Ge, C. C.; Zhou, R. H. Differential Pd-nanocrystal facets demonstrate distinct antibacterial activity against gram-positive and gram-negative bacteria. Nat. Commun. 2018, 9,129

[64] Budanov, A. V.; Sablina, A. A.; Feinstein, E.; Koonin, E. V.; Chumakov, P. M. Regeneration of peroxiredoxins by p53-regulated sestrins, homologs of bacterial ahpd. Science 2004, 304, 596-600.

[65] Dalrymple, O. K.; Stefanakos, E.; Trotz, M. A.; Goswami, D. Y. A review of the mechanisms and modeling of photocatalytic disinfection. Appl. Catal. B Environ. 2010, 98, 27-38.

[66] Apel, K.; Hirt, H. Reactive oxygen species: Metabolism, oxidative stress, and signal transduction. Annu. Rev. Plant Biol. 2004, 55, 373-399. 
[67] Levy, M.; Chowdhury, P. P.; Nagpal, P. Quantum dot therapeutics: A new class of radical therapies. J. Biol. Eng. 2019, 13, 48.

[68] Ray, S. K.; Dhakal, D.; Hur, J.; Lee, S. W. Visible light driven $\mathrm{MoS}_{2} / \alpha-\mathrm{NiMoO}_{4}$ ultra-thin nanoneedle composite for efficient staphylococcus aureus inactivation. J. Hazard. Mater. 2020, 385, 121553.

[69] Kim, T. I.; Kwon, B.; Yoon, J.; Park, I. J.; Bang, G. S.; Park, Y.; Seo, Y. S.; Choi, S. Y. Antibacterial activities of graphene oxide molybdenum disulfide nanocomposite films. ACS Appl. Mater. Inter. 2017, 9, 7908-7917.

[70] Zhang, G. N.; Zhang, X. Y.; Yang, Y. Q.; Chi, R. F.; Shi, J.; Hang, R. Q.; Huang, X. B.; Yao, X. H.; Chu, P. K.; Zhang, X. Y. Dual light-induced in situ antibacterial activities of biocompatible $\mathrm{TiO}_{2} /$ $\mathrm{MoS}_{2} / \mathrm{PDA} / \mathrm{RGD}$ nanorod arrays on titanium. Biomater. Sci. 2020, $8,391-404$

[71] Fujishima, A.; Honda, K. Electrochemical photolysis of water at a semiconductor electrode. Nature 1972, 238, 37-38.

[72] Liu, J.; Liu, Y.; Liu, N. Y.; Han, Y. Z.; Zhang, X.; Huang, H.; Lifshitz, Y.; Lee, S. T.; Zhong, J.; Kang, Z. H. Metal-free efficient photocatalyst for stable visible water splitting via a two-electron pathway. Science 2015, 347, 970-974.

[73] Wang, F. L.; Ho, J. H.; Jiang, Y. J.; Amal, R. Tuning phase composition of $\mathrm{TiO}_{2}$ by $\mathrm{Sn}^{4+}$ doping for efficient photocatalytic hydrogen generation. ACS Appl. Mater. Inter. 2015, 7, 23941-23948.

[74] Pelaez, M.; Nolan, N. T.; Pillai, S. C.; Seery, M. K.; Falaras, P.; Kontos, A. G.; Dunlop, P. S. M.; Hamilton, J. W. J.; Byrne, J. A.; O'Shea, K. et al. A review on the visible light active titanium dioxide photocatalysts for environmental applications. Appl. Catal. B Environ. 2012, 125, 331-349.

[75] Konstantinou, I. K.; Albanis, T. A. $\mathrm{TiO}_{2}$-assisted photocatalytic degradation of azo dyes in aqueous solution: Kinetic and mechanistic investigations - a review. Appl. Catal. B Environ. 2004, 49, 1-14.

[76] Chong, M. N.; Jin, B.; Chow, C. W. K.; Saint, C. Recent developments in photocatalytic water treatment technology: A review. Water Res. 2010, 44, 2997-3027.

[77] Wang, L. W.; Zhang, X.; Yu, X.; Gao, F. E.; Shen, Z. Y.; Zhang, X. L; Ge, S. G.; Liu, J.; Gu, Z. J.; Chen, C. Y. An all-organic semiconductor $\mathrm{C}_{3} \mathrm{~N}_{4} / \mathrm{PDINH}$ heterostructure with advanced antibacterial photocatalytic therapy activity. Adv. Mater. 2019, 31, 1901965.

[78] Waiskopf, N.; Ben-Shahar, Y.; Banin, U. Photocatalytic hybrid semiconductor-metal nanoparticles; from synergistic properties to emerging applications. Adv. Mater. 2018, 30, 1706697.

[79] Li, Y.; Liu, X. M.; Tan, L.; Cui, Z D.; Jing, D. D.; Yang, X. J.; Liang, Y. Q.; Li, Z. Y.; Zhu, S. L.; Zheng, Y. F. et al. Eradicating multidrugresistant bacteria rapidly using a multi functional g- $\mathrm{C}_{3} \mathrm{~N}_{4} @ B \mathrm{Bi}_{2} \mathrm{~S}_{3}$ nanorod heterojunction with or without antibiotics. Adv. Funct. Mater. 2019, 29, 1900946.

[80] Wang, F. L.; Jiang, Y. J.; Lawes, D. J.; Ball, G. E.; Zhou, C. F.; Liu, Z. W.; Amal, R. Analysis of the promoted activity and molecular mechanism of hydrogen production over fine $\mathrm{Au}-\mathrm{Pt}$ alloyed $\mathrm{TiO}_{2}$ photocatalysts. ACS Catal. 2015, 5, 3924-3931.

[81] Wang, F. L.; Wong, R. J.; Ho, J. H.; Jiang, Y. J.; Amal, R. Sensitization of $\mathrm{Pt} / \mathrm{TiO}_{2}$ using plasmonic $\mathrm{Au}$ nanoparticles for hydrogen evolution under visible-light irradiation. ACS Appl. Mater. Inter. 2017, 9, 30575-30582.

[82] Wang, L. D.; Xu, D.; Gao, J.; Chen, X.; Duo, Y. H.; Zhang, H. Semiconducting quantum dots: Modification and applications in biomedical science. Sci. China Mater. 2020, 63, 1631-1650.

[83] Wang, F. L.; Jiang, Y. J.; Gautam, A.; Li, Y. R.; Amal, R. Exploring the origin of enhanced activity and reaction pathway for photocatalytic $\mathrm{H}_{2}$ production on $\mathrm{Au} / \mathrm{B}-\mathrm{TiO}_{2}$ catalysts. ACS Catal. 2014, 4, $1451-1457$

[84] Li, Y.; Zhang, W.; Niu, J. F.; Chen, Y. S. Mechanism of photogenerated reactive oxygen species and correlation with the antibacterial properties of engineered metal-oxide nanoparticles. ACS Nano 2012, 6, 5164-5173.

[85] Liu, Y.; Zeng, X. K.; Hu, X. Y.; Hu, J.; Zhang, X. W. Twodimensional nanomaterials for photocatalytic water disinfection: Recent progress and future challenges. J. Chem. Technol. Biotechnol. 2019, 94, 22-37.

[86] Zhang, X. Y.; Zhang, G. N.; Zhang, H. Y.; Liu, X. P.; Shi, J.; Shi, H. X.; Yao, X. H.; Chu, P. K.; Zhang, X. Y. A bifunctional hydrogel incorporated with $\mathrm{CuS} @ \mathrm{MoS}_{2}$ microspheres for disinfection and improved wound healing. Chem. Eng. J. 2020, 382.

[87] Lin, Y. F.; Han, D. L.; Li, Y.; Tan, L.; Liu, X.; Cui, Z. D.; Yang, X. J.; Li, Z. Y.; Liang, Y. Q.; Zhu, S. L. et al. $\mathrm{Ag}_{2} \mathrm{~S} @ \mathrm{WS}_{2}$ heterostructure for rapid bacteria-killing using near-infrared light. ACS Sustain. Chem. Eng. 2019, 7, 14982-14990.

[88] Shang, E. X.; Niu, J. F.; Li, Y.; Zhou, Y. J.; Crittenden, J. C. Comparative toxicity of $\mathrm{Cd}, \mathrm{Mo}$, and $\mathrm{W}$ sulphide nanomaterials toward E. coli under UV irradiation. Environ. Pollut. 2017, 224, 606-614.

[89] Wei, H.; Wang, E. K. Nanomaterials with enzyme-like characteristics (nanozymes): Next-generation artificial enzymes. Chem. Soc. Rev. 2013, 42, 6060-6093.

[90] Wu, J. X.; Wang, X. Y.; Wang, Q.; Lou, Z. P.; Li, S. R.; Zhu, Y. Y.; Qin, L.; Wei, H. Nanomaterials with enzyme-like characteristics (nanozymes): Next-generation artificial enzymes (II). Chem. Soc. Rev. 2019, 48, 1004-1076.

[91] Lin, Y. H.; Ren, J. S.; Qu, X. G. Catalytically active nanomaterials: A promising candidate for artificial enzymes. Acc. Chem. Res. 2014, 47, 1097-1105.

[92] Cao, F. F.; Zhang, L.; Wang, H.; You, Y. W.; Wang, Y.; Gao, N.; Ren, J. S.; Qu, X. G. Defect-rich adhesive nanozymes as efficient antibiotics for enhanced bacterial inhibition. Angew. Chem., Int. Ed. 2019, 58, 16236-16242.

[93] Shan, J. Y.; Li, X.; Yang, K. L.; Xiu, W. J.; Wen, Q. R.; Zhang, Y. Q.; Yuwen, L. H.; Weng, L. X.; Teng, Z. G.; Wang, L. H. Efficient bacteria killing by $\mathrm{Cu}_{2} \mathrm{WS}_{4}$ nanocrystals with enzyme-like properties and bacteria-binding ability. ACS Nano 2019, 13, 13797-13808.

[94] Wang, W. S.; Li, B. L.; Yang, H. L.; Lin, Z. F.; Chen, L. L.; Li, Z.; Ge, J. Y.; Zhang, T.; Xia, H.; Li, L. H. et al. Efficient elimination of multidrug-resistant bacteria using copper sulfide nanozymes anchored to graphene oxide nanosheets. Nano Res. 2020, 13, 2156-2164.

[95] Masimukku, S.; Hu, Y. C.; Lin, Z. H.; Chan, S. W.; Chou, T. M.; Wu, J. M. High efficient degradation of dye molecules by pdms embedded abundant single-layer tungsten disulfide and their antibacterial performance. Nano Energy 2018, 46, 338-346.

[96] Chou, T. M.; Chan, S. W.; Lin, Y. J.; Yang, P. K.; Liu, C. C.; Lin, Y. J.; Wu, J. M.; Lee, J. T.; Lin, Z. H. A highly efficient Au-MoS 2 nanocatalyst for tunable piezocatalytic and photocatalytic water disinfection. Nano Energy 2019, 57, 14-21.

[97] Tian, Q. W.; Tang, M. H.; Sun, Y. G.; Zou, R. J.; Chen, Z. G.; Zhu, M. F.; Yang, S. P.; Wang, J. L.; Wang, J. L.; Hu, J. Q. Hydrophilic flower-like CuS superstructures as an efficient $980 \mathrm{~nm}$ laser-driven photothermal agent for ablation of cancer cells. Adv. Mater. 2011, 23, 3542-3547.

[98] Cheng, L.; Liu, J. J.; Gu, X.; Gong, H.; Shi, X. Z.; Liu, T.; Wang, C.; Wang, X. Y.; Liu, G.; Xing, H. Y. et al. Pegylated $\mathrm{WS}_{2}$ nanosheets as a multifunctional theranostic agent for in vivo dual-modal ct/photoacoustic imaging guided photothermal therapy. Adv. Mater. 2014, 26, 1886-1893.

[99] Li, X.; Shan, J. Y.; Zhang, W. Z.; Su, S.; Yuwen, L. H.; Wang, L. H. Recent advances in synthesis and biomedical applications of two-dimensional transition metal dichalcogenide nanosheets. Small 2017, 13, 28.

[100] Wang, X. C.; Lv, F.; Li, T.; Han, Y. M.; Yi, Z. F.; Liu, M. Y.; Chang, J.; $\mathrm{Wu}, \mathrm{C}$. T. Electrospun micropatterned nanocomposites incorporated with $\mathrm{Cu}_{2} \mathrm{~S}$ nanoflowers for skin tumor therapy and wound healing. ACS Nano 2017, 11, 11337-11349.

[101] Hsu, S. W.; On, K.; Tao, A. R. Localized surface plasmon resonances of anisotropic semiconductor nanocrystals. J. Am. Chem. Soc. 2011, 133, 19072-19075.

[102] Kriegel, I.; Jiang, C. Y.; Rodríguez-Fernández, J.; Schaller, R. D.; Talapin, D. V.; Da Como, E.; Feldmann, J. Tuning the excitonic and plasmonic properties of copper chalcogenide nanocrystals. J. Am. Chem. Soc. 2012, 134, 1583-1590.

[103] Huang, J. L.; Zhou, J. F.; Zhuang, J. Y.; Gao, H. Z.; Huang, D. H.; Wang, L. X.; Wu, W. L.; Li, Q. B.; Yang, D. P.; Han, M. Y. Strong near-infrared absorbing and biocompatible $\mathrm{CuS}$ nanoparticles for rapid and efficient photothermal ablation of Gram-positive and -negative bacteria. ACS Appl. Mater. Inter. 2017, 9, 36606-36614.

[104] Chen, J. Q.; Ning, C. Y.; Zhou, Z. N.; Yu, P.; Zhu, Y.; Tan, G. X.; Mao, C. B. Nanomaterials as photothermal therapeutic agents. Prog. 
Mater. Sci. 2019, 99, 1-26.

[105] Lee, H. P.; Gaharwar, A. K. Light-responsive inorganic biomaterials for biomedical applications. Adv. Sci. 2020, 7, 2000863.

[106] Zhu, M.; Liu, X. M.; Tan, L.; Cui, Z. D.; Liang, Y. Q.; Li, Z. Y.; Wai, K.; Yeung, K.; Wu, S. L. Photo-responsive chitosan/Ag/MoS 2 for rapid bacteria-killing. J. Hazard. Mater. 2020, 383, 121122.

[107] Liu, X. Y.; Li, X. Y.; Shan, Y.; Yin, Y. X.; Liu, C. R.; Lin, Z. Y.; Kumar, S. S. CuS nanoparticles anchored to $\mathrm{g}^{-} \mathrm{C}_{3} \mathrm{~N}_{4}$ nanosheets for photothermal ablation of bacteria. RSC Adv. 2020, 10, 1218312191.

[108] Zhang, C.; Hu, D. F.; Xu, J. W.; Ma, M. Q.; Xing, H. B.; Yao, K.; $\mathrm{Ji}, \mathrm{J} . ; \mathrm{Xu}, \mathrm{Z}$. K. Polyphenol-assisted exfoliation of transition metal dichalcogenides into nanosheets as photothermal nanocarriers for enhanced antibiofilm activity. ACS Nano 2018, 12, 12347-12356.

[109] Li, M.; Li, L. Q.; Su, K.; Liu, X. M.; Zhang, T. J.; Liang, Y. Q.; Jing, D. D.; Yang, X. J.; Zheng, D.; Cui, Z. D. et al. Highly effective and noninvasive near-infrared eradication of a Staphylococcus aureus biofilm on implants by a photoresponsive coating within 20 min. Adv. Sci. 2019, 6, 1900599.

[110] Yin, W. Y.; Yu, J.; Lv, F. T.; Yan, L.; Zheng, L. R.; Gu, Z. J.; Zhao, Y. L. Functionalized nano-MoS 2 with peroxidase catalytic and near-infrared photothermal activities for safe and synergetic wound antibacterial applications. ACS Nano 2016, 10, 11000-11011.

[111] Sun, W.; Wu, F. G. Two-dimensional materials for antimicrobial applications: Graphene materials and beyond. Chem. Asian J. 2018, 13, 3378-3410.

[112] Mei, L. Q.; Zhu, S.; Yin, W. Y.; Chen, C. Y.; Nie, G. J.; Gu, Z. J.; Zhao, Y. L. Two-dimensional nanomaterials beyond graphene for antibacterial applications: Current progress and future perspectives. Theranostics 2020, 10, 757-781.

[113] Neupane, G. P.; Zhang, L.; Yildirim, T.; Zhou, K.; Wang, B. W.; Tang, Y. L.; Ma, W. D.; Xue, Y. Z.; Lu, Y. R. A prospective future towards bio/medical technology and bioelectronics based on $2 \mathrm{D}$ vdWs heterostructures. Nano Res. 2020, 13, 1-17.

[114] Han, W.; Wu, Z. N.; Li, Y.; Wang, Y. Y. Graphene family nanomaterials (GFNs)-promising materials for antimicrobial coating and film: A review. Chem. Eng. J. 2019, 358, 1022-1037.

[115] Yang, X.; Li, J.; Liang, T.; Ma, C. Y.; Zhang, Y. Y.; Chen, H. Z.; Hanagata, N.; Su, H. X.; Xu, M. S. Antibacterial activity of twodimensional $\mathrm{MoS}_{2}$ sheets. Nanoscale 2014, 6, 10126-10133.

[116] Wu, R. R.; Ou, X. W.; Tian, R. R.; Zhang, J.; Jin, H. S.; Dong, M. D.; Li, J. Y.; Liu, L. Membrane destruction and phospholipid extraction by using two-dimensional $\mathrm{MoS}_{2}$ nanosheets. Nanoscale 2018, 10, 20162-20170.

[117] Roy, S.; Mondal, A.; Yadav, V.; Sarkar, A.; Banerjee, R.; Sanpui, P.; Jaiswal, A. Mechanistic insight into the antibacterial activity of chitosan exfoliated $\mathrm{MoS}_{2}$ nanosheets: Membrane damage, metabolic inactivation, and oxidative stress. ACS Appl. Bio Mater. 2019, 2, $2738-2755$.

[118] Liu, X.; Duan, G. X.; Li, W. F.; Zhou, Z. F.; Zhou, R. H. Membrane destruction-mediated antibacterial activity of tungsten disulfide (WS 2 ). Rsc Adv. 2017, 7, 37873-37880.

[119] Navale, G. R.; Rout, C. S.; Gohil, K. N.; Dharne, M. S.; Late, D. J.; Shinde, S. S. Oxidative and membrane stress-mediated antibacterial activity of $\mathrm{WS}_{2}$ and RGO-WS $\mathrm{W}_{2}$ nanosheets. Rsc $A d v .2015,5$, 74726-74733.

[120] Hoseinnejad, M.; Jafari, S. M.; Katouzian, I. Inorganic and metal nanoparticles and their antimicrobial activity in food packaging applications. Crit. Rev. Microbiol. 2018, 44, 161-181.

[121] Cao, F. F.; Ju, E. G.; Zhang, Y.; Wang, Z. Z.; Liu, C. Q.; Huang, Y. Y.; Dong, K.; Ren, J.; Qu, X. G. An efficient and benign antimicrobial depot based on silver-infused $\mathrm{MoS}_{2}$. ACS Nano 2017, 11, 46514659.

[122] Dobias, J.; Bernier-Latmani, R. Silver release from silver nanoparticles in natural waters. Environ. Sci. Technol. 2013, 47, 4140-4146.

[123] Pang, M. L.; Hu, J. Y.; Zeng, H. C. Synthesis, morphological control, and antibacterial properties of hollow/solid $\mathrm{Ag}_{2} \mathrm{~S} / \mathrm{Ag}$ heterodimers. J. Am. Chem. Soc. 2010, 132, 10771-10785.

[124] Addae, E.; Dong, X.; McCoy, E.; Yang, C.; Chen, W.; Yang, L. J. Investigation of antimicrobial activity of photothermal therapeutic gold/copper sulfide core/shell nanoparticles to bacterial spores and cells. J.Biol. Eng. 2014, 8, 11 .
[125] Delgado-Beleño, Y.; Martinez-Nuñez, C. E.; Cortez-Valadez, M.; Flores-López, N. S.; Flores-Acosta, M. Optical properties of silver, silver sulfide and silver selenide nanoparticles and antibacterial applications. Mater. Res. Bull. 2018, 99, 385-392.

[126] Qiao, Y.; Ping, Y.; Zhang, H. B.; Zhou, B.; Liu, F. Y.; Yu, Y. H.; Xie, T. T.; Li, W. L.; Zhong, D. N.; Zhang, Y. Z. et al. Laser-activatable $\mathrm{CuS}$ nanodots to treat multidrug-resistant bacteria and release copper ion to accelerate healing of infected chronic nonhealing wounds. ACS Appl. Mater. Inter. 2019, 11, 3809-3822.

[127] Wang, X. X.; Li, L. Y.; Fu, Z.; Cui, F. L. Carbon quantum dots decorated CuS nanocomposite for effective degradation of methylene blue and antibacterial performance. J. Mol. Liq. 2018, 268, 578-586.

[128] Wang, W. S.; Cheng, X. H.; Liao, J. W.; Lin, Z. F.; Chen, L. L.; Liu, D. D.; Zhang, T.; Li, L. H.; Lu, Y.; Xia, H. Synergistic photothermal and photodynamic therapy for effective implant-related bacterial infection elimination and biofilm disruption using $\mathrm{Cu}_{9} \mathrm{~S}_{8}$ nanoparticles. ACS Biomater. Sci. Eng. 2019, 5, 6243-6253.

[129] Xu, Z. B.; Qiu, Z. Y.; Liu, Q.; Huang, Y. X.; Li, D. D.; Shen, X. G.; Fan, K. L.; Xi, J. Q.; Gu, Y. H.; Tang, Y. et al. Converting organosulfur compounds to inorganic polysulfides against resistant bacterial infections. Nat. Commun. 2018, 9, 3713.

[130] Wu, N.; Yu, Y. D.; Li, T.; Ji, X. J.; Jiang, L.; Zong, J. J.; Huang, H. Investigating the influence of $\mathrm{MoS}_{2}$ nanosheets on E. coli from metabolomics level. Plos One 2016, 11, e0167245.

[131] Pandit, S.; Karunakaran, S.; Boda, S. K.; Basu, B.; De, M. High antibacterial activity of functionalized chemically exfoliated $\mathrm{MoS}_{2}$. ACS Appl. Mater. Inter. 2016, 8, 31567-31573.

[132] Tian, X.; Sun, Y. R.; Fan, S. H.; Boudreau, M. D.; Chen, C. Y.; Ge, C. C.; Yin, J. J. Photogenerated charge carriers in molybdenum disulfide quantum dots with enhanced antibacterial activity. $A C S$ Appl. Mater. Inter. 2019, 11, 4858-4866.

[133] Liu, C.; Kong, D.; Hsu, P. C.; Yuan, H. T.; Lee, H. W.; Liu, Y. Y.; Wang, H. T.; Wang, S.; Yan, K.; Lin, D. C. et al. Rapid water disinfection using vertically aligned $\mathrm{MoS}_{2}$ nanofilms and visible light. Nat. Nanotechnol. 2016, 11, 1098-1104.

[134] Chen, X.; Berner, N. C.; Backes, C.; Duesberg, G. S.; McDonald, A. R. Functionalization of two-dimensional $\mathrm{MoS}_{2}$ : On the reaction between $\mathrm{MoS}_{2}$ and organic thiols. Angew.Chem., Inter. Ed. 2016, 55, 5803-5808

[135] Wang, W. J.; Li, G. Y.; Xia, D. H.; An, T. C.; Zhao, H. J.; Wong, P. K. Photocatalytic nanomaterials for solar-driven bacterial inactivation: Recent progress and challenges. Environ. Sci. Nano 2017, 4, 782-799.

[136] Novoselov, K. S.; Mishchenko, A.; Carvalho, A.; Neto, A. H. C. 2D materials and van der waals heterostructures. Science 2016, 353, aac9439.

[137] Wang, F. L.; Kusada, K.; Wu, D. S.; Yamamoto, T.; Toriyama, T.; Matsumura, S.; Nanba, Y.; Koyama, M.; Kitagawa, H. Solid-solution alloy nanoparticles of the immiscible iridium-copper system with a wide composition range for enhanced electrocatalytic applications. Angew. Chem., Int. Ed. 2018, 57, 4505-4509.

[138] Wang, H. Y.; Hua, X. W.; Wu, F. G.; Li, B. L.; Liu, P. D.; Gu, N.; Wang, Z. F.; Chen, Z. Synthesis of ultrastable copper sulfide nanoclusters via trapping the reaction intermediate: Potential anticancer and antibacterial applications. ACS Appl. Mater. Inter. 2015, 7, 7082-7092.

[139] Ellis, J. K.; Lucero, M. J.; Scuseria, G. E. The indirect to direct band gap transition in multilayered $\mathrm{MoS}_{2}$ as predicted by screened hybrid density functional theory. Appl. Phys. Lett. 2011, 99, 261908.

[140] Molina-Sánchez, A.; Wirtz, L. Phonons in single-layer and fewlayer $\mathrm{MoS}_{2}$ and $\mathrm{WS}_{2}$. Phys. Rev. B 2011, 84, 155413.

[141] He, X.; Singh, D. J.; Boon-On, P.; Lee, M. W.; Zhang, L. J. Dielectric behavior as a screen in rational searches for electronic materials: Metal pnictide sulfosalts. J. Am. Chem. Soc. 2018, 140, 18058-18065.

[142] Cheng, P. F.; Zhou, Q. W.; Hu, X. B.; Su, S. Q.; Wang, X.; Jin, M. L.; Shui, L. L.; Gao, X. S.; Guan, Y. Q.; Nozel, R. et al. Transparent glass with the growth of pyramid-type $\mathrm{MoS}_{2}$ for highly efficient water disinfection under visible-light irradiation. ACS Appl. Mater. Inter. 2018, 10, 23444-23450.

[143] Karunakaran, S.; Pandit, S.; Basu, B.; De, M. Simultaneous exfoliation and functionalization of $2 \mathrm{H}-\mathrm{MoS}_{2}$ by thiolated surfactants: 
Applications in enhanced antibacterial activity. J. Am. Chem. Soc. 2018, 140, 12634-12644.

[144] Dai, X. M.; Zhao, Y.; Yu, Y. J.; Chen, X. L.; Wei, X. S.; Zhang, X. G.; $\mathrm{Li}, \mathrm{C}$. X. Single continuous near-infrared laser-triggered photodynamic and photothermal ablation of antibiotic-resistant bacteria using effective targeted copper sulfide nanoclusters. ACS Appl. Mater. Inter. 2017, 9, 30470-30479.

[145] Gabriel, G. J.; Maegerlein, J. A.; Nelson, C. F.; Dabkowski, J. M.; Eren, T.; Nüsslein, K.; Tew, G. N. Comparison of facially amphiphilic versus segregated monomers in the design of antibacterial copolymers. Chem. Eur. J 2009, 15, 433-439.

[146] Nguyen, E. P.; Carey, B. J.; Ou, J. Z.; van Embden, J.; Della Gaspera, E.; Chrimes, A. F.; Spencer, M. J. S.; Zhuiykov, S.; Kalantar-zadeh, $\mathrm{K}$.; Daeneke, T. Electronic tuning of $2 \mathrm{D} \mathrm{MoS}_{2}$ through surface functionalization. Adv. Mater. 2015, 27, 6225-6229.

[147] Li, H.; Tsai, C.; Koh, A. L.; Cai, L. L.; Contryman, A. W.; Fragapane, A. H.; Zhao, J. H.; Han, H. S.; Manoharan, H. C.; AbildPedersen, F. et al. Activating and optimizing $\mathrm{MoS}_{2}$ basal planes for hydrogen evolution through the formation of strained sulphur vacancies. Nat. Mater. 2016, 15, 48-53.

[148] Gao, Q.; Zhang, X.; Yin, W. Y.; Ma, D. Q.; Xie, C. J.; Zheng, L. R.; Dong, X. H.; Mei, L. Q.; Yu, J.; Wang, C. Z. et al. Functionalized $\mathrm{MoS}_{2}$ nanovehicle with near-infrared laser-mediated nitric oxide release and photothermal activities for advanced bacteria-infected wound therapy. Small 2018, 14, 1802290.

[149] Ren, Y. J.; Zeng, D. Q.; Ong, W. J. Interfacial engineering of graphitic carbon nitride $\left(\mathrm{g}_{-} \mathrm{C}_{3} \mathrm{~N}_{4}\right)$-based metal sulfide heterojunction photocatalysts for energy conversion: A review. Chinese J. Catal. 2019, 40, 289-319.

[150] Low, J. X.; Yu, J. G.; Jaroniec, M.; Wageh, S.; Al-Ghamdi, A. A. Heterojunction photocatalysts. Adv. Mater. 2017, 29, 1601694.

[151] Zhang, X. Y.; Zhang, C.; Yang, Y. Q.; Zhang, H. Y.; Huang, X. B.; Hang, R. Q.; Yao, X. H. Light-assisted rapid sterilization by a hydrogel incorporated with $\mathrm{Ag}_{3} \mathrm{PO}_{4} / \mathrm{MoS}_{2}$ composites for efficient wound disinfection. Chem. Eng. J. 2019, 374, 596-604.

[152] Wang, H. L.; Zhang, L. S.; Chen, Z. G.; Hu, J. Q.; Li, S. J.; Wang, Z. H.; Liu, J. S.; Wang, X. C. Semiconductor heterojunction photocatalysts: Design, construction, and photocatalytic performances. Chem. Soc. Rev. 2014, 43, 5234-5244.

[153] Baek, M.; Kim, E. J.; Hong, S. W.; Kim, W.; Yong, K. Environmentally benign synthesis of $\mathrm{CuInS}_{2} / \mathrm{ZnO}$ heteronanorods: Visible light activated photocatalysis of organic pollutant/bacteria and study of its mechanism. Photochem. Photobiol. Sci. 2017, 16, 1792-1800.

[154] Meng, X. C.; Li, Z. Z.; Zeng, H. M.; Chen, J.; Zhang, Z. S. $\mathrm{MoS}_{2}$ quantum dots-interspersed $\mathrm{Bi}_{2} \mathrm{WO}_{6}$ heterostructures for visible lightinduced detoxification and disinfection. Appl. Catal. B Environ. 2017, 210, 160-172.

[155] Xu, Q. L.; Zhang, L. Y.; Yu, J. G.; Wageh, S.; Al-Ghamdi, A. A.; Jaroniec, M. Direct Z-scheme photocatalysts: Principles, synthesis, and applications. Mater. Today 2018, 21, 1042-1063.

[156] Bard, A. J. Photoelectrochemistry and heterogeneous photocatalysis at semiconductors. J. Photochem. 1979, 10, 59-75.

[157] Zhou, P.; Yu, J.; Jaroniec, M. All-solid-state Z-scheme photocatalytic systems. Adv. Mater. 2014, 26, 4920-4935.

[158] Low, J. X.; Jiang, C. J.; Cheng, B.; Wageh, S.; Al-Ghamdi, A. A.; Yu, J. G. A review of direct Z-scheme photocatalysts. Small Methods 2017, 1, 1700080.

[159] Li, Y. R.; Li, L. L.; Gong, Y. Q.; Bai, S.; Ju, H. X.; Wang, C. M.; $\mathrm{Xu}, \mathrm{Q}$.; Zhu, J. F.; Jiang, J.; Xiong, Y. J. Towards full-spectrum photocatalysis: Achieving a Z-scheme between $\mathrm{Ag}_{2} \mathrm{~S}$ and $\mathrm{TiO}_{2}$ by engineering energy band alignment with interfacial Ag. Nano Res. 2015, 8, 3621-3629.

[160] Chen, Y. X.; Liang, Y.; Zhao, M. J.; Wang, Y.; Zhang, L.; Jiang, Y. Y.; Wang, G. T.; Zou, P.; Zeng, J.; Zhang, Y. S. In situ ion exchange synthesis of $\mathrm{Ag}_{2} \mathrm{~S} / \mathrm{AgVO}_{3}$ graphene aerogels for enhancing photocatalytic antifouling efficiency. Ind. Eng. Chem. Res. 2019, $58,3538-3548$.

[161] Zhang, C.; Wang, J. M.; Chi, R. F.; Shi, J.; Yang, Y. Q.; Zhang, X. Y. Reduced graphene oxide loaded with $\mathrm{MoS}_{2}$ and $\mathrm{Ag}_{3} \mathrm{PO}_{4}$ nanoparticles/PVA interpenetrating hydrogels for improved mechanical and antibacterial properties. Mater. Des. 2019, 183, 108166.

[162] Di, T. M.; Xu, Q. L.; Ho, W. K.; Tang, H.; Xiang, Q. J.; Yu, J. G. Review on metal sulphide-based Z-scheme photocatalysts. ChemCatChem 2019, 11, 1394-1411.

[163] Wang, M. Y.; Ye, M. D.; Iocozzia, J.; Lin, C. J.; Lin, Z. Q. Plasmonmediated solar energy conversion via photocatalysis in noble metal/semiconductor composites. Adv. Sci. 2016, 3, 1600024.

[164] Jiang, R. B.; Li, B. X.; Fang, C. H.; Wang, J. F. Metal/semiconductor hybrid nanostructures for plasmon-enhanced applications. $A d v$. Mater. 2014, 26, 5274-5309.

[165] Zhang, X. M.; Chen, Y. L.; Liu, R. S.; Tsai, D. P. Plasmonic photocatalysis. Rep. Prog. Phys. 2013, 76, 046401.

[166] Dreaden, E. C.; Alkilany, A. M.; Huang, X. H.; Murphy, C. J.; El-Sayed, M. A. The golden age: Gold nanoparticles for biomedicine. Chem. Soc. Rev. 2012, 41, 2740-2779.

[167] Wu, L.; Li, F.; Xu, Y. Y.; Zhang, J. W.; Zhang, D. Q.; Li, G. S.; Li, H. X. Plasmon-induced photoelectrocatalytic activity of Au nanoparticles enhanced $\mathrm{TiO}_{2}$ nanotube arrays electrodes for environmental remediation. Appl. Catal. B Environ. 2015, 164, 217-224.

[168] Zeng, S. W.; Baillargeat, D.; Ho, H. P.; Yong, K. T. Nanomaterials enhanced surface plasmon resonance for biological and chemical sensing applications. Chem. Soc. Rev. 2014, 43, 3426-3452.

[169] Yang, J. J.; Wang, F. L.; Yuan, H. Q.; Zhang, L. S.; Jiang, Y. Y.; Zhang, X.; Liu, C.; Chai, L.; Li, H.; Stenzel, M. Recent advances in ultra-small fluorescent $\mathrm{Au}$ nanoclusters toward oncological research. Nanoscale 2019, 11, 17967-17980.

[170] Gupta, R.; Eswar, N. K.; Modak, J. M.; Madras, G. Effect of morphology of zinc oxide in $\mathrm{ZnO}-\mathrm{CdS}-\mathrm{Ag}$ ternary nanocomposite towards photocatalytic inactivation of $E$. coli under $\mathrm{UV}$ and visible light. Chem. Eng. J. 2017, 307, 966-980.

[171] Chen, X. B.; Shen, S. H.; Guo, L. J.; Mao, S. S. Semiconductorbased photocatalytic hydrogen generation. Chem. Rev. 2010, 110, 6503-6570.

[172] Tang, K. W.; Wang, L. Y.; Geng, H.; Qiu, J. J.; Cao, H. L.; Liu, X. Y. Molybdenum disulfide $\left(\mathrm{MoS}_{2}\right)$ nanosheets vertically coated on titanium for disinfection in the dark. Arab. J. Chem. 2020, 13, $1612-1623$.

[173] Fakhri, A.; Pourmand, M.; Khakpour, R.; Behrouz, S. Structural, optical, photoluminescence and antibacterial properties of copperdoped silver sulfide nanoparticles. J. Photochem. Photobiol. B Biol. 2015, 149, 78-83.

[174] Patel, N. H.; Deshpande, M. P.; Chaki, S. H.; Keharia, H. R. Tuning of optical, thermal and antimicrobial capabilities of CdS nanoparticles with incorporated Mn prepared by chemical method. J. Mater. Sci. Mater. Electron. 2017, 28, 10866-10876.

[175] Ristic, B. Z.; Milenkovic, M. M.; Dakic, I. R.; TodorovicMarkovic, B. M.; Milosavljevic, M. S.; Budimir, M. D.; Paunovic, V. G.; Dramicanin, M. D.; Markovic, Z. M.; Trajkovic, V. S. Photodynamic antibacterial effect of graphene quantum dots. Biomaterials 2014, $35,4428-4435$.

[176] Li, R. B.; Mansukhani, N. D.; Guiney, L. M.; Ji, Z. X.; Zhao, Y. C.; Chang, C. H.; French, C. T.; Miller, J. F.; Hersam, M. C.; Nel, A. E. et al. Identification and optimization of carbon radicals on hydrated graphene oxide for ubiquitous antibacterial coatings. ACS Nano 2016, 10, 10966-10980.

[177] Liu, S. B.; Hu, M.; Zeng, T. H.; Wu, R.; Jiang, R. R.; Wei, J.; Wang, L.; Kong, J.; Chen, Y. Lateral dimension-dependent antibacterial activity of graphene oxide sheets. Langmuir 2012, 28, 12364-12372.

[178] Rajendiran, K.; Zhao, Z. Z.; Pei, D. S.; Fu, A. L. Antimicrobial activity and mechanism of functionalized quantum dots. Polymers 2019, 11,1670

[179] Han, D. L.; Ma, M. X.; Han, Y. J.; Cui, Z. D.; Liang, Y. Q.; Liu, X. M.; Li, Z. Y.; Zhu, S. L.; Wu, S. L. Eco-friendly hybrids of carbon quantum dots modified $\mathrm{MoS}_{2}$ for rapid microbial inactivation by strengthened photocatalysis. ACS Sustain. Chem. Eng. 2020, 8, 534-542.

[180] Wang, W. N.; Zhang, C. Y.; Zhang, M. F.; Pei, P.; Zhou, W.; Zha, Z. B.; Shao, M.; Qian, H. S. Precisely photothermal controlled releasing of antibacterial agent from $\mathrm{Bi}_{2} \mathrm{~S}_{3}$ hollow microspheres triggered by nir light for water sterilization. Chem. Eng. J. 2020, 381, 122630.

[181] Zhang, G.; Zhang, Z. H.; Xia, D. H.; Qu, Y.; Wang, W. Q. Solar driven self-sustainable photoelectrochemical bacteria inactivation in scale-up reactor utilizing large-scale fabricable $\mathrm{Ti} / \mathrm{MoS}_{2} / \mathrm{MoO}_{x}$ photoanode. J. Hazard. Mater. 2020, 392, 122292. 
[182] Gao, P.; Liu, J.; Sun, D. D.; Ng, W. Graphene oxide-CdS composite with high photocatalytic degradation and disinfection activities under visible light irradiation. J. Hazard. Mater. 2013, 250, 412-420.

[183] Li, W. P.; Su, C. H.; Wang, S. J.; Tsai, F. J.; Chang, C. T.; Liao, M. C.; Yu, C. C.; Thi-Tuong Vi, T.; Lee, C. N.; Chiu, W. T. et al. $\mathrm{CO}_{2}$ delivery to accelerate incisional wound healing following single irradiation of near-infrared lamp on the coordinated colloids. ACS Nano 2017, 11, 5826-5835.

[184] Agarwal, V.; Chatterjee, K. Recent advances in the field of transition metal dichalcogenides for biomedical applications. Nanoscale 2018, 10, 16365-16397.

[185] Yuwen, L. H.; Sun, Y. T.; Tan, G. L.; Xiu, W. J.; Zhang, Y. Q.; Weng, L. X.; Teng, Z. G.; Wang, L. H. MoS @ polydopamine-Ag nanosheets with enhanced antibacterial activity for effective treatment of Staphylococcus aureus biofilms and wound infection. Nanoscale 2018, 10, 16711-16720.

[186] Yuan, Z.; Tao, B. L.; He, Y.; Liu, J.; Lin, C. C.; Shen, X. K.; Ding, Y.; Yu, Y. L.; Mu, C. Y.; Liu, P. et al. Biocompatible $\mathrm{MoS}_{2} / \mathrm{PDA}-\mathrm{RGD}$ coating on titanium implant with antibacterial property via intrinsic ROS-independent oxidative stress and nir irradiation. Biomaterials 2019, 217, 119290.

[187] Feng, Z. Z.; Liu, X. M.; Tan, L.; Cui, Z. D.; Yang, X. J.; Li, Z. Y.; Zheng, Y. F.; Yeung, K. W. K.; Wu, S. L. Electrophoretic deposited stable chitosan@MoS 2 coating with rapid in situ bacteria-killing ability under dual-light irradiation. Small 2018, 14, 1704347.

[188] Shalabayev, Z.; Baláž, M.; Daneu, N.; Dutková, E.; Bujňáková, Z.; Kanuchová, M.; Danková, Z.; Balážová, Ĺ.; Urakaev, F.; Tkaciková, Ĺ. et al. Sulfur-mediated mechanochemical synthesis of spherical and needle-like copper sulfide nanocrystals with antibacterial activity. ACS Sustain. Chem. Eng. 2019, 7, $12897-$ 12909.

[189] Cecioni, S.; Imberty, A.; Vidal, S. Glycomimetics versus multivalent glycoconjugates for the design of high affinity lectin ligands. Chem. Rev. 2015, 115, 525-561.

[190] Novoa, A.; Eierhoff, T.; Topin, J.; Varrot, A.; Barluenga, S.; Imberty, A.; Römer, W.; Winssinger, N. A leca ligand identified from a galactoside-conjugate array inhibits host cell invasion by pseudomonas aeruginosa. Angew. Chem., Int. Ed. 2014, 53, $8885-8889$.

[191] Lundquist, J. J.; Toone, E. J. The cluster glycoside effect. Chem. Rev. 2002, 102, 555-578.

[192] Bernardi, A.; Jiménez-Barbero, J.; Casnati, A.; De Castro, C.; Darbre, T.; Fieschi, F.; Finne, J.; Funken, H.; Jaeger, K. E.; Lahmann, M. et al. Multivalent glycoconjugates as anti-pathogenic agents. Chem. Soc. Rev. 2013, 42, 4709-4727.

[193] Versteeg, H. H.; Heemskerk, J. W. M.; Levi, M.; Reitsma, P. H. New fundamentals in hemostasis. Physiol. Rev. 2013, 93, 327-358.
[194] Li, J.; Tan, L.; Liu, X. M.; Cui, Z. D.; Yang, X. J.; Yeung, K. W. K.; Chu, P. K.; Wu, S. L. Balancing bacteria-osteoblast competition through selective physical puncture and biofunctionalization of $\mathrm{ZnO} /$ polydopamine/arginine-glycine-aspartic acid-cysteine nanorods. ACS Nano 2017, 11, 11250-11263.

[195] Midwood, K. S.; Williams, L. V.; Schwarzbauer, J. E. Tissue repair and the dynamics of the extracellular matrix. Int. J. Biochem. Cell Biol. 2004, 36, 1031-1037.

[196] Chang, H. Y.; Sneddon, J. B.; Alizadeh, A. A.; Sood, R.; West, R. B.; Montgomery, K.; Chi, J. T.; van de Rijn, M.; Botstein, D.; Brown, P. O. Gene expression signature of fibroblast serum response predicts human cancer progression: Similarities between tumors and wounds. PLoS Biol. 2004, 2, 206-214.

[197] Li, M.; Liu, X. M.; Tan, L.; Cui, Z. D.; Yang, X. J.; Li, Z. Y.; Zheng, Y. F.; Yeung, K. W. K.; Chu, P. K.; Wu, S. L. Noninvasive rapid bacteria-killing and acceleration of wound healing through photothermal/photodynamic/copper ion synergistic action of a hybrid hydrogel. Biomater. Sci. 2018, 6, 2110-2121.

[198] Su, K.; Tan, L.; Liu, X. M.; Cui, Z. D.; Zheng, Y. F.; Li, B.; Han, Y.; Li, Z. Y.; Zhu, S. L.; Liang, Y. Q. et al. Rapid photosonotherapy for clinical treatment of bacterial infected bone implants by creating oxygen deficiency using sulfur doping. ACS Nano 2020, 14, 2077-2089.

[199] Hench, L. L.; Polak, J. M. Third-generation biomedical materials. Science 2002, 295, 1014-1017.

[200] Lee, C. T.; Huang, Y. W.; Zhu, L.; Weltman, R. Prevalences of peri-implantitis and peri-implant mucositis: Systematic review and meta-analysis. J. Dent. 2017, 62, 1-12.

[201] Zhu, W. D.; Liu, X. M.; Tan, L.; Cui, Z. D.; Yang, X. J.; Liang, Y. Q.; Li, Z. Y.; Zhu, S. L.; Yeung, K. W. K.; Wu, S. L. AgBr nanoparticles in situ growth on $2 \mathrm{D} \mathrm{MoS}$ nanosheets for rapid bacteria-killing and photodisinfection. ACS Appl. Mater. Inter. 2019, 11, 3436434375 .

[202] Awasthi, G. P.; Adhikari, S. P.; Ko, S.; Kim, H. J.; Park, C. H.; $\mathrm{Kim}, \mathrm{C}$. S. Facile synthesis of $\mathrm{ZnO}$ flowers modified graphene like $\mathrm{MoS}_{2}$ sheets for enhanced visible-light-driven photocatalytic activity and antibacterial properties. J. Alloys Compd. 2016, 682, 208-215.

[203] Shariati, M. R.; Samadi-Maybodi, A.; Colagar, A. H. Exploration of charge carrier delocalization in the iron oxide/CdS type-ii heterojunction band alignment for enhanced solar-driven photocatalytic and antibacterial applications. J. Hazard. Mater. 2019, 366, 475-481.

[204] Gao, P.; Liu, J. C.; Zhang, T.; Sun, D. D.; Ng, W. Hierarchical $\mathrm{TiO}_{2} / \mathrm{CdS}$ "spindle-like" composite with high photodegradation and antibacterial capability under visible light irradiation. J. Hazard. Mater. 2012, 229, 209-216. 